\title{
LATERAL AND LONGITUDINAL CHLORIDE DYNAMICS IN AN URBANIZING WATERSHED IN SOUTHERN ONTARIO: A SPATIAL CROSS-CORRELATION MODELLING APPROACH
}

by

Bhaswati Mazumder

BSc, University of Toronto, 2014

\author{
A MRP \\ presented to Ryerson University \\ in partial fulfillment of the \\ requirements for the degree of \\ Master of Spatial Analysis \\ In the Program of \\ Spatial Analysis
}

Toronto, Ontario, Canada, 2017

CBhaswati Mazumder, 2017 


\section{Author's Declaration for Electronic Submission of a MRP}

I hereby declare that I am the sole author of this MRP. This is a true copy of the MRP, including any required final revisions.

I authorize Ryerson University to lend this MRP to other institutions or individuals for the purpose of scholarly research.

I further authorize Ryerson University to reproduce this MRP by photocopying or by other means, in total or in part, at the request of other institutions or individuals for the purpose of scholarly research.

I understand that my MRP may be made electronically available to the public. 


\title{
LATERAL AND LONGITUDINAL CHLORIDE DYNAMICS \\ IN AN URBANIZING WATERSHED IN SOUTHERN ONTARIO: \\ A SPATIAl Cross-CORRElation MODELling APPROACH
}

\author{
Bhaswati Mazumder \\ Master of Spatial Analysis \\ Ryerson University, 2017
}

\begin{abstract}
The application of spatial cross-correlation modelling was tested on continuous time series of electrical conductivity to estimate lateral and longitudinal chloride dynamics in an urbanizing watershed in Southern Ontario. Overall, the model appeared more robust for the winter salting season than for the summer growing season. The winter results showed shorter travel times with higher velocity longitudinally (upstream to downstream) in an urban stream reach with more impervious surfaces than in a rural reach with more permeable surfaces. The lateral exchange rates (stream-hyporheic zone) were observed to be affected by both local and catchment-scale land use and soil profiles. Cross-correlation results and time series data also indicated that road-salt applications in the urban catchment may be leading to underground storage of chloride, contributing to the streams in summer and producing year-round peaks of chloride in the urban stream reach.
\end{abstract}




\section{ACKNOWLEDGEMENTS}

This project was made possible by the constant guidance of Dr. Claire J. Oswald, who has been exceptionally kind and resourceful since the beginning of my program last year. I would also like to take this opportunity to thank all of my family who, though oceans away, never fail to send me their love and support.

This study is indebted to the Watershed Ecohydrology Research team at Ryerson University for the collection, maintenance, and field records of the time series data used here. A special thanks to Colin Ash and Felix Chan in the team, for lending a helping hand whenever I needed it. 


\section{Table of Contents}

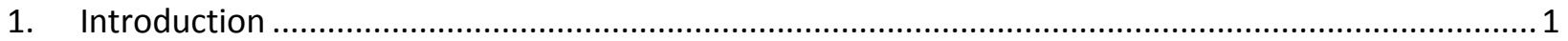

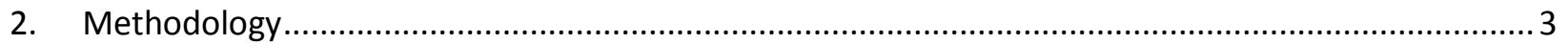

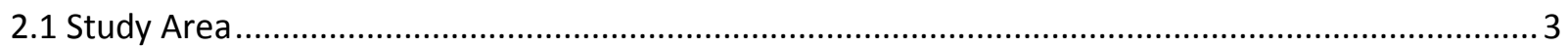

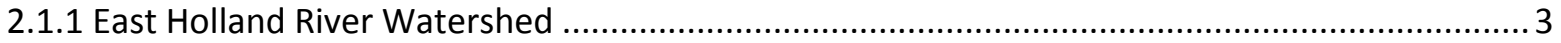

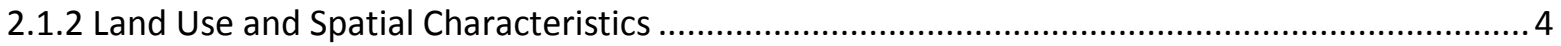

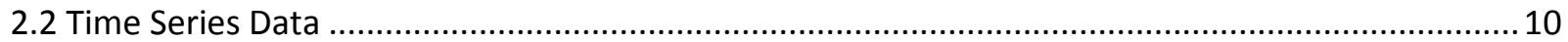

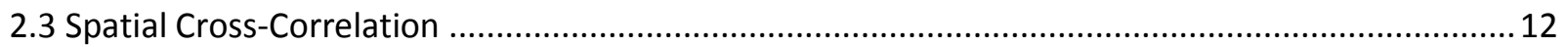

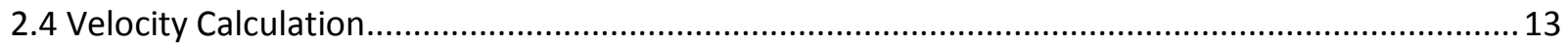

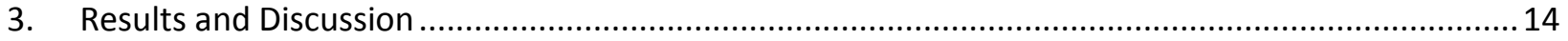

3.1 Catchment Characteristics for Longitudinal Trend Analysis ...................................................... 14

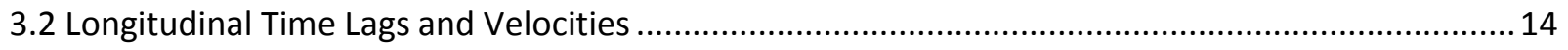

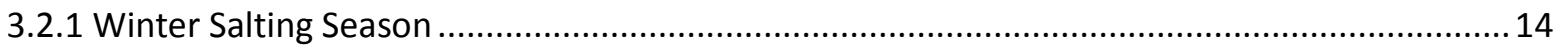

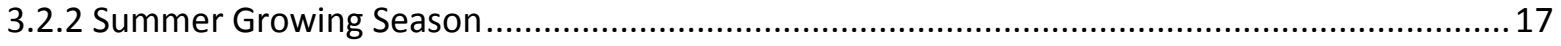

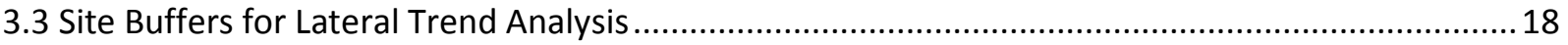

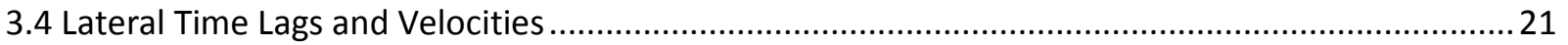

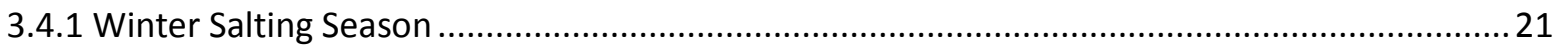

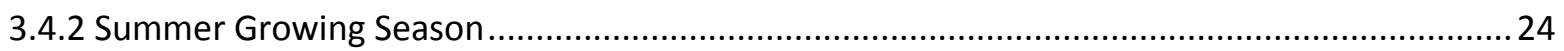

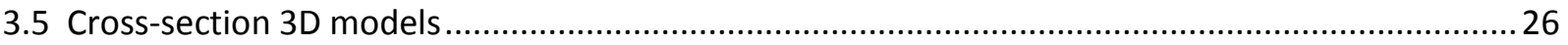

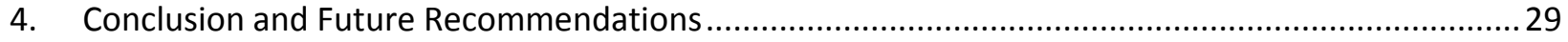

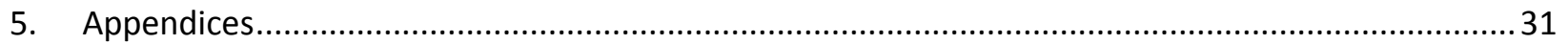

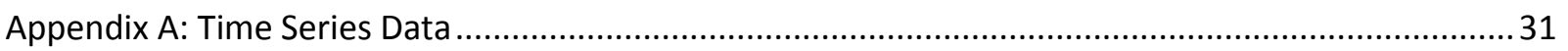

A-1 Winter Salting Season (15-minute interval) …....................................................................... 31

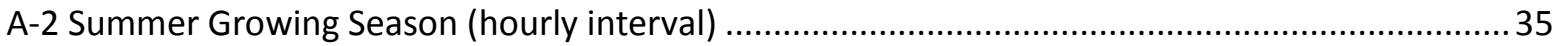

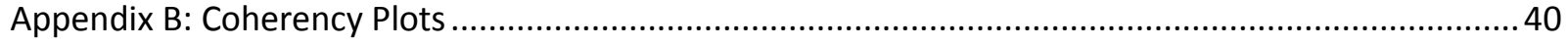

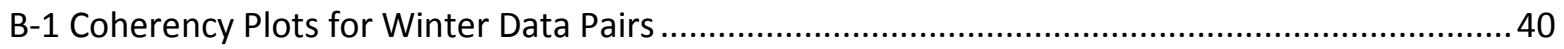

B-2 Coherency Plots for Summer Data Pairs......................................................................... 43

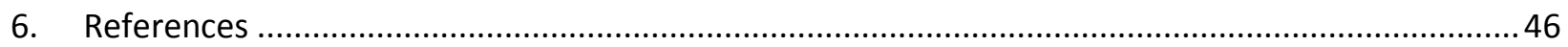




\section{List of Tables}

Table 1. Summary of general land cover in the urban and rural catchments ............................................4

Table 2. Summary of catchment characteristics computed for the urban and rural catchments ..............14

Table 3. Cross-correlation and velocity results for longitudinal (upstream to downstream) analysis in the urban and rural catchments during a winter salting season

Table 4. Cross-correlation and velocity results for longitudinal (upstream to downstream) analysis in the urban and rural catchments during a summer growing season

Table 5. Cross-correlation and velocity results for lateral (stream to hyporheic zone) analysis in the urban and rural catchments during a winter salting season

Table 6. Cross-correlation and velocity results for lateral (stream to hyporheic zone) analysis in the urban and rural catchments during a summer growing season 


\section{List of Figures}

Figure 1. The two catchments studied within the East Holland River watershed, located in York Region under the Greater Golden Horseshoe urban growth region

Figure 2. Land use profiles of the two catchments extracted from a detailed land classification layer by the Lake Simcoe Region Conservation Authority 5

Figure 3. Road networks of the two catchments from York Region Voyager open data license

Figure 4. Elevation (meters) profile for upstream and downstream longitudinal streamflow, created from $10 \mathrm{~m}$ DEM of the two catchments.

Figure 5. Elevation (meters) profile for lateral cross-section of stream sites in the urban catchment ........8

Figure 6. Elevation (meters) profile for lateral cross-section of stream sites in the rural catchment ..........8

Figure 7. Soil profiles of the two catchments extracted from a Soil Survey Complex by the Ontario Ministry of Agricultural, Food and Rural Affairs

Figure 8. Sample of time series showing conductivity from winter salting season at the upstream and downstream sites of the urban catchment, including a close-up view ...

Figure 9. Cross-correlation results for longitudinal time lags in the urban and rural catchments during the winter salting season

Figure 10. Cross-correlation results for longitudinal time lags in the urban and rural catchments during the summer growing season ...

Figure 11. Radial maps for $1 \mathrm{~km}$ buffer areas in the urban upstream and downstream sites

Figure 12. Radial maps for $1 \mathrm{~km}$ buffer areas in the rural upstream and downstream sites

Figure 13. Cross-correlation results for lateral time lags in the urban and rural catchments during the winter salting season

Figure 14. Cross-correlation results for lateral time lags in the urban and rural catchments during the summer growing season

Figure 15. Spatial representation of a cross-section of the urban catchment .27

Figure 16. Spatial representation of a cross-section of the rural catchment 


\section{Introduction}

In cold countries like Canada, road salt application to impervious surfaces is a routine practice in winter. Rock salt, composed of sodium chloride $(\mathrm{NaCl})$, is the most common de-icer used in Southern Ontario, which leads to meltwater with high concentrations of chloride $(\mathrm{Cl})$ anions that can be transported to streams via multiple flow pathways. In urban landscapes, large areas are covered in impervious surfaces that favor overland runoff due to low infiltration rates. Overland flow pathways are a quick route for $\mathrm{Cl}$ laden runoff to reach receiving water bodies like streams and lakes. In non-urban areas a higher coverage of permeable surfaces allow meltwater to infiltrate through the surface and percolate to groundwater. Groundwater and lateral throughflow in the unsaturated zone in soil can also transport $\mathrm{Cl}$ to streams by mixing with stream water in the hyporheic zone. The effects of the high $\mathrm{Cl}$ concentrations on stream water quality (Environment Canada, 2001), groundwater quality (Meriano et al., 2009; Williams et al., 2000), and aquatic life (Colins and Russell, 2009; Corsi et al. 2010; Findlay and Kelly, 2011) pose a growing concern today. This is especially true for urbanizing regions such as the Lake Simcoe watershed, where $\mathrm{Cl}$ levels in tributaries flowing into the lake have been rising since the 1990s, and often exceed the Canadian Council for Ministers of the Environment (CCME) guidelines for protection of aquatic life (Winter et al., 2011).

Previous studies have reported long-term storage of $\mathrm{Cl}$ within watersheds (Casey et al., 2013; Corsi et al., 2015; Kelly et al., 2008; Perera et al., 2013). Other studies have discussed the importance of the hyporheic zone in surface-groundwater exchange and chemical retention (Boano et al., 2014; Ryan and Boufadel, 2007; Valett et al., 1996). This suggests that $\mathrm{Cl}$ applied onto impervious surfaces in winter are not all flushed from a watershed during the spring melt, but rather delayed along slower flow pathways in the stream, including subsurface mixing in the hyporheic zone and infiltration to groundwater. Current research has firmly established the impact of urban drivers such as land use change, paved roads and other impervious surfaces on the extent of salinization and $\mathrm{Cl}$ concentration (Dugan et al., 2017; Kaushal et al, 2005; Kelting et al., 2012; Martin et al., 2016; Morgan et al., 2012), especially in Canada (Kerr, 2017). These studies have all used monthly, biennial or annual data to connect spatial characteristics with water quality. While researchers often identify the potential of continuous data to better understand $\mathrm{Cl}$ dynamics over shorter time scales (Kirchner et al., 2004; Long et al., 2015), to the best of our knowledge no previous studies have used continuous sensors to estimate travel times of $\mathrm{Cl}$ along and within a stream in an urbanizing watershed. As watershed structure and geometry can play an important role in solute transport (Bergstrom, 2016), these factors also need to be integrated with land use to analyze $\mathrm{Cl}$ dynamics. There is a paucity of information linking in-stream and subsurface $\mathrm{Cl}$ dynamics to specific spatial and structural 
characteristics of a stream and its catchment. This information is key to developing a mechanistic understanding of $\mathrm{Cl}$ fate and transport, that can inform a coupled hydrology-Cl model. In addition, an improved understanding of the processes and landscape characteristics that drive in-stream $\mathrm{Cl}$ dynamics in urbanizing watersheds will support decision-making around road salt use (Lake Simcoe Regional Authority, 2015) and adaptive winter maintenance strategies (Dietz et al., 2017).

This study supplies a spatial cross-correlation analysis to continuous electrical conductivity (EC) data to estimate longitudinal (along a stream reach) and lateral (stream-hyporheic zone) time lags for two stream reaches in the East Holland River watershed in Southern Ontario. In geographical research, cross correlation is a relationship between two spatially and temporally shifted measurements. It is similar to spatial autocorrelation, but with a time lag between two correlated data series (Chen, 2015). In signal processing, cross correlation methods are often used to measure the time delay from an input series to an output or response series. In spatial modelling of the environment, this method has previously been applied to long term data (including $\mathrm{Cl}$ ) to examine lags in the relationship between precipitation, streamflow, stream chemistry, etc. (DeWalle et al., 2016; Ko and Cheng, 2004; Schmidt et al., 2012). Besides investigating the potential of this method for estimating $\mathrm{Cl}$ travel time and velocity, this paper aimed to answer the following questions:

1. How does the longitudinal (upstream to downstream) time lag and velocity for $\mathrm{Cl}$ vary between an urban stream reach with more impervious surfaces in its catchment and a rural stream reach with more permeable surfaces in its catchment?

2. How do lateral (stream-hyporheic zone) time lags and velocities for $\mathrm{Cl}$ vary between an urban and rural stream reach?

3. Are there seasonal differences in the longitudinal and lateral time lags estimated for the urban and rural stream reaches?

As impervious surfaces limit infiltration and increase runoff, causing water to move rapidly downstream (Booth, 1991), the urban stream is expected to show a shorter lag and higher velocity of $\mathrm{Cl}$ longitudinally compared to the rural stream. For lateral flow, hyporheic connectivity may be affected by urbanization (Ryan and Packman, 2006), in some cases creating unique scenarios of groundwater storage contributing to stream $\mathrm{Cl}$ levels throughout the year due to long-term road salt applications in urban watersheds (Eyles and Meriano, 2010; Mayer et al., 2006). The results from the lateral lags and velocities are expected to show whether hyporheic connectivity is being hampered by increasing urbanization, while exploring the possibility of subsurface contribution to stream $\mathrm{Cl}$ levels in this watershed. 


\section{Methodology}

\subsection{Study Area}

\subsubsection{East Holland River Watershed}

In 2012, the Lake Simcoe Region Conservation Authority's (LSRCA) daily monitoring station at Holland Landing reported 44 occasions of $\mathrm{Cl}$ exceeding the Salt Acute Exposure Guideline (640 mg/L). Throughout that year, $\mathrm{Cl}$ levels remained mostly above the Chronic Exposure Guideline $(120 \mathrm{mg} / \mathrm{L})$ at this station in East Holland River (Lake Simcoe Science Newsletters, n.d.). Among Lake Simcoe's subwatersheds, East Holland River is one of the most populated and contains the second-largest impervious surface (LSRCA, 2010). It falls almost entirely within the regional municipality of York in the Greater Golden Horseshoe Region plan for urban growth, with Whitchurch-Stouffville to the south-east, Newmarket and central York in the middle and Aurora in the southwest. Highway 404, a 6-lane expressway, passes through the southern half of the watershed (Figure 1). Although urban land use currently covers only

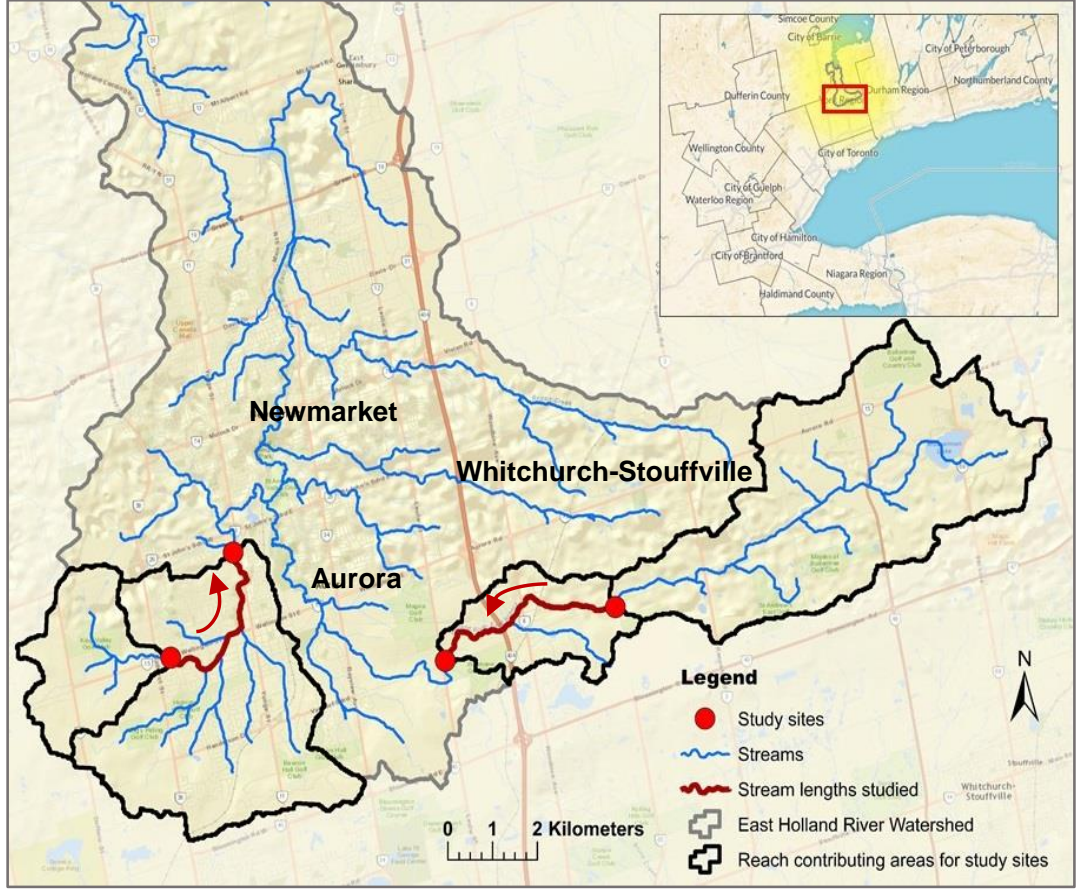

Figure 1. The two catchments studied within the East Holland River Watershed, located in York Region under the Greater Golden Horseshoe urban growth region. Stream lengths from the upstream to downstream sites are highlighted in red within the complete stream network, and the reach contributing areas are delineated for each site monitored within the two catchments. over $26 \%$ of its total area, this watershed is projected to undergo increasing stress due to urbanization. The York Region's 2041 growth forecasts indicate further population increase and land cover change in the immediate future, along with higher residential growth towards the southeast in the next 25 years (with almost five-fold population increase), while Newmarket and Aurora continue to grow significantly (Regional Municipality of York, 2015). 
Upstream and downstream sites were monitored in two stream reaches located in the southeast and southwest portions of the watershed. The catchment in the southwest is mostly urban, approximately 29.5 $\mathrm{km}^{2}$ in area and drains locally into the Tannery Creek (a tributary of East Holland River), which has a mean annual flow of $0.23 \mathrm{~m}^{2} / \mathrm{s}$ (Ontario Ministry of Natural Resources and Forestry, 2013). With many urban residential areas and paved roads surrounding the stream, it falls almost entirely within the town of Aurora. The catchment in the southeast is mostly rural with many natural heritage areas, falling mainly under Whitchurch-Stouffville, with a small section of the downstream area west of the Highway 404 falling under Aurora. It has a total drainage area of about $36.4 \mathrm{~km}^{2}$ that drains into East Holland River, which has a mean annual flow rate similar to the urban catchment- about $0.25 \mathrm{~m}^{2} / \mathrm{s}$.

\subsubsection{Land Use and Spatial Characteristics}

Overall, the urban catchment in the southwest is about 50\% urbanized and 30\% agricultural, while the rural catchment is about $20 \%$ urbanized and $40 \%$ agricultural, with many natural areas. These are summarized in Table 1. The Ontario Flow Assessment Tool (OFAT) was used to delineate the reach contributing areas in Figure 1 and generate streamflow and overall land cover information. This is a spatial web application by the Ministry of Natural Resources and Forestry that uses a provincial land cover layer from 2013. A more detailed land cover layer, based on $15 \mathrm{~cm}$ high resolution aerial photography from 2013, was provided by the LSRCA through the Ontario Geospatial Data Exchange agreement in April 2017. This was used for mapping the catchment land use profiles in Figure 2. Road densities for each catchment were calculated from a roads network layer using the Voyager open data license in York Region (n.d). Figure 2 shows the different road classes in the two catchments, as found in this road network data. While the Highway 404 passes near the downstream site of the rural catchment, the urban catchment in the southwest has a relatively dense road network with many local roads and residential lanes.

Table 1. Summary of general land cover for the urban catchment in the west and rural catchment in the east. Upstream reach contributing areas indicate the area that drains into the upstream catchment, while the downstream reach contributing area indicates the whole catchment area that drains into it.

\begin{tabular}{lllllll}
\hline $\begin{array}{l}\text { Reach Contributing } \\
\text { Area }\end{array}$ & $\begin{array}{l}\text { Community / } \\
\text { Infrastructure } \\
(\boldsymbol{\%})\end{array}$ & $\begin{array}{l}\text { Road } \\
\text { Length } \\
\text { Density } \\
(\mathbf{k m})\end{array}$ & $\begin{array}{l}\text { Agriculture and } \\
\text { Undifferentiated } \\
\text { Rural Land Use } \\
(\boldsymbol{\%})\end{array}$ & $\begin{array}{l}\text { Deciduous } \\
\text { Forest } \\
(\boldsymbol{\%})\end{array}$ & $\begin{array}{l}\text { Coniferous } \\
\text { Forest } \mathbf{( \% )})\end{array}$ & $\begin{array}{l}\text { Mixed } \\
\text { Forest } \\
(\boldsymbol{\%})\end{array}$ \\
\hline Urban Upstream & 14.16 & 1.74 & 59.74 & 1.83 & 1.08 & 4.80 \\
\hline Urban Downstream & 52.02 & 5.24 & 27.33 & 3.78 & 2.42 & 5.40 \\
\hline Rural Upstream & 20.62 & 2.58 & 38.42 & 13.05 & 2.77 & 4.61 \\
\hline Rural Downstream & 19.84 & 2.51 & 39.68 & 11.67 & 3.31 & 5.15 \\
\hline
\end{tabular}




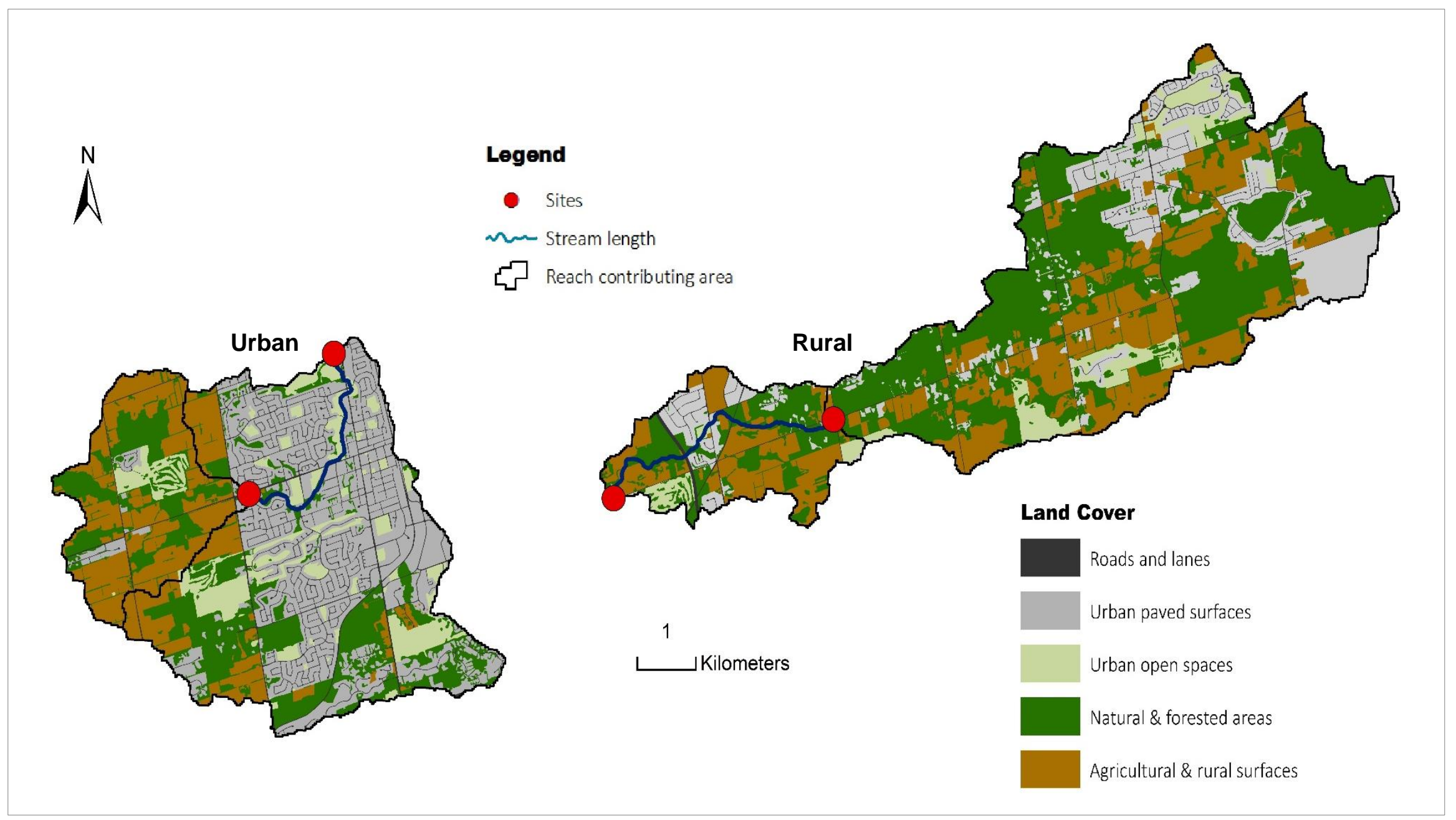

Figure 2. Land use profiles of the two catchments extracted from a detailed land classification layer by the Lake Simcoe Region Conservation Authority, based on 2013 aerial photography with $15 \mathrm{~cm}$ resolution. Only the study stream lengths are shown in the map. 


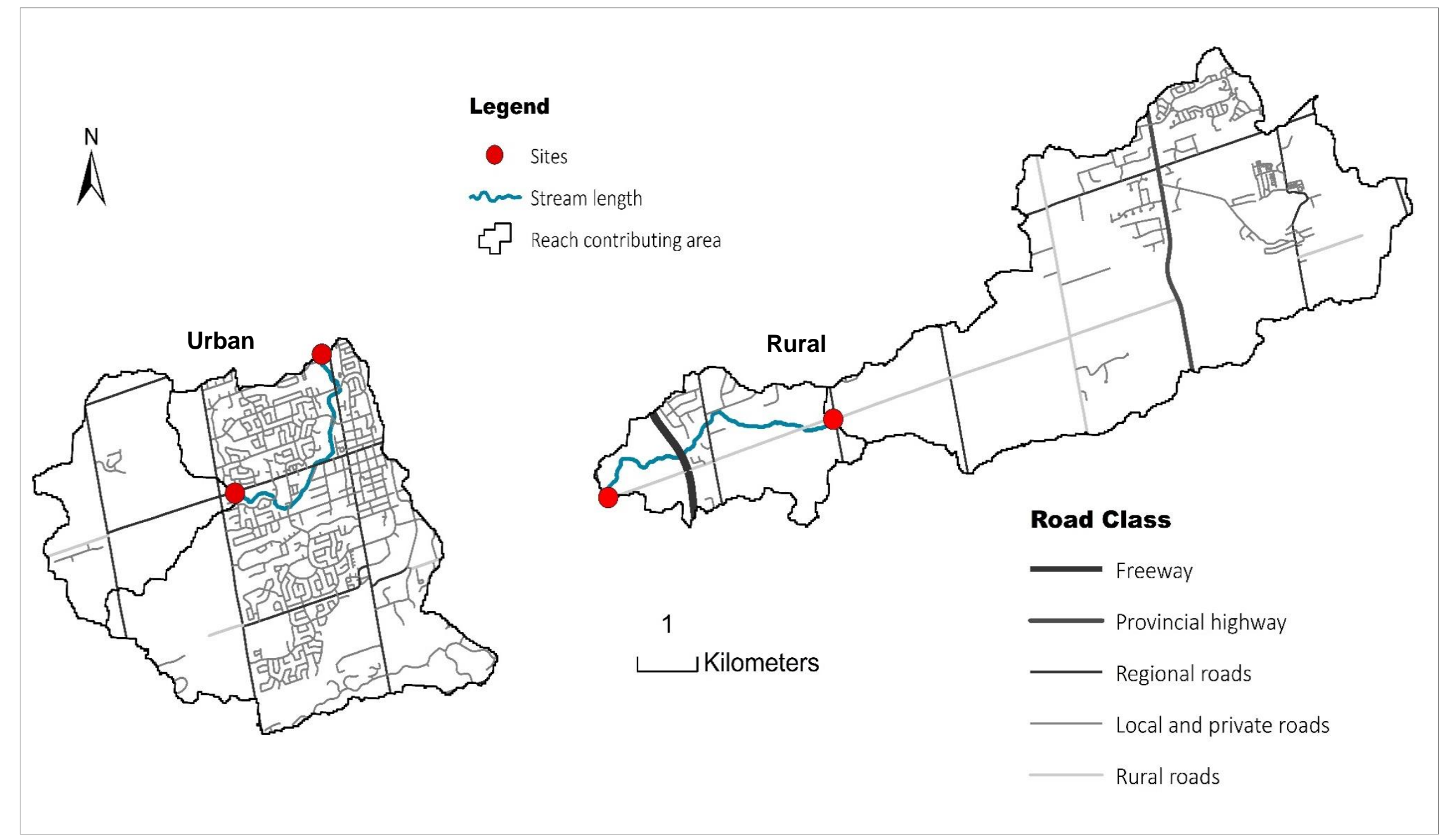

Figure 3. Road networks of the two catchments from York Region Voyager open data license (2017). Only the study stream lengths are shown in the map. 
A 10m Digital Elevation Model (DEM) was downloaded from the Ontario Open Data Catalogue (2017) for generating the stream network for the catchments. The Ontario Integrated Hydrology Data from Ontario Open Data also provides a provincial stream network with stream order and stream-enforced DEM in 30m resolution. This stream network was used for cross-checking the accuracy of the generated stream and pour points. The study stream length was calculated by clipping and measuring the polyline connecting the upstream and downstream sites in each catchment. Using the 3D Analyst extension in ArcGIS 10.4.1, elevation profiles were created from the $10 \mathrm{~m}$ DEM for longitudinal and lateral sections of the stream. Figure 4 shows the DEM and the longitudinal (stream to stream) elevation profiles created from the DEM that was used for measuring slope. Figures 5 and 6 show the elevation profiles from lateral cross-section of the stream at each site, along with field photos. Together with site visits and fieldwork, the elevation profiles allowed an improved understanding of stream structure and behaviour. As shown in Figure 5, the urban sites in the southwest are both close to roads and impervious surfaces, with storm pipes connected directly to the streams. The rural sites are much more remote with intact riparian area and no storm pipes (Fig. 6).

For information about the soil type and permeability in each catchment, geospatial data was collected through Land Information Ontario from the Ontario Ministry of Agriculture, Food and Rural Affairs (OMAFRA, 2016). This came in the form of a Soil Survey Complex published in 2016 containing the soil name, stoniness ( 0 to 2 ) and drainage quality (poor, well, very well). Figure 7 shows the soil profile for the two catchments extracted from this Soil Survey Complex.

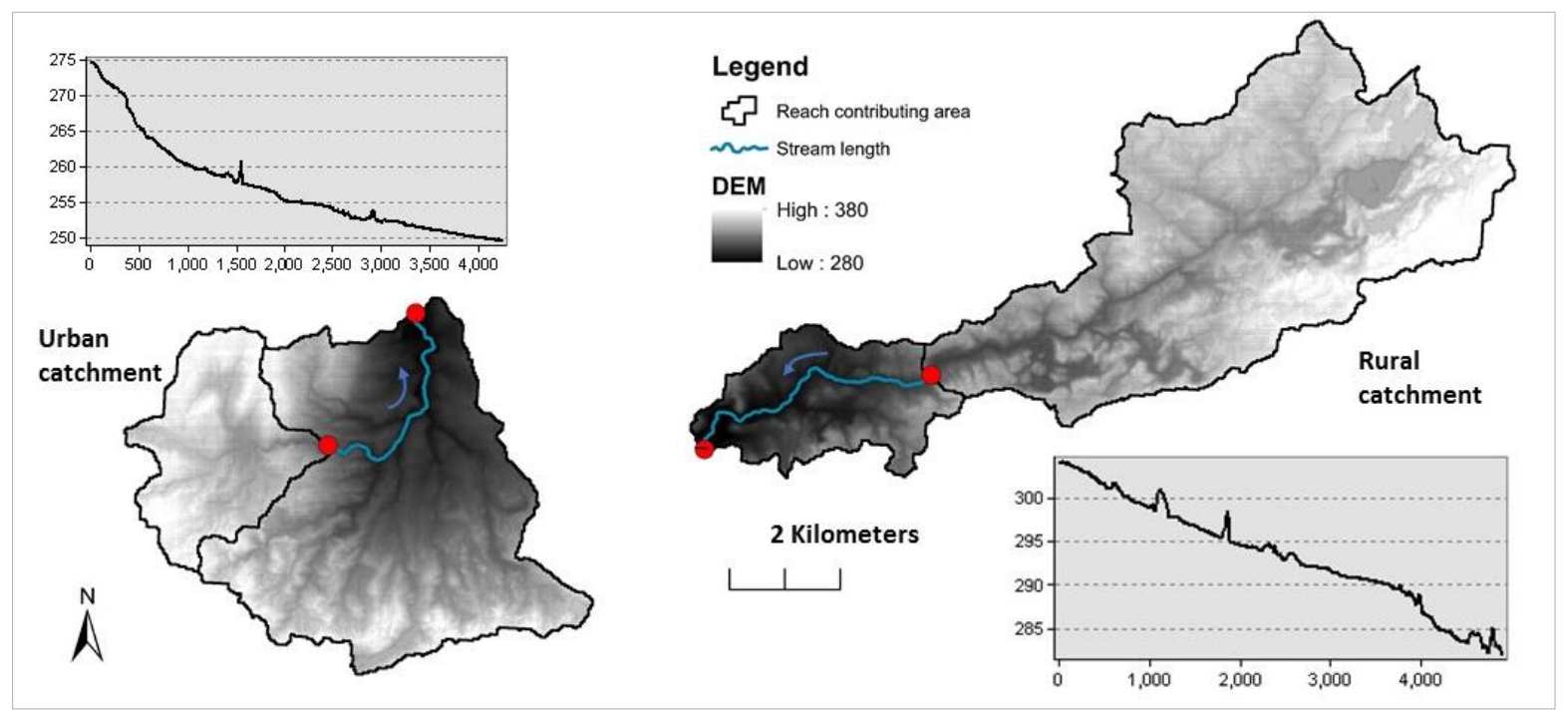

Figure 4. Elevation (meters) profile for upstream to downstream longitudinal streamflow, created from $10 \mathrm{~m}$ DEM of the two catchments. Only the study stream lengths moving from upstream to downstream are shown on the DEM. Length and slope of the study streams were calculated for the urban (west) and rural (east) catchments using GIS. 

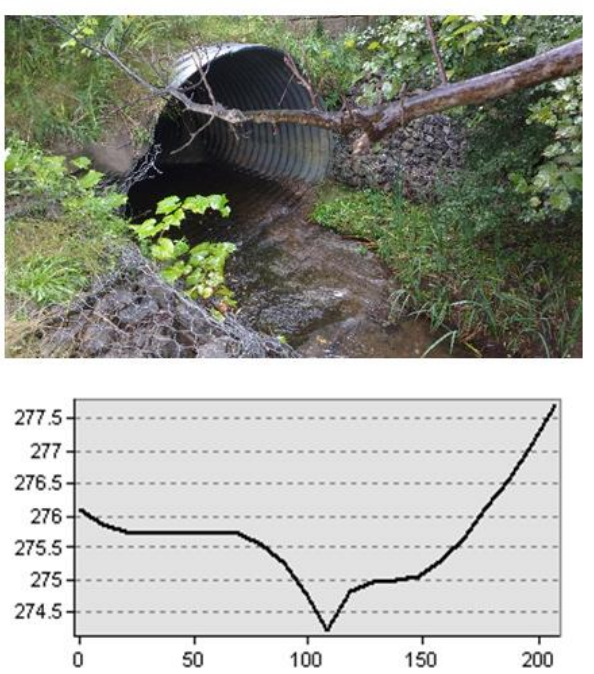

(a) Upstream site in the urban catchment
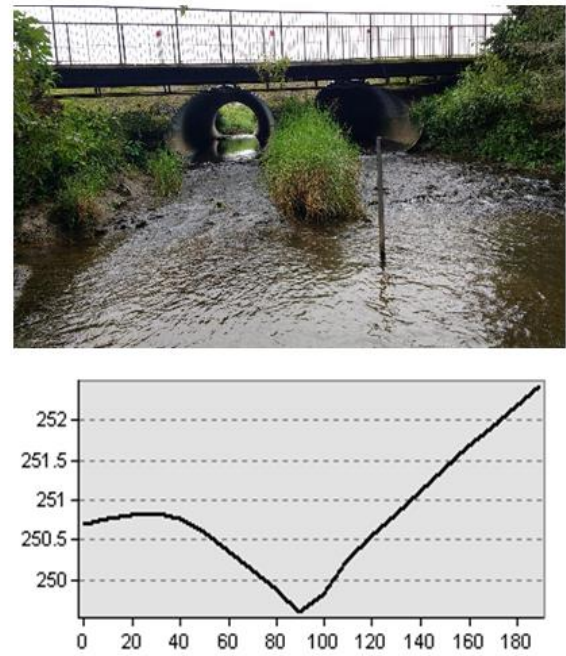

(b) Downstream site in the urban catchment

Figure 5 Elevation (meters) profile of a lateral cross-section of each stream site in the urban catchment, (a) shows the upstream site and (b) shows the downstream site.
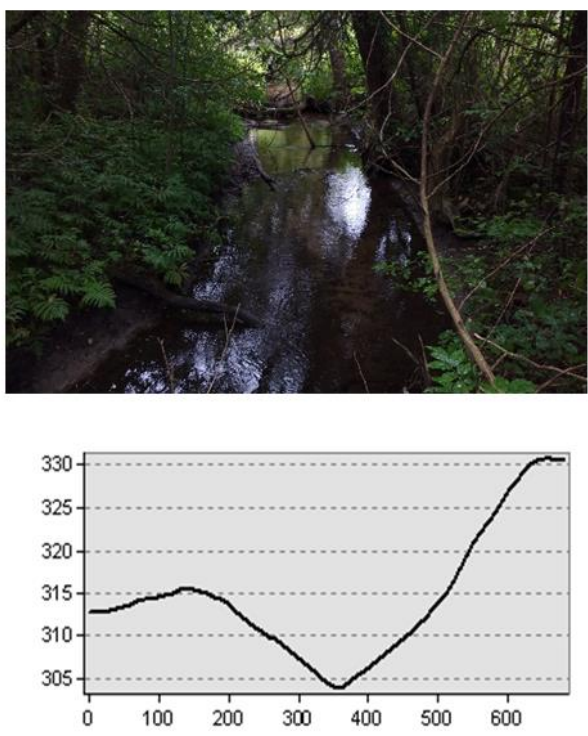

(a) Upstream site in the rural catchment
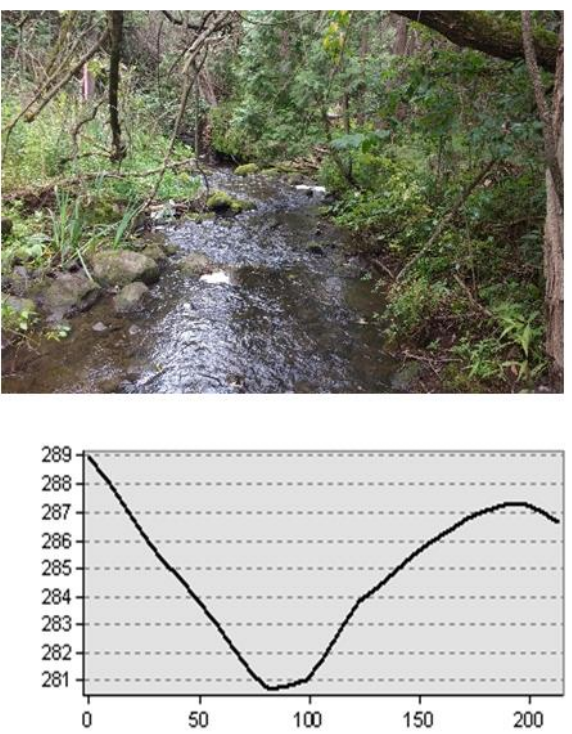

(b) Downstream site in the rural catchment

Figure 6 Elevation (meters) profile of a lateral cross-section of each stream site in the rural catchment, (a) shows the upstream site and (b) shows the downstream site. 


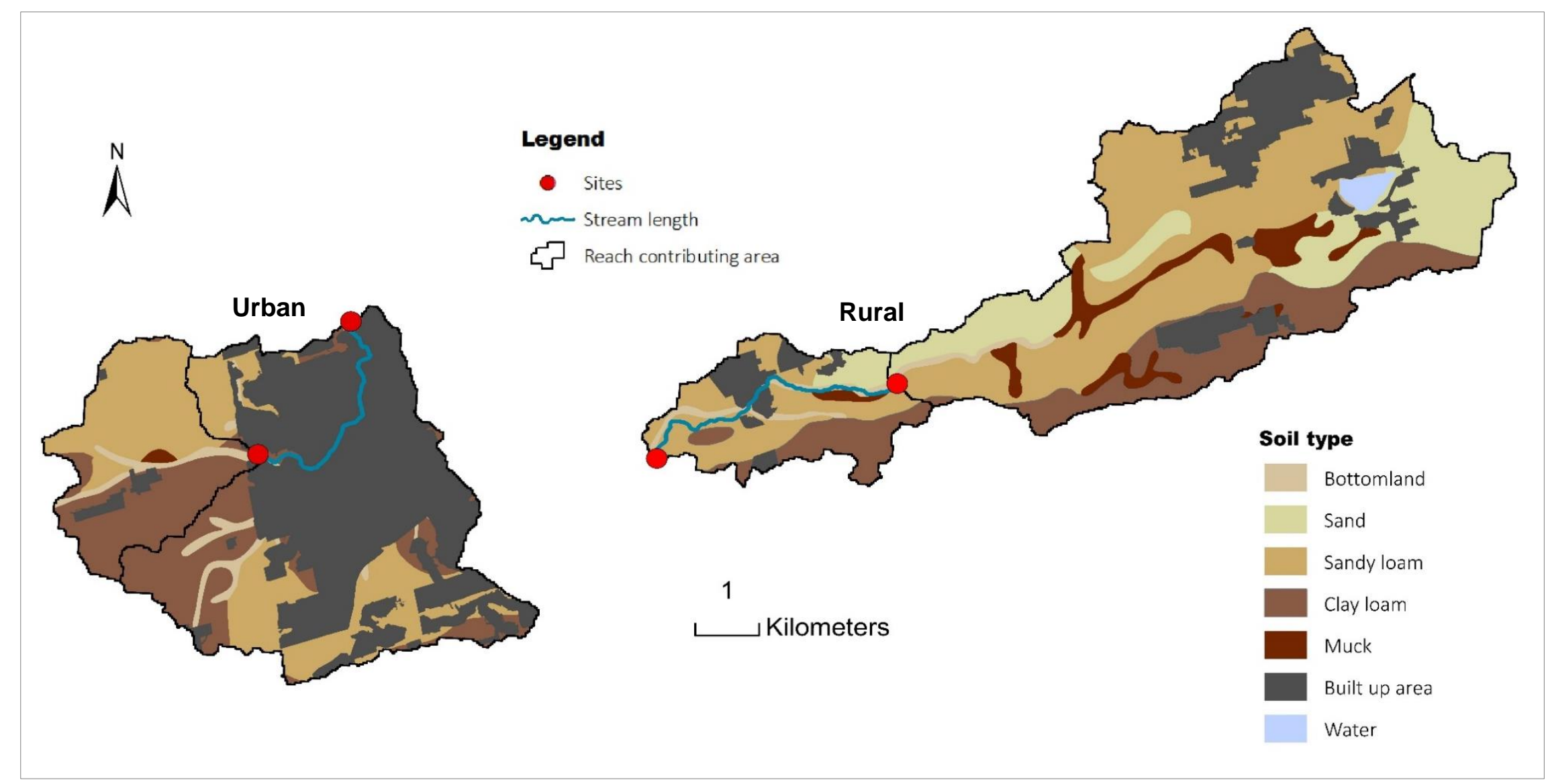

Figure 7 Soil profiles of the two catchments extracted from a Soil Survey Complex by Ontario Ministry of Agricultural, Food and Rural Affairs (2015). Only the study stream lengths are shown in the map. 
Even within the catchments, there are spatial and structural differences among the sites and their reach contributing areas, as suggested in Table 1 and Figures 2,3 and 7 showing the land use, road networks, and soil profiles on the two catchments. The upstream site in the urban catchment in the west has not been urbanized yet and contains lots of natural and agricultural coverage. The downstream location in the rural and natural catchment in the west has more overall percentage of urbanized areas as the urban infrastructure in Aurora keeps growing. In addition, the downstream site in the rural catchment is a km downslope from a major highway. The longitudinal time lags were analyzed from the catchment-scale land use, soil, and roads network maps. For analyzing the lateral exchange from stream to hyporheic zone, a closer look at the possible exchange pathways was required. Buffers were drawn with $1 \mathrm{~km}$ radius around each site, and land use, soil profile, and road networks were clipped for the buffers using the Spatial Analysis extension in ArcMap 10.4.1. These buffers were analyzed for an overall perception of hyporheic connectivity in the sampled area.

Additionally, the land use and soil profiles in this section were combined with the elevation profiles to create 3D visualizations of catchment cross-sections in ArcScene, which considerably aided the conceptual understanding of streamflow and $\mathrm{Cl}$ transport with respect to spatial and structural characteristics. The LSRCA land cover allowed for further delineation of buildings (in the urban catchment) and designated forests (in the rural catchment) that were used in the 3D representations.

\subsection{Time Series Data}

Each of the four sites (upstream and downstream on the two reaches) were equipped with two Solinst LTC Levelogger sensors to measure water level (total head), temperature and specific conductivity (EC): one in the stream (resting in a PVC housing on the stream bed), and another in the hyporheic zone (suspended inside a PVC piezometer with a $20 \mathrm{~cm}$ slotted section located $20-40 \mathrm{~cm}$ below the surface in the stream bank). The horizontal distance between the stream and hyporheic sensors varied from 2 to $5 \mathrm{~m}$. Continuous data from the Leveloggers were corrected for atmospheric pressure using data from a Solinst Barologger located within $10 \mathrm{~km}$ of the sites. Each dataset was also corrected for manual sampling events according to the field logs, and all missing data were removed. Data for all four sites were available from 2016-04-05 to 2017-04-11, at hourly intervals till 2016-09-15 and at 15-minute intervals thereafter. For the purpose of this study, we used data from the winter salting season and summer growing season, in order to explore seasonal differences as well as the effects of data intervals in cross-correlation. Therefore, this study was based on 15-minute data from the winter salting period (2016-11-15 to 2017-02-28) when most of the snowfall had occurred, and hourly data from the summer growing period (2016-05-01 to 2016-08-31) when 
most of the spring melt would have ended and a particularly dry summer season had started. The corrected time series for water level and EC of all sites can be found in Appendix A.

When discussing the complexity of exchange pathways between stream and groundwater through the subsurface, Fleckenstein et al. (2010) concluded that EC is a viable natural tracer for a better understanding of these pathways. This was of primary interest in this study as it aimed to explain subsurface lateral exchange in the hyporheic zone along with the longitudinal stream-to-stream flow. To relate EC with $\mathrm{Cl}$, a commonly used approach (e.g. Perera et al., 2009) was used, where grab samples were collected approximately twice per month between September 2015 and April 2016 at all sites. Chloride concentrations were measured in these samples at the University of Waterloo and the results were used to develop linear relationships between $\mathrm{EC}$ and $\mathrm{Cl}$ concentration. The correlation coefficient $\left(\mathrm{R}^{2}\right)$ was 0.78 for streams and 0.93 for hyporheic zones using data from all sites, suggesting a strong linear relationship. At the time of this study, $\mathrm{Cl}$ measurements from grab samples were not available for the full study period of May 2016 to February 2017, therefore EC was used as a more reliable proxy for Cl. Figure 8 shows an example of corrected EC time series at the upstream and downstream sites of the urban catchment during the winter salting period, with a close-up view of 15-minute data from 2017-02-27 showing the lagged downstream trends following the upstream EC.

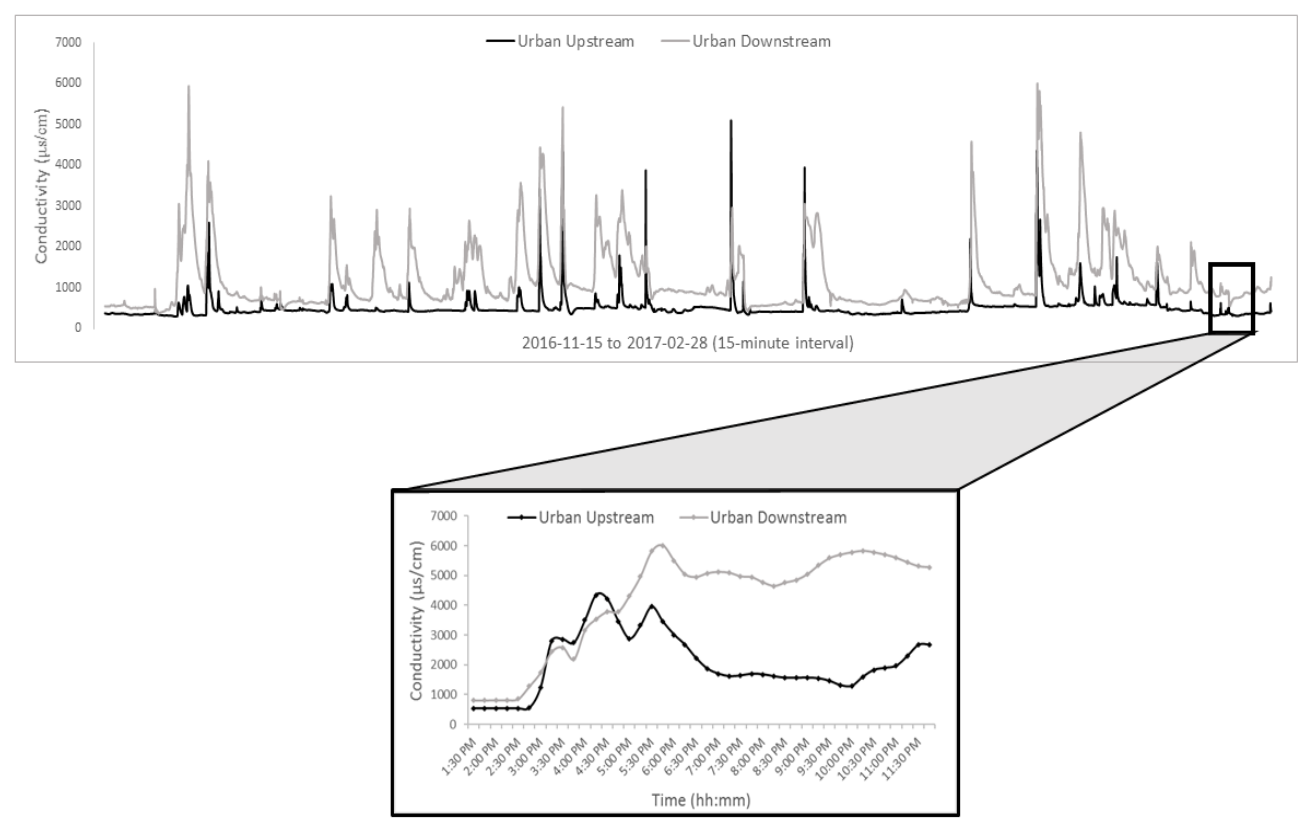

Figure 8. Sample of time series showing conductivity (EC) from winter salting season (2016-11-15 to 2017-02-28) at the upstream and downstream sites of the urban catchment. Close-up view shows data at 15-minute interval on 2017-02-27. 


\subsection{Spatial Cross-Correlation}

Cross correlation function $(\mathrm{CCF})$ is a process that matches the observations at one data series to those of another at different time lags and leads. The optimum time lag required for a signal (or trend) to appear from an input series to an output is found at the highest correlation coefficient. A negative time lag is found when the second series in the pair is leading in the trends rather than having a lagged response. For two data series $\mathrm{X}$ and $\mathrm{Y}$ that are functions of time, the cross-correlation function at a time lag $\Delta t$ can be calculated as:

$r_{\Delta t}=\frac{(N-\Delta t)\left[\sum Y_{i+\Delta t} X_{i}-\sum Y_{i+\Delta t} \sum X_{i}\right]}{\left.\sqrt{\left((N-\Delta t) \sum Y^{2}{ }_{i+\Delta t}-\left(Y^{2}{ }_{i+\Delta t}\right)^{2}\right)(N-\Delta t)} \sum X_{i}^{2}-\left(\sum X_{i}{ }^{2}\right)\right)}$

where $r_{\Delta t}$ is the cross-correlation coefficient for a total of $N$ number of data pairs and $(N-\Delta t)$ is the overlapping times in the two series (Davis, 1986). Statistical software IBM SPSS was used for all calculations of CCF. For longitudinal time lags, each upstream data as an input series and was paired with the downstream data as the output or response series. For lateral exchange, the stream sensor data were used as input series, although regular stream-hyporheic mixing suggests we may observe both lags and leads here. A negative value for lag, in this case, meant that the hyporheic zone is leading the EC trends.

For testing the accuracy and significance of cross-correlation results, t-tests are often used to determine a critical $r$ at which the resultant time lags will be significant (Feinstein, 1996). This has been practiced for previous spatial-environmental modelling studies that used cross-correlation analysis on monthly or yearly data, where the maximum number of data pairs (i.e. $N$ ) were up to 200-300 (Dewalle et al., 2016; Ko and Cheng, 2004). However, in a large time series with dynamic waveform, the correlation of two series is also a changing process (Chandler and Scott, 2011). Unlike traditional correlation coefficients (e.g. Pearson correlation), the cross-correlation coefficient $r$ is not a good measure of correlation between two time series, rather an indicator of where the optimum time lag is located. This becomes more evident for continuous time series data where the value for $N$ can be exceedingly large. For example, the lowest number of data pairs was $N=2952$ for summer when only hourly data was recorded. Following a t-test becomes extraneous for such a large $N$, and with a z-test for large samples, p-value at 0.01 (i.e. $99 \%$ confidence interval), $r>0.081$ or $r<-0.081$ would be statistically significant to reject the null hypothesis. For winter (15-minute data), the value for $N$ became as large as 10170 , meaning that the critical $r$ value would be closer to 0 . Therefore, for any time series analysis, testing for coherency is more appropriate than the regression coefficient (Warner, 1998). In signal processing, coherency, or squared coherence $\left(\omega^{2}\right)$ plotted over frequency, is the equivalent to regression coefficient (generally represented as the $\mathrm{R}^{2}$ value) and is considered a good measure for causality between two series even when they are shifted 
in time (Granger, 1969). Cross-spectral analyses were conducted in IBM SPSS to obtain coherency plots over frequency, and maximum peaks of squared coherence $\left(\omega^{2}\right)$ were recorded for each time series pair.

\subsection{Velocity Calculation}

Due to structural differences in stream length and slope, flow velocities rather than time lags should be compared to study the land use effects on the two catchments. Longitudinal flow velocities from upstream to downstream site in each catchment were calculated by dividing the stream length from Fig. 2 over the measured time lag. For better comparison of these velocities by accounting for the difference in stream slope calculated in Figure 4, the velocity $V$ was divided by the square-root of slope. This was done by solving the Manning's equation for open channel flow for velocity (Stanley et al., 2015):

$$
\begin{aligned}
& V=\frac{k}{n}\left(R^{2 / 3}\right) \sqrt{\text { slope }} \\
& \frac{V}{\sqrt{\text { slope }}}=\frac{k}{n}\left(R^{2 / 3}\right)
\end{aligned}
$$

where $k$ is a constant, $R$ is the wetted perimeter of the stream channel, and $n$ is Manning's roughness coefficient that varies for different land cover surfaces. Thus, velocity over $\sqrt{\text { slope }}$ is a more appropriate measure for comparing the effect of land use while factoring in the elevation difference in the two catchments. Also, since the relationship between velocity and slope is not linear but monotonic, comparing $V / \sqrt{ }$ slope provides an acceptable way to account for the variation of slope. Further specificity can be added to this process by calculating the wetted perimeter for each stream using measurements from lateral elevation profiles in Figure 3. However, exact depth and shape profiles for lateral cross-sections of the stream could not be measured for this study, and estimates from the 10-m DEM did not produce any significant change in the velocities as some of the streams were less than $10-\mathrm{m}$ in width and/or depth. Furthermore, as these perimeters can vary with seasonal flow conditions, a better approximation might be to calculate them in future models by putting in observed $V$ and $n$ values from cross-correlation results and land cover profiles. For the purpose of this study, $V / \sqrt{ }_{\text {slope }}$ provided sufficient information about the influence of spatial differences in the two catchments. In case of the lateral time lags, velocities were calculated by dividing the distance between the stream and hyporheic sensor over the observed time lag from CCF. Almost all sites had a $2 \mathrm{~m}$ distance between the stream and hyporheic sensors, with the exception of the wider urban upstream site where the hyporheic sensor near the riparian zone was $5 \mathrm{~m}$ away from the stream sensor. At this small spatial scale, the slope between the sensors did not appear to make significant difference in the lateral exchange velocities (less than 0.002), so these could be compared directly. 


\subsection{Catchment Characteristics for Longitudinal Trend Analysis}

Table 2 summarizes the catchment characteristics computed for each reach contributing area in this study. The stream lengths from upstream to downstream were measured from the stream network generated from the $10 \mathrm{~m}$ DEM, and stream slopes were calculated from the elevation profiles shown in Figure 4 . The measured stream lengths and slopes were used for velocity calculation from the longitudinal crosscorrelation results.

Table 2. Summary of catchment characteristics computed for the urban catchment in the west and rural catchment in the east. Upstream reach contributing areas indicate the area that drains into the upstream catchment, while the downstream reach contributing area indicates the whole catchment area that drains into it.

\begin{tabular}{|c|c|c|c|c|c|c|c|}
\hline $\begin{array}{l}\text { Reach Contributing } \\
\text { Area }\end{array}$ & $\begin{array}{l}\text { Drainage } \\
\text { Area } \\
\left(\mathbf{k m}^{2}\right)\end{array}$ & $\begin{array}{l}\text { Length } \\
\text { of main } \\
\text { channel }\end{array}$ & $\begin{array}{l}\text { Slope of } \\
\text { Main } \\
\text { Channel } \\
(\%)\end{array}$ & $\begin{array}{l}\text { Mean } \\
\text { Slope of } \\
\text { Catchment } \\
(\%)\end{array}$ & $\begin{array}{l}\text { Length } \\
\text { of } \\
\text { Studied } \\
\text { Stream }\end{array}$ & $\begin{array}{l}\text { Slope } \\
\text { of } \\
\text { Studied } \\
\text { Stream } \\
(\%)\end{array}$ & $\begin{array}{l}\text { Mean } \\
\text { Annual } \\
\text { Flow } \\
\left(\mathbf{m}^{3} / \mathbf{s}\right)\end{array}$ \\
\hline Urban Upstream & 7.28 & 5.98 & 1.17 & 4.99 & NA & NA & NA \\
\hline Urban Downstream & 29.52 & 11.56 & 0.82 & 4.78 & 5.59 & 0.63 & 0.23 \\
\hline Rural Upstream & 29.58 & 15.70 & 0.41 & 4.01 & NA & NA & NA \\
\hline Rural Downstream & 36.36 & 22.00 & 0.39 & 4.01 & 6.31 & 0.07 & 0.25 \\
\hline
\end{tabular}

\subsection{Longitudinal Time Lags and Velocities}

\subsubsection{Winter Salting Season}

The cross-correlation function $(\mathrm{CCF})$ for all time-series pairs resulted in statistically significant maximum coefficients i.e. $-0.081>r>0$. 081. Figure 9 show the resultant time lags from the longitudinal (upstream to downstream) pairs for the urban and rural catchment in winter. Table 3 shows a summary of these time lags and their calculated velocities. For the longitudinal data where slope differences were more prominent for the two stream reaches, the $V / \sqrt{ }$ Slope $(\mathrm{km} / \mathrm{h})$ is compared. 
Cross-spectral analysis for each time series pairs produced strong coherency values throughout most of the frequency. Coherency plots for all data series can be found in Appendix B. The default smoothing provided by SPSS (Tukey-Humming) for cross-spectral plots was sufficient in this case, as coherency was only used to ensure the validity of the cross-correlation time lag results, i.e. to ensure that one time series is indeed responding to the trends in the other series before/after the lead/lag time observed. Coherency values showed strong peaks for both longitudinal values in winter. This indicates that EC trends are indeed being carried from the input series to the output series.

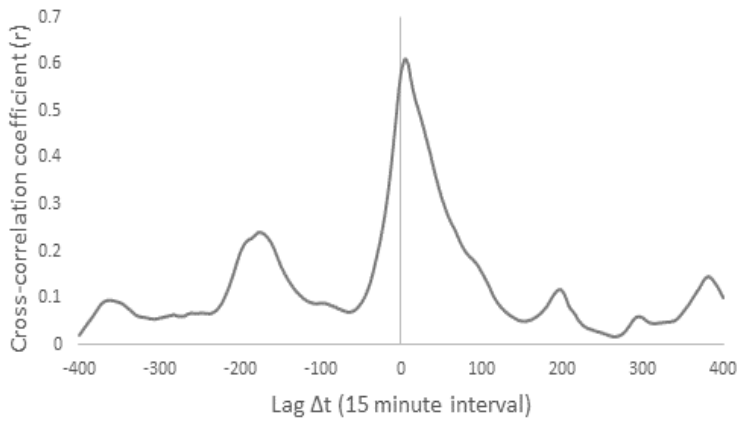

(a) Urban upstream to downstream lag

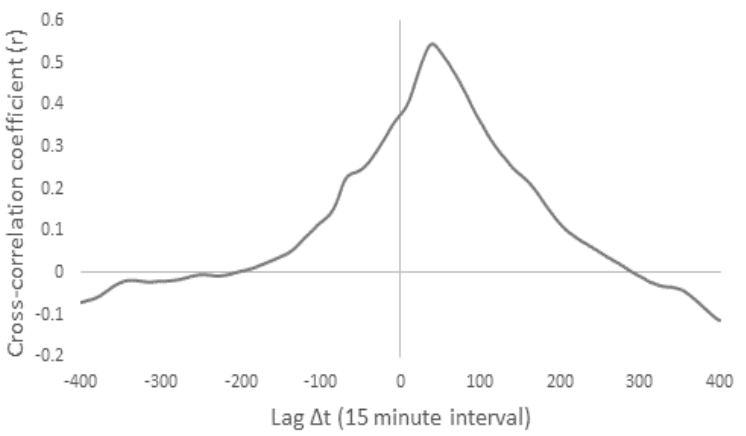

(b) Rural upstream to downstream lag

Figure 9. Cross-correlation results for longitudinal (upstream to downstream) time lags in the urban and rural catchments during the winter salting season (data at 15-minute interval from 15 November 2016 to 28 February 2017).

Table 3. Cross-correlation and velocity results for longitudinal (upstream to downstream) analysis in the urban and rural catchments during a winter salting season (data at 15-minute interval from 15 November 2016 to 28 February 2017).

\begin{tabular}{llclccc} 
Stream & $\begin{array}{l}\text { Lag } \Delta t \\
(\text { hours) }\end{array}$ & $\begin{array}{l}\text { Highest Correlation } \\
\text { Coefficient } \boldsymbol{r}\end{array}$ & $\begin{array}{l}\text { Standard } \\
\text { Error }\end{array}$ & $\begin{array}{l}\text { Velocity } \\
(\mathbf{k m} / \mathbf{h})\end{array}$ & $\begin{array}{l}\boldsymbol{V} / \sqrt{ } \text { Slope } \\
(\mathbf{k m} / \mathbf{h})\end{array}$ & $\begin{array}{l}\text { Maximum } \\
\text { Coherency } \\
\text { Peaks }\left(\omega^{2}\right)\end{array}$ \\
\hline Urban & 1.25 & 0.61 & 0.01 & 4.47 & 5.65 & 0.82 \\
\hline Rural & 10 & 0.54 & 0.01 & 0.63 & 0.85 & 0.80
\end{tabular}


As seen in Table 3, the time lag for EC trends to appear from upstream to downstream location in the urban catchment was a little over an hour, while it took 10 hours from the rural upstream to downstream location. Factoring in the differences in length and slope of the two streams, longitudinal velocity in the urban stream $(5.65 \mathrm{~km} / \mathrm{h})$ was observed to be almost 7 times higher than the rural $(0.85 \mathrm{~km} / \mathrm{h})$. The urban catchment in the west is altogether 52\% urbanized with most of its agricultural lands located in the upstream reach area (Table 1). From the land use profiles and road networks in Fig. 2 and 3, it is clear that the urban stream reach runs along the urbanized areas of the catchment in Aurora, passing the dense road network that contributed to its total road length density of $5.24 \mathrm{~km}$. In contrast, the rural catchment in the east is about $20 \%$ urbanized with half the road length density $(2.51 \mathrm{~km})$, and the stream length flows from a highly natural area through a combination of rural and natural areas to the downstream. The soil profiles (Figure 7) also show that the urban stream is surrounded by impervious surfaces while the rural stream is mostly surrounded by bottomland and sandy loam. These differences point towards the effects of urbanization on the variation of time lags and velocities for longitudinal EC movement in these two catchments.

These results are consistent with a number of studies that have examined the hydrologic impacts of land use changing from natural to agricultural to urban on the quantity of streamflow and solute transport (Conrad and Booth, 2002; Germer, 2009; Burges, 1998). In urban areas with extensive impervious surfaces, most of the precipitation and meltwater (which contains $\mathrm{Cl}$ in the wintertime) will migrate to the streams directly through overland flow via stormwater pipes and, once in stream, move rapidly with little chance of infiltration (Booth, 1991). This is also supported by the relationship seen in equation (3), where velocity is seen to be inversely related to Manning's roughness coefficient $n$. As the Manning's $n$ values are lower for urban impervious surfaces than for natural, agricultural and open surfaces (Kalyanapu, 2010; McCuen, 1998), the flow velocity increases over urban surfaces.

$\mathrm{As} \mathrm{Cl}$ is a conservative ion (i.e. non-reactive), it is often used as a tracer for streamflow (Kirchner et al., 2010). Conversely, the same factors that affect streamflow largely influence $\mathrm{Cl}$ movement through the watershed. However, Martin et al. (2017) identified a gap in the literature that links conservative ions such as $\mathrm{Cl}$ to landscape features. The results from winter salting season, where $\mathrm{Cl}$ is the main contributor of EC, suggest that the velocity of $\mathrm{Cl}$ transport longitudinally through these streams may indeed be connected to variations in land use. 


\subsubsection{Summer Growing Season}

Time lags and velocities over the summer growing season appear to be more difficult to estimate with the conductivity (EC) data. Unlike winter, where $\mathrm{Cl}$ from road salt applications is the chief component of surface water EC values, summer EC is equally affected by multiple sources such as agriculture, sewers, etc. (Eyles and Meriano, 2010). As seen in Figure 10, the cross-correlation coefficients in the urban and rural catchment show a lot of fluctuation in summer compared to the observations in winter (Figure 9). Table 4 summarizes the cross-correlation results for the time lags as well as the calculated velocities. The standard error increased for the summer longitudinal results $(0.02)$ than in winter $(0.01)$. However, the results were still statistically significant for two coherent time series, and can indicate important drivers of EC migration in summer.

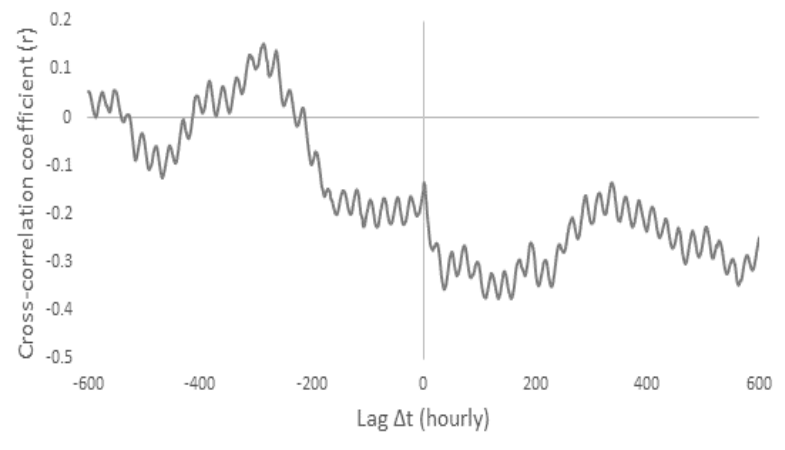

(a) Urban upstream to downstream lag

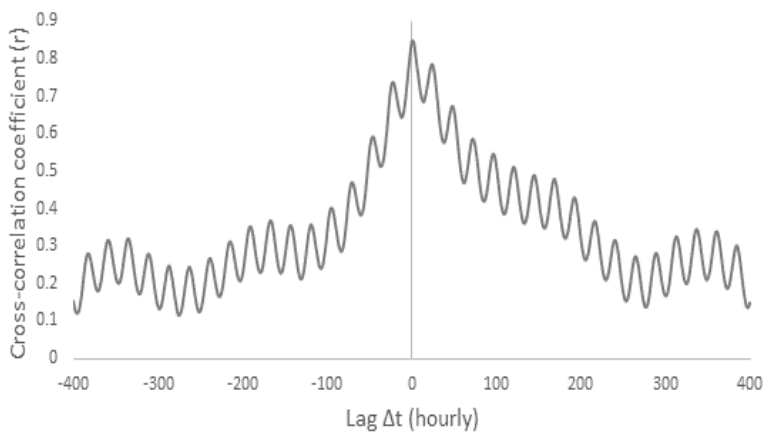

(b) Rural upstream to downstream lag

Figure 10. Cross-correlation results for longitudinal (upstream to downstream) time lags in the urban and rural catchments during the summer growing season (hourly data from 1 May to 30 August, 2016).

Table 4. Cross-correlation and velocity results for longitudinal (upstream to downstream) analysis in the urban and rural catchment during a summer growing season (hourly data from 1 May to 30 August, 2016).

\begin{tabular}{lllllll}
\hline Stream & $\begin{array}{l}\text { Lag } \Delta t \\
\text { (hours) }\end{array}$ & $\begin{array}{l}\text { Highest Correlation } \\
\text { Coefficient } \boldsymbol{r}\end{array}$ & $\begin{array}{l}\text { Standard } \\
\text { Error }\end{array}$ & $\begin{array}{l}\text { Velocity } \\
\boldsymbol{V}(\mathbf{k m} / \mathbf{h})\end{array}$ & $\begin{array}{l}\boldsymbol{V} / \sqrt{\text { Slope }} \\
(\mathbf{k m} / \mathbf{h})\end{array}$ & $\begin{array}{l}\text { Maximum } \\
\text { Coherency } \\
\text { Peaks }\left(\omega^{2}\right)\end{array}$ \\
\hline Urban & $\begin{array}{l}133 \text { to } \\
134\end{array}$ & -0.37 & 0.02 & 0.04 & 0.05 & 0.79 \\
\hline Rural & 1 & 0.85 & 0.02 & 6.31 & 8.46 & 0.92
\end{tabular}


Unlike during the winter salting season, the cross-correlation function returned a longer time lag of 133-134 hours (at velocity $0.05 \mathrm{~km} / \mathrm{h}$ ) for the urban catchment and a shorter time lag of 1 hour $(8.46 \mathrm{~km} / \mathrm{h}$ ) for the rural catchment. The summer of 2016 was a particularly dry one in this part of Southern Ontario, with little to no precipitation and low flow conditions throughout the season. Eyles and Meriano (2010) found that for the urban basins in Pickering, Ontario, groundwater contributions to surface water EC during the summer led to brackish water throughout the year. This is discussed in more detail in the Results and Discussion (Section 3.4.2) for lateral exchange in summer. For longitudinal flow, this meant the crosscorrelation results may not be producing realistic results for upstream to downstream time lags in the urban area, as water and EC may not be migrating at the same rates. As seen in Tables 3 and 4, the longitudinal coherency also decreased slightly for the urban stream in summer than in winter.

In the rural catchment, the longitudinal time series pairs were strongly coherent with an increase in the coherency maximum peaks in summer. With no frozen conditions, the EC appeared to have readily flowed downslope through the stream length in an hour or less (at velocity $8.46 \mathrm{~km} / \mathrm{hr}$ ), possibly aided by subsurface outflow from groundwater storage of both water and EC. This can be related to the results of Germer et al. (2009) and Tanaka (1992), who found quickflow predominated in forested and pasture lands in both wet and dry conditions, with forested catchments exporting some of their solutes such as $\mathrm{Cl}$ through groundwater outflow. Although quickflow possibly dominated in the urban catchment as well (crosscorrelation of water levels showed a lag of an hour or less), the subsurface outflow of water and EC to the stream may be more complex here and at different rates at different spots, likely producing different EC peaks in upstream and downstream leading to unpredictable longitudinal results (Appendix A2.1-A2.2).

\subsection{Site Buffers for Lateral Trend Analysis}

While the longitudinal flow velocities rely mostly on factors such as land use and impervious cover of the whole reach-contributing area, subsurface interactions vary according to the riparian cover, the soil drainage quality under stream bed, the specific types of land use and roads that provide the $\mathrm{Cl}$ input to the reach, $\mathrm{Cl}$ concentration, etc. Therefore, this not only varies across catchments but also within a catchment. Local information gathered through GIS and field observations provided greater insight into the potential drivers of lateral subsurface transport than catchment-scale land cover. Buffers were created around $1 \mathrm{~km}$ radius of each site and clipped for the profiles shown in Figure 2, 3 and 7 for land use, roads network, and soil complex. These buffer profiles helped analyze the stream-hyporheic lags and velocities by considering potential pathways for lateral exchange. Figures 11 shows the buffers clipped for each site (upstream and downstream) in the urban catchment and Figure 12 shows those in the rural catchment. 


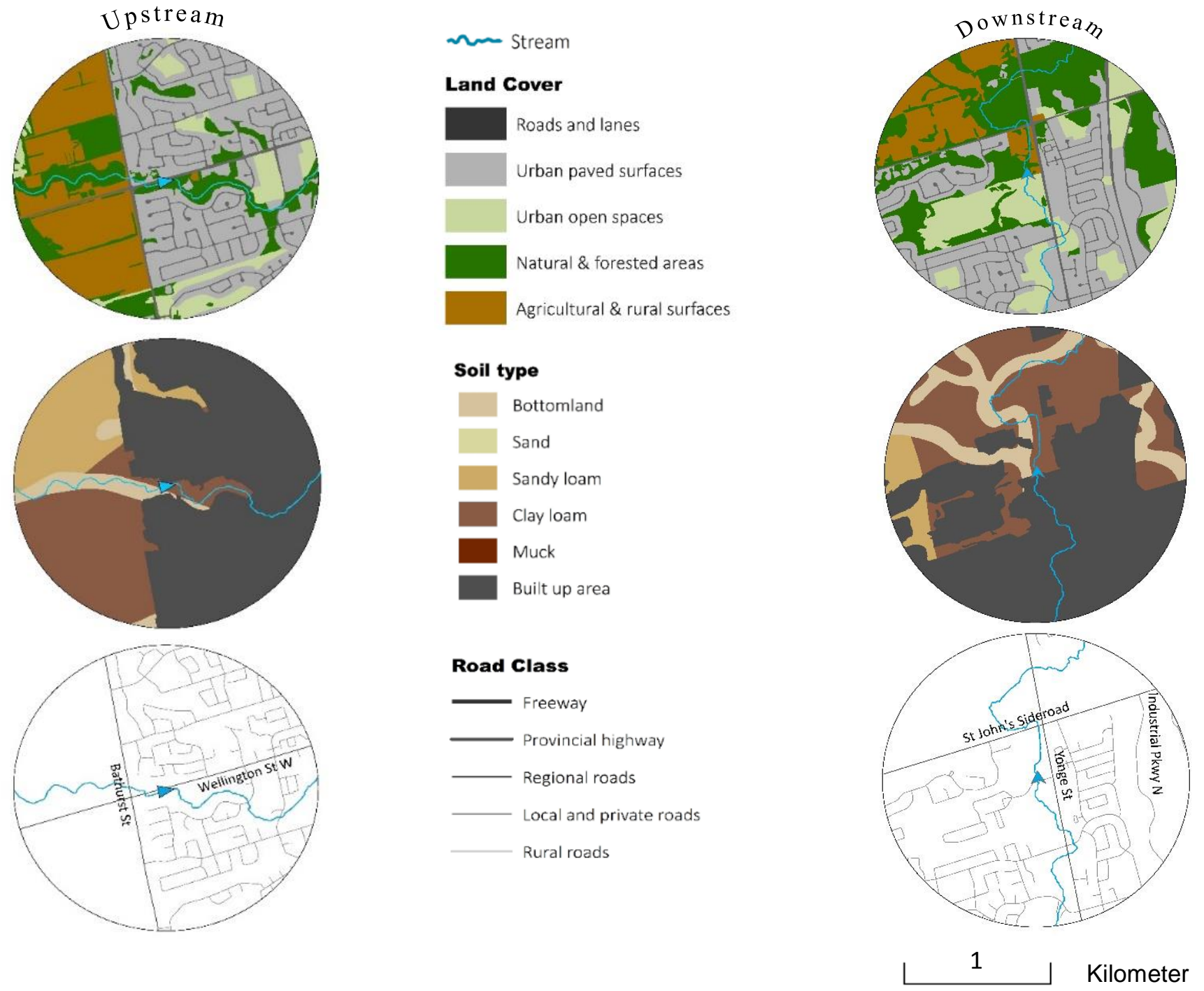

Figure 11. Radial maps for $1 \mathrm{~km}$ buffer areas in the urban upstream and downstream sites, each buffer showing the land cover, soil profile, and road network within a kilometer of the stream and hyporheic sensors. 


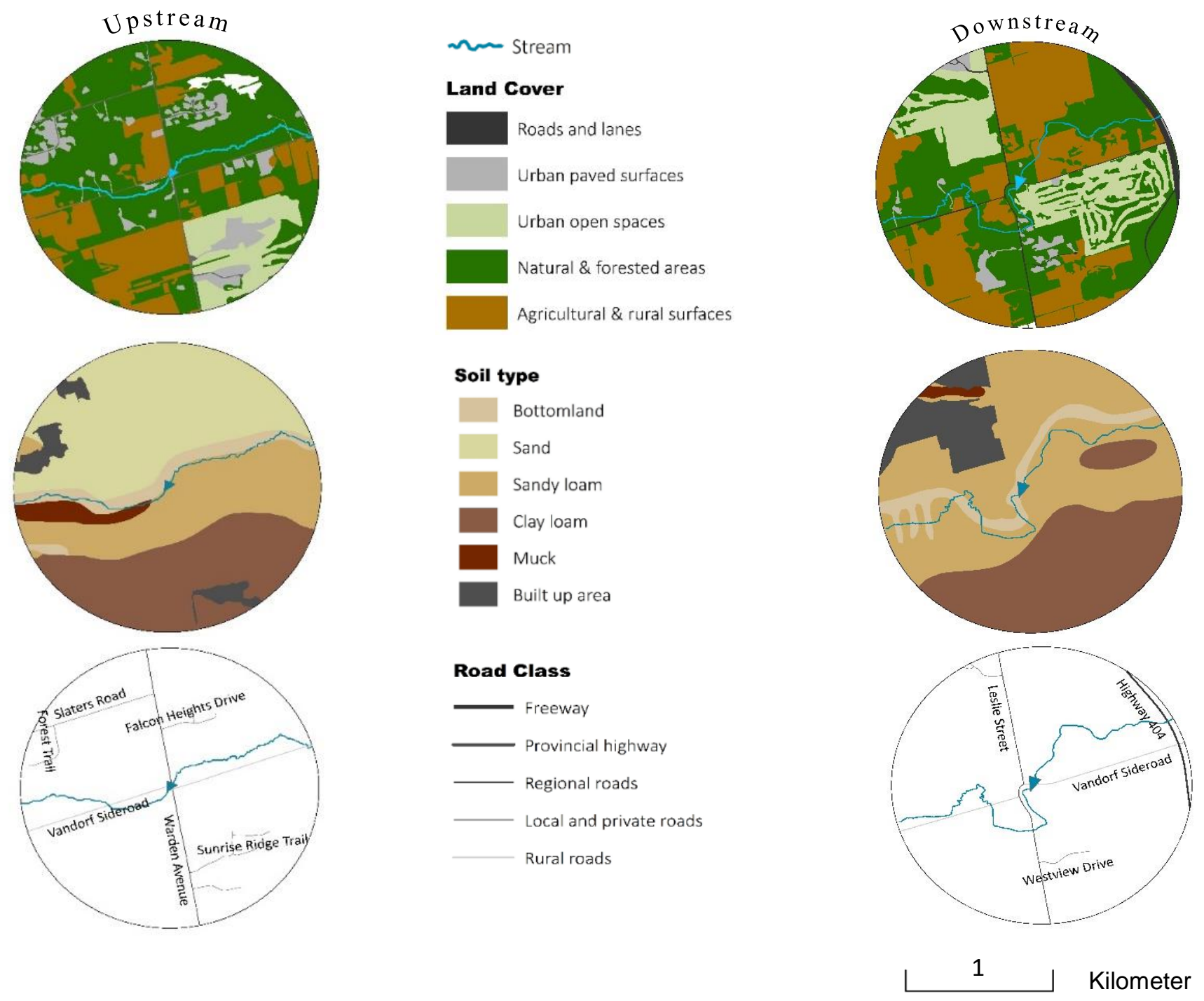

Figure 12. Radial maps for $1 \mathrm{~km}$ buffer areas in the rural upstream and downstream sites, each buffer showing the land cover, soil profile, and road network within a kilometer of the stream and hyporheic sensors. 


\subsection{Lateral Time Lags and Velocities}

\subsubsection{Winter Salting Season}

The stream and hyporheic sensors were located $2 \mathrm{~m}$ apart in the urban upstream site and $5 \mathrm{~m}$ apart in the urban downstream site where the stream is wider with the riparian zone a bit further away from the central stream (see field photos and lateral elevation profiles in Figure 5). The sensors were $2 \mathrm{~m}$ apart in both the rural sites (upstream and downstream). Accurate measurements of slope could not be obtained from the $10 \mathrm{~m} \mathrm{DEM}$ at such small distances. At this scale however, the velocity of water and $\mathrm{Cl}$ through pores in the soil appear to be more affected by factors such as soil structure, texture, water content, and solute application, as suggested by Zhou and Wang (2017), than on elevation. These factors can all be affected by land use and soil profiles. Thus, lateral exchange velocity computed using the distance between sensors were compared for the different sites. The winter cross-correlation results for lateral streamhyporheic exchange are presented in Figure 13 and Table 5 as follows. The time series pairs for lateral exchange were strongly coherent (coherency peaks from 0.70 to 0.88 ) in winter, and cross-correlation results were statistically significant $(r>0.081)$ with a standard error of 0.01 .

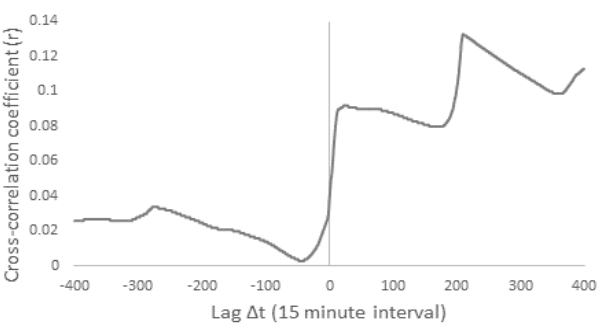

(a) Stream to hyporheic zone lag in the urban upstream site

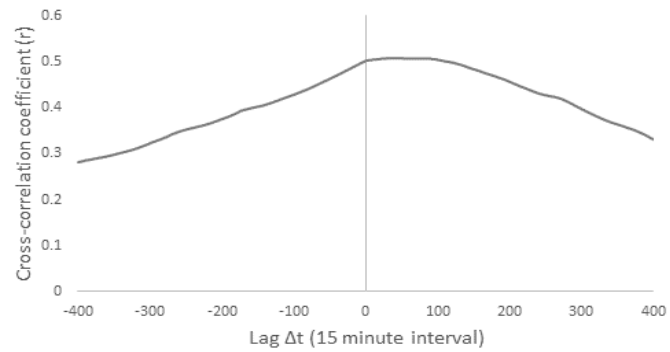

(c) ) Stream to hyporheic zone lag in the rural upstream site

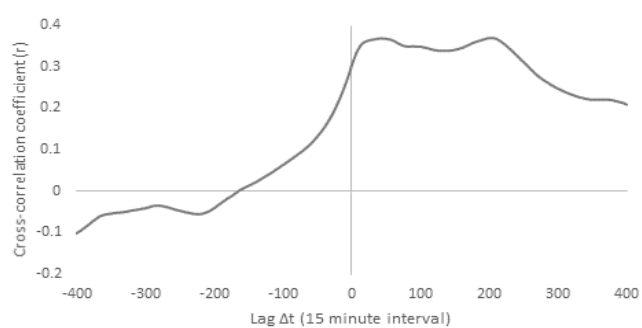

(b) Stream to hyporheic zone lag in the urban downstream site

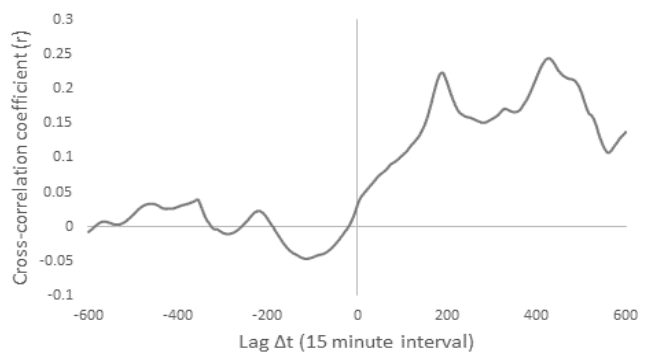

(d) Stream to hyporheic zone lag in the rural downstream site

Figure 13. Cross-correlation results for lateral (stream to hyporheic zone) time lags in the urban and rural catchments during the winter salting season (data at 15-minute interval from 15 November 2016 to 28 February 2017). 
Table 5. Cross-correlation and velocity results for lateral (stream to hyporheic zone) analysis in the four sampled sites during a winter salting season (data at 15-minute interval from 15 November 2016 to 28 February 2017).

\begin{tabular}{llllll}
\hline Stream & $\begin{array}{l}\text { Lag } \Delta t \\
\text { (hours) }\end{array}$ & $\begin{array}{l}\text { Highest } \\
\text { Correlation } \\
\text { Coefficient } \boldsymbol{r}\end{array}$ & $\begin{array}{l}\text { Standard } \\
\text { Error }\end{array}$ & $\begin{array}{l}\text { Velocity } \\
\boldsymbol{V}(\mathbf{c m} / \mathbf{h})\end{array}$ & $\begin{array}{l}\text { Maximum } \\
\text { Coherency } \\
\text { Peaks }\left(\omega^{2}\right)\end{array}$ \\
\hline Urban Upstream & 52.50 & 0.13 & 0.01 & 3.81 & 0.87 \\
\hline Urban Downstream & 50 to 51.75 & 0.37 & 0.01 & 9.66 & 0.70 \\
\hline Rural Upstream & 7.25 to 12.75 & 0.51 & 0.01 & 15.7 & 0.71 \\
\hline Rural Downstream & 106.25 to 107.75 & 0.25 & 0.01 & 1.86 & 0.88 \\
\hline
\end{tabular}

Although the cross-correlation results for time lag were similar for the two urban sites (52.5 and 50-51.75 km/hr), considering the distance between the sensors the velocities calculated were very different: about $3.81 \mathrm{~cm} / \mathrm{hr}$ upstream and $9.66 \mathrm{~cm} / \mathrm{hr}$ downstream. The resulting velocities suggest lateral exchange rate is more than double downstream than upstream in the urban catchment. From the buffer maps and field visits, it was found that the upstream site is located right beside a road (within 15-20 m), with paved areas closing in from both sides of the stream. Although this upstream site has a reach contributing area that is almost entirely agricultural, the soil profile is also getting narrower here as we begin to enter the paved area of the developed section of this urban catchment (Figure 11). According to the soil complex data from OMAFRA, the site itself sits on a poorly drained bottomland with only a small section of the comparatively well-drained Schlomberg clay loam surrounding it. Field visits showed that the stream here is shallow with clay incisions in the bank that may slow down the lateral exchange. In contrast, the urban downstream site is located inside a park and surrounded by a private school campus with a lot of green spaces. The nearest road is at least $100 \mathrm{~m}$ away from the stream, and although the stream moves from the urbanized section of the catchment, at this site it starts opening up to more natural and rural grounds. The soil profile here also shows the clay loam along with more of the bottomland opening up to at least $200 \mathrm{~m}$ of the well-drained clay loam on each side. The open green spaces as well as the soil complex likely lead to greater hyporheic connectivity at the downstream site than is observed upstream. These relative variations in water and EC absorption in different parts of an urban catchment are important considerations for developing urban towns, where local hyporheic pathways play an important role in contamination attenuation by capturing the excess flow during storm events (Lawrence et al., 2013).

Lateral exchange was observed to be the fastest in the upstream site of the rural catchment among all four sites, at a rate of about $15.7 \mathrm{~cm} / \mathrm{hr}$. On the other hand, the downstream site resulted in the slowest hyporheic exchange of all sites, at about $1.86 \mathrm{~cm} / \mathrm{hr}$. An examination of the spatial and structural profiles for these sites suggests that we may be observing the results of infiltration at the upstream site and 
underground storage at the downstream site. The rural upstream site in Whitchurch-Stouffville is a heavily forested area with some rural development on the north side and a small residential estate in the east. The upstream radial map for land use (Figure 12) shows the $1 \mathrm{~km}$ buffer around this site that has minimal urban impervious area in it. Closer to the site, forested lands cover about $50 \%$ of a $100 \mathrm{~m}^{2}$ buffer around it. These include natural heritage areas such as mixed forests, woodlands, and wetlands designated by the Ministry of Natural Resources. The undisturbed riparian zone in this site along with the highly porous sandy loam it sits on, allows for better hyporheic connectivity and a capacity to infiltrate the excess flow and $\mathrm{Cl}$, slowing down its path downstream (as observed in the longitudinal lags during the same winter period, section 3.2.1).

Of all the four sites with varying levels of urban, rural, and natural land cover, the downstream site in the rural catchment created the most unique scenario. Although largely natural, cross-correlation results showed unexpectedly high lags of about 107 hours (i.e. over 4 days) for lateral hyporheic exchange in this site. The time series data for this site (Appendix A, Figure A-1.11 and A-1.12) show that although water levels had similar trends in both stream and hyporheic sensors, the EC trends in the hyporheic zone have very high peaks towards the end of February that were not found in the stream sensor $2 \mathrm{~m}$ away from it. The $1 \mathrm{~km}$ road buffer for this site (Fig. 9) shows the location of Highway 404, a 6-lane expressway, just $1 \mathrm{~km}$ upstream of this site. The land and soil buffers show the highly permeable sandy loam surrounding the bottomland this stream is on, and the rural and agricultural lands that overlay it- all the way from the highway down to the stream site. The times series and cross-correlation observations suggest that the theories by Booth (1991) may be applicable here. Shortly after a salting event, the highly saline meltwater from the highway likely infiltrates into the ditches close to it and moves through the subsurface porous layers rather than flowing down to the stream through overland runoff, and as such, may not go into the stream. While this downstream site in Aurora is more urbanized compared to the upstream site in Whitchurch-Stouffville, the natural areas as well as the large green spaces (e.g. golf course south of the Vandorf Sideroad) around it favor immediate infiltration after salting events rather than direct runoff to the stream through impervious surfaces.

This makes an important observation for $\mathrm{Cl}$ monitoring plans in rural and natural areas with a source of high salt inputs in the proximity. In the rural downstream site, surface water monitoring at the stream may never reveal the extent of salinization from the highway after a salting event. Tracer injection of $\mathrm{Cl}$ at regular intervals from the highway to this site may be one way to determine the time it takes for $\mathrm{Cl}$ to move through the subsurface downstream. An added consideration for this site is that diffusion (from high concentration to low concentration) rather an advection (following the bulk flow) may at times dominate $\mathrm{Cl}$ migration through sandy layers of soil at near-saturated conditions (Rowe and Badv, 1996), 
which could alter the exchange of $\mathrm{Cl}$ to areas of lower concentration (such as stream) during storm events in the winter when higher peaks are observed in the subsurface than in stream. From the lateral and longitudinal profiles (Figures 4 and 5), this site has a fairly deep riparian area around the stream where water and $\mathrm{Cl}$ could be moving in any direction depending on soil porosity and saturation. More hyporheic data at various points around the stream may indicate the true direction and velocity of $\mathrm{Cl}$ at specific depths from the surface.

Overall, the lateral exchange rate was the highest in the most forested site at Whitchurch-Stouffville (i.e. the upstream rural site), compared to the others that were relatively more urbanized. This is supported by the findings of Batchelor and $\mathrm{Gu}$ (2014), who concluded that urbanization alters the hyporheic exchange, limiting its capacity to remove nutrients or solutes, which is a more common process in rural or forested catchments with larger storage zones and solute residence times. Ryan and Packman (2006) also found urbanization may cause silt-clay content to increase in streambeds, hampering hyporheic exchange and decreasing the cross-sectional area at which the lateral exchange takes place. With the clay loam soil profile in the urban catchment in this study, this could potentially create small localized pools for $\mathrm{Cl}$ in the more developed areas.

\subsubsection{Summer Growing Season}

Time series for all lateral exchange pairs were less coherent in summer (coherency peaks at 0.52 0.66) than in winter (peaks at 0.70-0.88). The standard error also increased slightly in the summer crosscorrelation results from 0.01 to 0.02 . As discussed before, multiple sources of $\mathrm{Cl}$ equally contributing to EC appears to add complexity to the trends, especially around the urbanized areas. The lateral coherency and standard errors also suggest that the cross-correlation model is more robust in winter than summer. Nevertheless, the summer results provide important insight towards the processes that may be adding complexity to $\mathrm{Cl}$ dynamics in summer. These results are showed in Figure 14 and summarized in Table 6. 


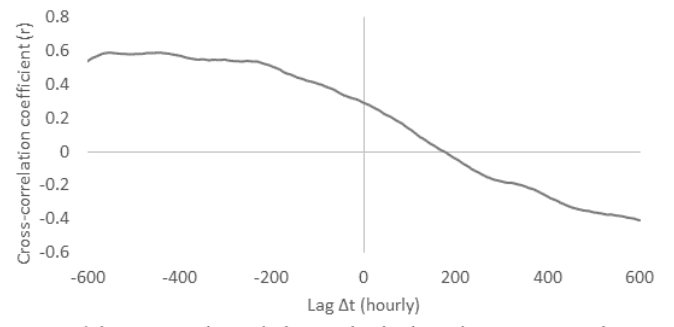

(a) Stream to hyporheic zone lag in the urban upstream site

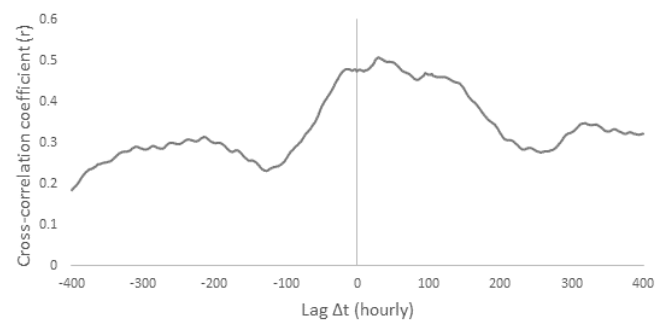

(c) ) Stream to hyporheic zone lag in the rural upstream site

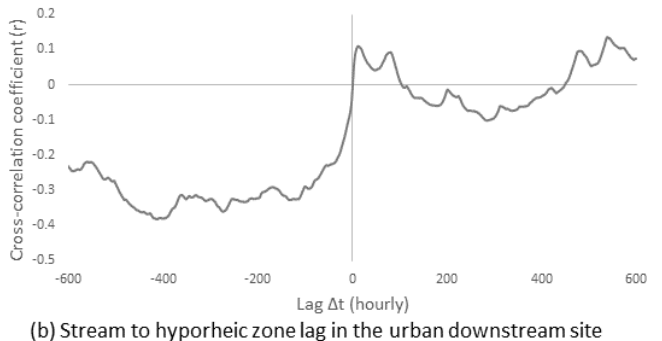

(b) Stream to hyporheic zone lag in the urban downstream site

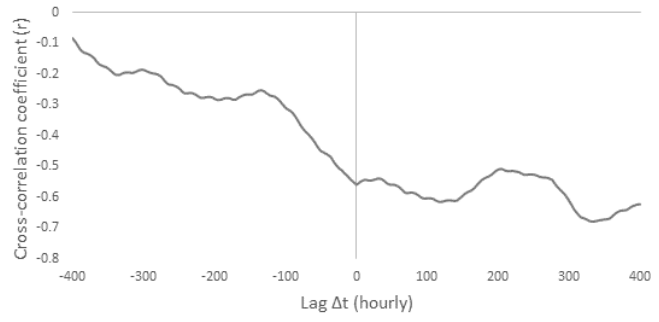

(d) Stream to hyporheic zone lag in the rural downstream site

Figure 14. Cross-correlation results for lateral (stream to hyporheic zone) time lags in the urban and rural catchments during the summer growing season (hourly data from 1 May to 30 August, 2016).

Table 6. Cross-correlation and velocity results for lateral (stream to hyporheic zone) analysis in the four sampled sites during a summer growing season (hourly data from 1 May to 30 August, 2016).

\begin{tabular}{llllll} 
Stream & $\begin{array}{l}\text { Lag } \Delta t \\
\text { (hours) }\end{array}$ & $\begin{array}{l}\text { Highest } \\
\text { Correlation } \\
\text { Coefficient } \boldsymbol{r}\end{array}$ & $\begin{array}{l}\text { Standard } \\
\text { Error }\end{array}$ & $\begin{array}{l}\text { Velocity } \\
\boldsymbol{V}(\mathbf{c m} / \mathbf{h})\end{array}$ & $\begin{array}{l}\text { Maximum } \\
\text { Coherency } \\
\text { Peaks }\left(\omega^{2}\right)\end{array}$ \\
\hline Urban Upstream & -441 to $-449(\mathrm{Lead})$ & 0.589 & 0.02 & 4.45 & 0.52 \\
\hline Urban Downstream & $-412(\mathrm{Lead})$ & -0.382 & 0.02 & 1.21 & 0.62 \\
\hline Rural Upstream & 29 & 0.507 & 0.02 & 6.90 & 0.66 \\
\hline Rural Downstream & 332 to 335 & -0.679 & 0.02 & 0.60 & 0.61 \\
\hline
\end{tabular}

Similar to the winter results, the lateral exchange lag at the rural upstream site with the most forested land cover was again the lowest in summer compared to the other, more urbanized, sites. However, lags for the rural sites appeared 3-4 times higher in summer than in winter (29 hours for upstream and up to 335 hours for downstream). The urban sites showed even slower exchange rates, with lags of over 400 hours moving at velocities $4.45 \mathrm{~cm} /$ hour upstream and $1.21 \mathrm{~cm} /$ hour downstream. It is important to note that both the upstream and downstream location in the urban catchment showed hyporheic zone leading the EC trends rather than lagging. In 2006, Mayer et al. found that long-term road salting can create unique 
solute exchange pathways where $\mathrm{Cl}$ levels remain elevated throughout the year as groundwater continues to supply $\mathrm{Cl}$ to streams in the Chesapeake Bay watershed. Eyles and Meriano (2010) also reported brackish water with year-round EC peaks in urban drainage basins in Pickering, Ontario. The summer crosscorrelation results for lateral exchange imply that this could be the underlying reason for high $\mathrm{Cl}$ concentrations in summer across these catchments, which is a current concern. As suggested by the direction of EC transport, localized storage pools of $\mathrm{Cl}$ in the subsurface may be contributing to stream concentrations here. At the rural catchment, the constant mixing of groundwater outflow and agricultural inputs of EC could make it challenging to observe a realistic travel time.

It was observed through the winter results that the lateral flow of EC trends is at the rate of a few centimeters per hour. At this scale, we might not be observing the true direction of the subsurface flow from the current location of the sensors. Tracer injections of $\mathrm{Cl}$ at various points of the urban catchment might be needed for further investigation, especially in summer. Continuous data at equal depths from various points around the stream may also reveal more information about the hyporheic connectivity of the soil and seasonal flow of $\mathrm{Cl}$. These results indicate that the hyporheic flow measurements must be at a finer spatial scale to study $\mathrm{Cl}$ movement through the subsurface. Since $\mathrm{Cl}$ in the groundwater and hyporheic zone may not always move directly downslope but rather through the available and unsaturated soil pores, data from the various points at equal depths may indicate the optimum direction of $\mathrm{Cl}$ flow in the subsurface as well as the velocity in that direction.

\subsection{Cross-section 3D models}

For an improved understanding of the results and to summarize the longitudinal and lateral exchange that take place in the urban and rural catchments, each catchment was divided along the stream length to create a 3D representation of its cross-section. The land cover maps created for the catchments were overlaid on the corresponding soil profile. These combined with the lateral elevation profiles from Figures 4-6 were used for the conceptual visualization of structural and spatial variation in the two catchments and how they can influence streamflow and flow velocities of EC. By rotating the model from side to side, one can examine the different types of land use that can influence the longitudinal flow. By rotating it vertically, the soil profile can be examined to see how it may influence lateral hyporheic exchange. Figures 15 and 16 show these cross-sectional representations with the resultant EC velocities for winter. 


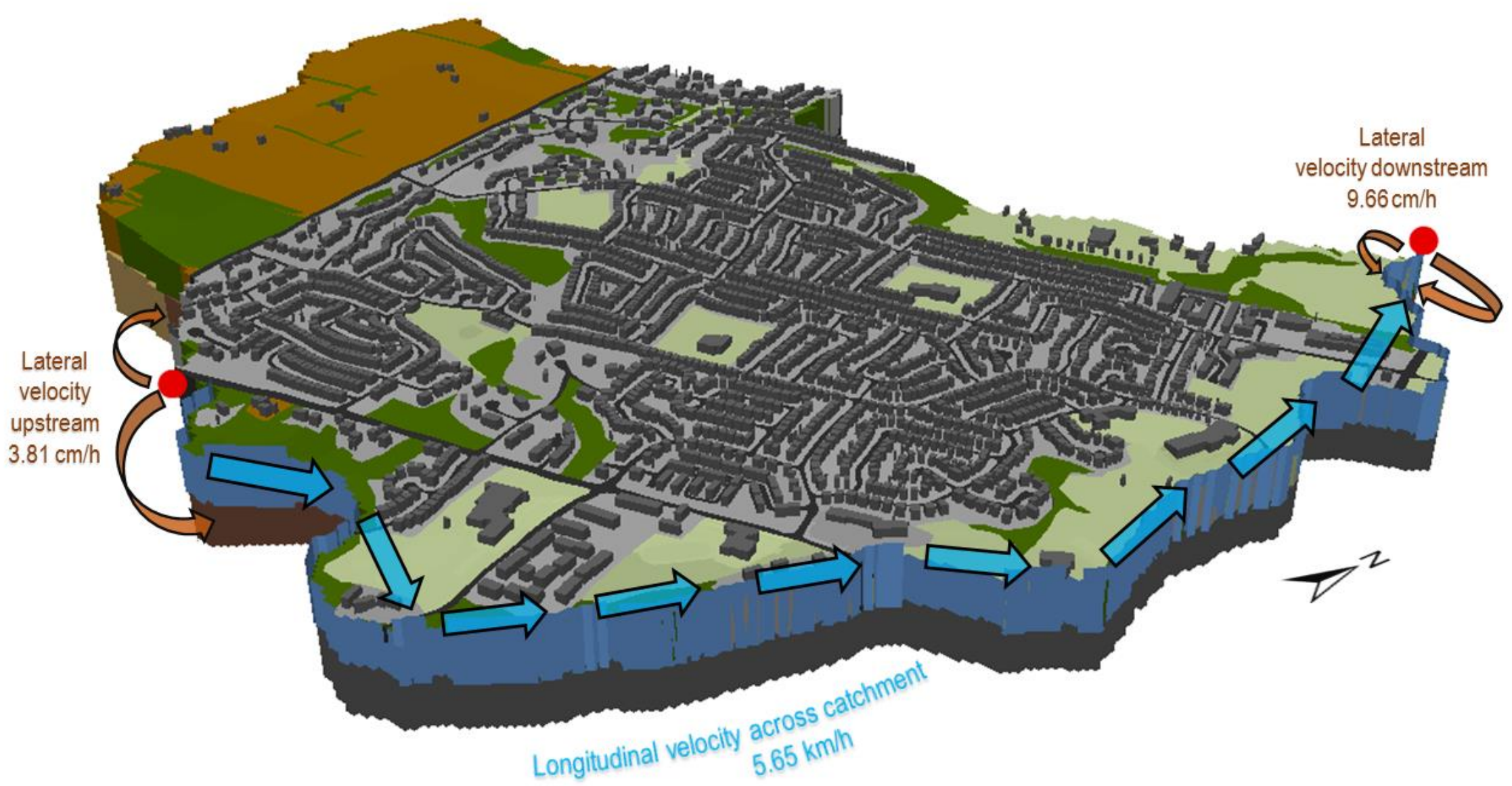

Figure 15. Spatial representation of a cross-section of the urban catchment along the studied stream, showing lateral and longitudinal velocities of electrical conductivity in winter 2016-17. Land cover is overlaid on top of soil profile, and combined with the information from lateral elevation profiles to aid conceptual visualization. 3D structures in grey highlight all buildings west of the urban stream studied. Color scheme used is the same as represented in catchment land and soil profiles in Figures 4 and 5. 


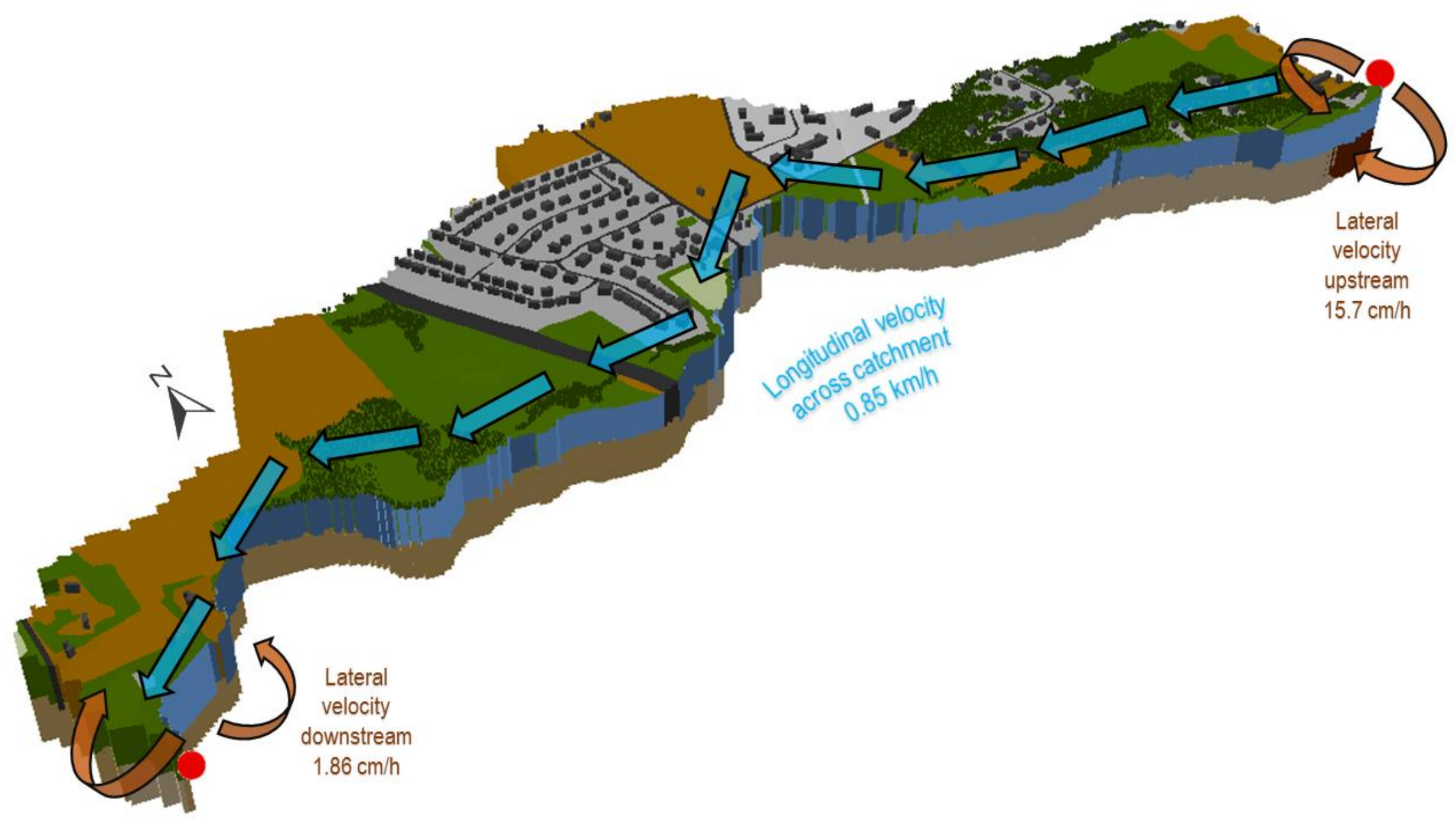

Figure 16. Spatial representation of a cross-section of the rural catchment along the studied stream, showing lateral and longitudinal velocities of electrical conductivity in winter 2016-17. Land cover is overlaid on top of soil profile, and combined with the information from lateral elevation profiles to aid conceptual visualization. 3D structures in grey highlight buildings while dark green 3D trees highlight designated forests on the north side of the rural stream studied. Color scheme used is the same as represented in catchment land and soil profiles in Figures 4 and 5. 


\section{Conclusion and Future Recommendations}

The spatial cross-correlation modelling approach on continuous conductivity (EC) time series data to estimate chloride $(\mathrm{Cl})$ travel time and flow velocities in streams appeared to be more effective in winter than in summer. The time lags resulting from cross-correlation and the calculated flow velocities appeared to be largely effected by the land use, roads network and soil profile surrounding the two stream reaches in this study. The longitudinal (upstream to downstream) time lag in winter was found to be shorter with higher velocity in the urban stream reach with more impervious surfaces than in the rural catchment with more permeable surface. The in-stream lateral exchange (stream-hyporheic zone) varied for each site, upstream and downstream, within a catchment. These appeared to be affected by not only the land use and soil profile of the whole reach contributing area, but also those in the immediate vicinity. Thus, within the urban catchment, the lateral exchange was faster in the downstream location that opened up to more green space and permeable soil layer. Within the rural catchment, lateral exchange was found to be slower in the downstream location that is more urbanized compared to the forested upstream site, and is in close proximity to a highway. Among all four sites, the rural upstream site with the most forested land cover showed the highest rate of lateral exchange in both winter and summer. In summer with the coarser (hourly) data, the longitudinal lags seemed more complex and challenging to predict in the urban stream. However, the lateral exchange results in summer showed the hyporheic zone to be leading the stream EC trends in both urban sites. The elevated $\mathrm{Cl}$ concentrations in summer and the direction of lateral exchange (from hyporheic zone to stream) observed in this study support the findings of Eyles and Meriano (2010) in Southern Ontario and Mayer et al. (2006) in the United States: road salt applications in urban catchments may be leading to year-round $\mathrm{Cl}$ peaks in streams by groundwater storage and seasonal contribution to stream through lateral exchange pathways. Further investigation of subsurface $\mathrm{Cl}$ movement is crucial for these urbanized sites.

Currently, data is being assembled for routine $\mathrm{Cl}$ measurements from monthly grab samples over

the full year, along with the collection of 15-minute data over spring and summer. The complete $\mathrm{Cl}$ data can be used to create predicted $\mathrm{Cl}$ time series from the EC time series, to be placed directly in a crosscorrelation analysis without using EC as a proxy. This may allow a better understanding of $\mathrm{Cl}$ travel times during the spring melting and summer growing seasons. One limitation of cross-correlation is that it is affected by non-stationarity in the time series pairs. However, as discussed by DeWalle et al. (2016), prewhitening or smoothing of the data to create stationarity can lead to the loss of important trends. This becomes a greater dilemma for continuous data over fine temporal resolutions, which allow the observation of trends that are not revealed in a smoothed series. Sir Granger (1964/2015), famously known for his 
theories in cross-spectral analysis and tests for causality in time series, argued that the coherency can remain robust even with changes in the stationarity assumption. According to him, cross-spectral methods can still provide useful information for realistic data that are often complicated and non-stationary. After testing with both original and smoothed series in this study, we suggest that the original data (manually corrected for sampling events) produce more meaningful and realistic time lags than a smoothed series.

For improvements in the model, a windowed approach in cross-correlation could be performed considering the transient nature of EC even within a season. However, finding a fixed window over which data would be completely stationary can be challenging. Only one paper could be found that discussed a dynamic time warping method, a windowed cross correlation algorithm, that can be applied to continuous EC time series (Schmidt et al., 2012). Due to its complexity and lack of availability in software packages, this could not be explored within the time constraints of this study. The lack of literature and available established methods, however, indicates the clear need for this study and its investigation of crosscorrelation applications on continuous sensor data. The results of this study suggest that cross-correlation methods show great promise for $\mathrm{Cl}$ transport modelling in urbanizing watersheds, and can be successfully implemented on future endeavors with few careful adjustments. 


\section{Appendices}

Appendix A: Time Series Data

A-1 Winter Salting Season (15-minute interval)

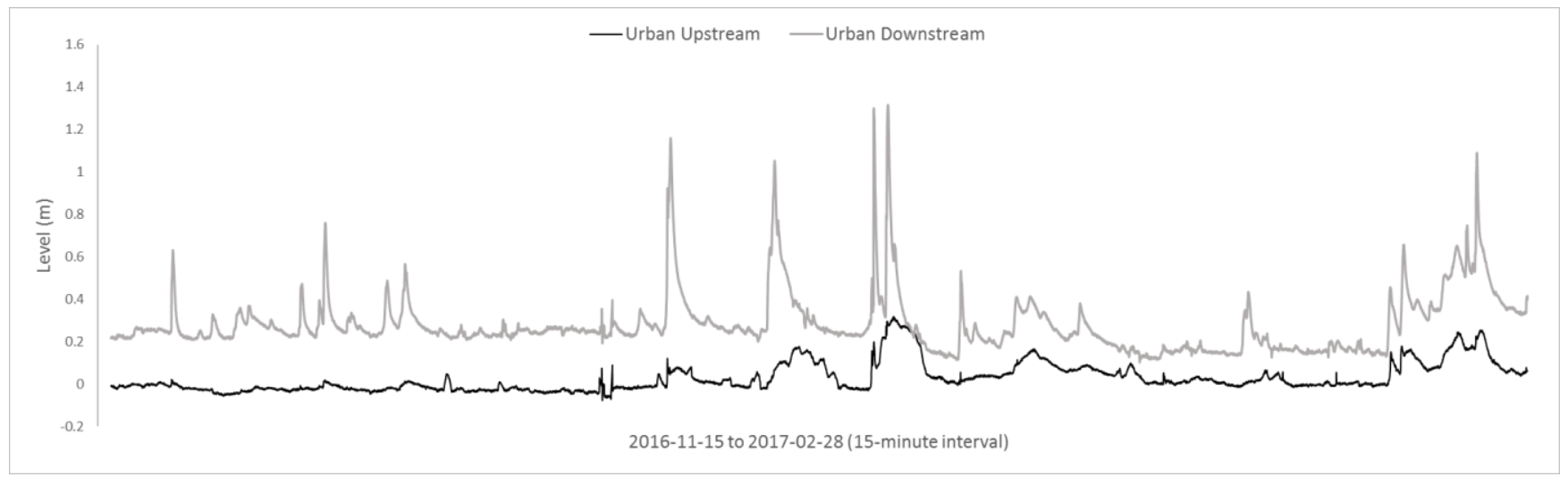

FIGURE A-1.1 Water level time series for the urban upstream and downstream stream sensors, from November 15, 2016 to February 28, 2017. Data were corrected for human errors on sampling events.

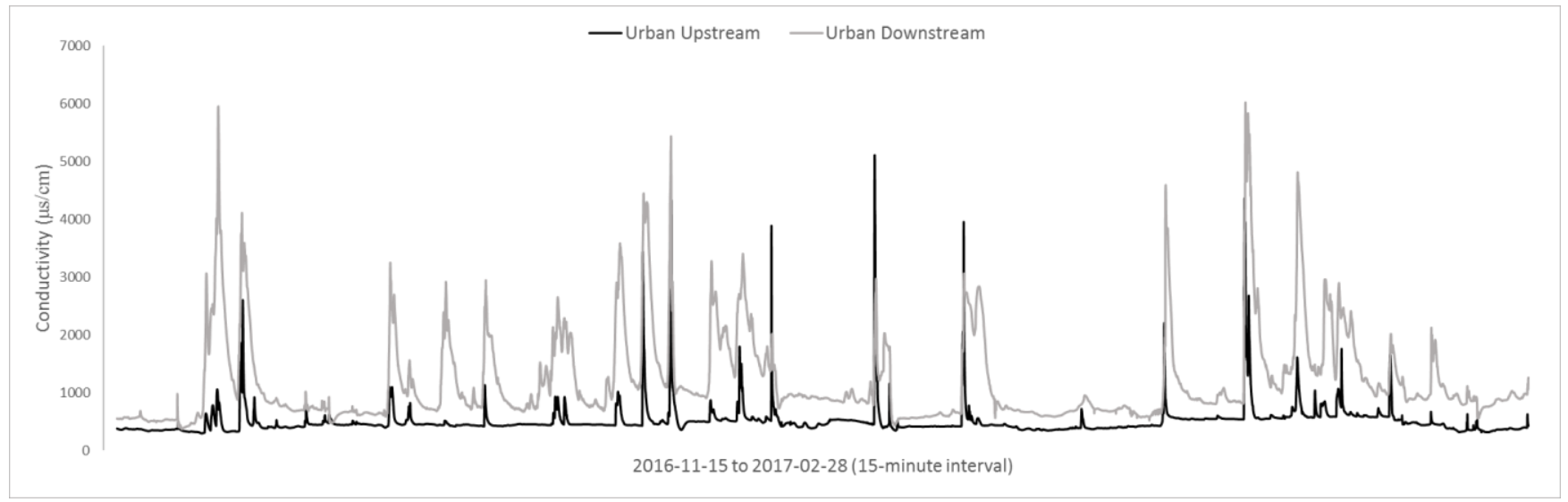

FIGURE A-1.2 Conductivity (EC) time series for the urban upstream and downstream stream sensors, from November 15, 2016 to February 28, 2017. Data were corrected for human errors on sampling events. 


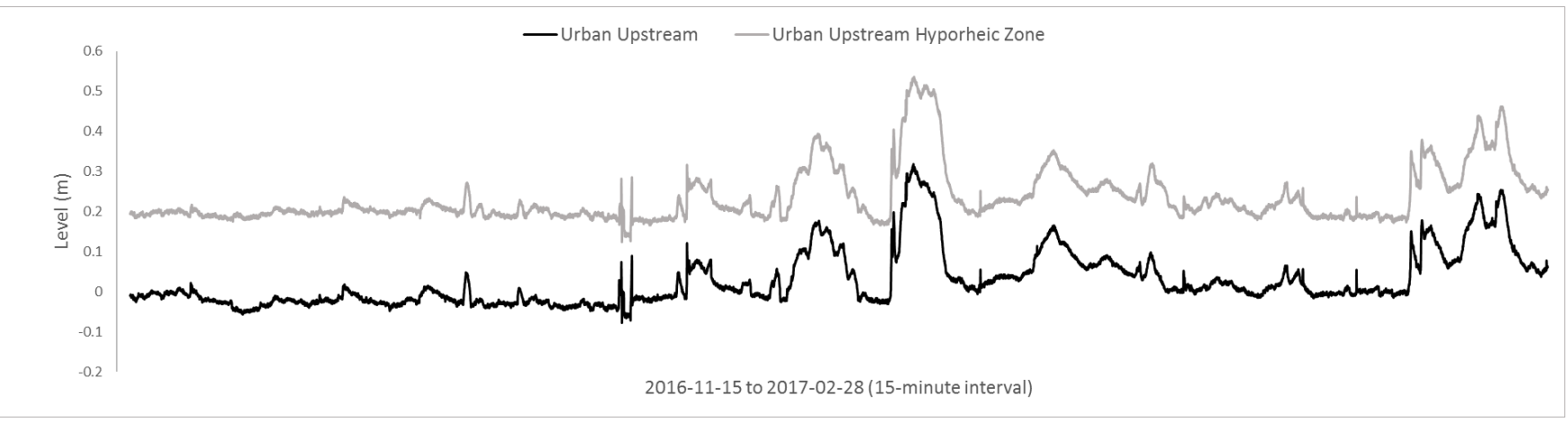

FIGURE A-1.3 Water level time series for the urban upstream stream and hyporheic zone sensors, from November 15, 2016 to February 28, 2017. Data were corrected for human errors on sampling events.

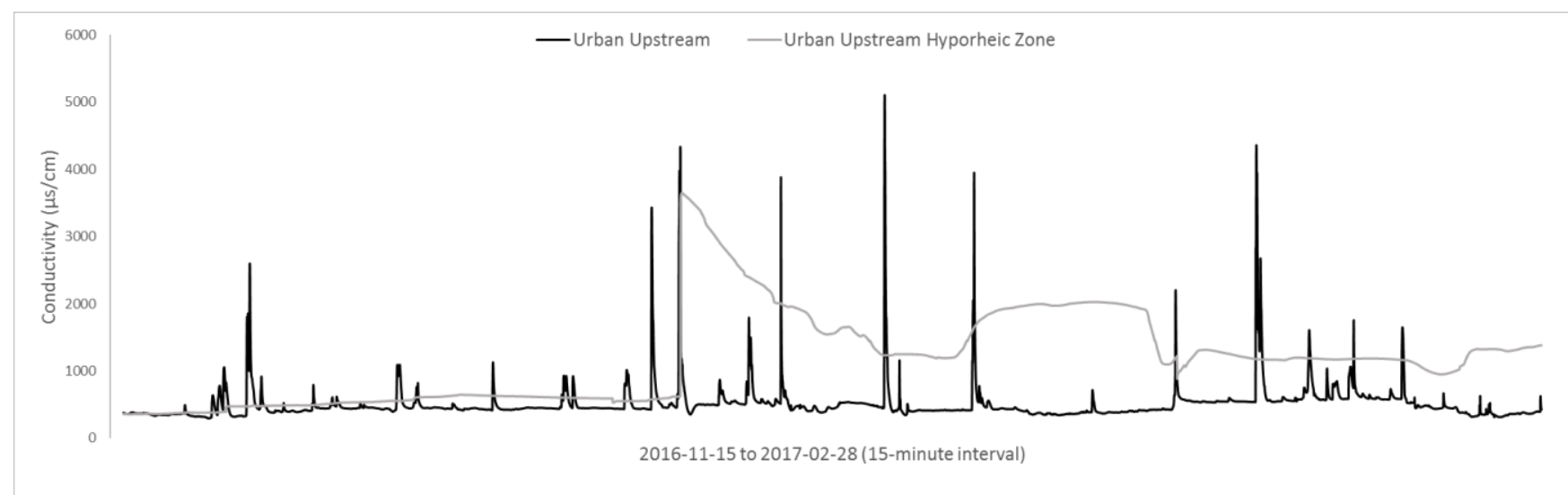

FIGURE A-1.4 Conductivity (EC) time series for the urban upstream stream and hyporheic zone sensors, from November 15, 2016 to February 28, 2017. Data were corrected for human errors on sampling events.

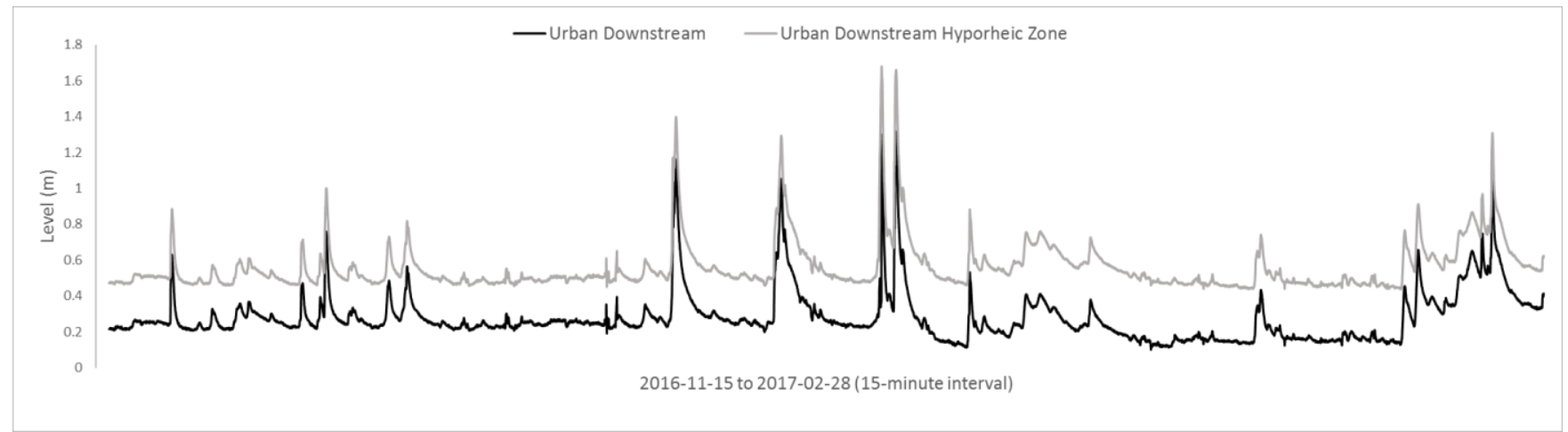

FIGURE A-1.5 Water level time series for the urban downstream stream and hyporheic zone sensors, from November 15, 2016 to February 28, 2017. Data were corrected for human errors on sampling events. 


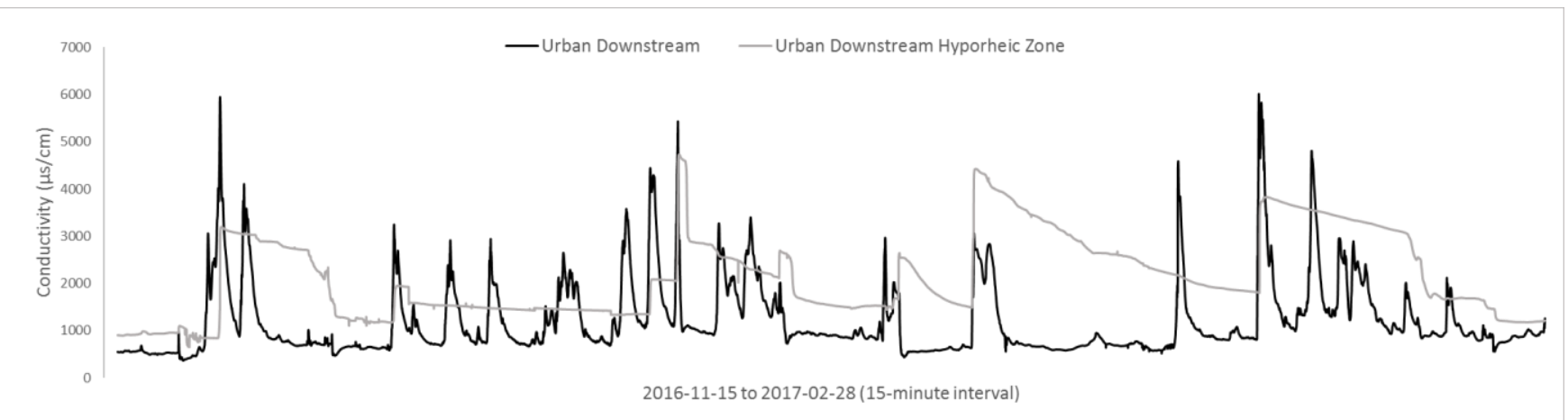

FIGURE A-1.6 Conductivity (EC) time series for the urban downstream stream and hyporheic zone sensors, from November 15, 2016 to February 28, 2017. Data were corrected for human errors on sampling events.

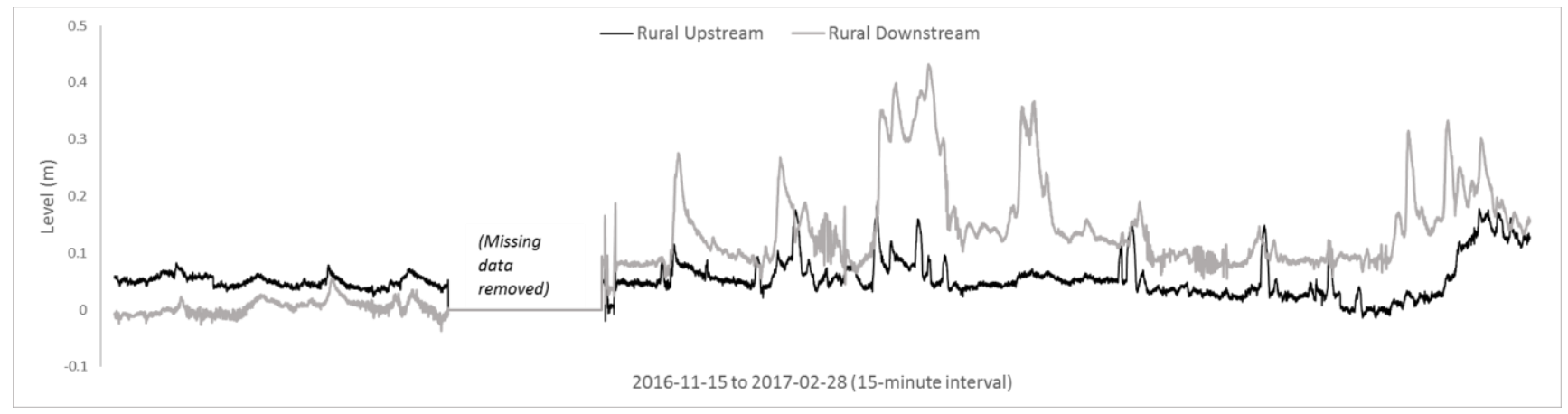

FIGURE A-1.7 Water level time series for the rural upstream and downstream stream sensors, from November 15, 2016 to February 28, 2017. Data were corrected for human errors on sampling events and missing data were removed.

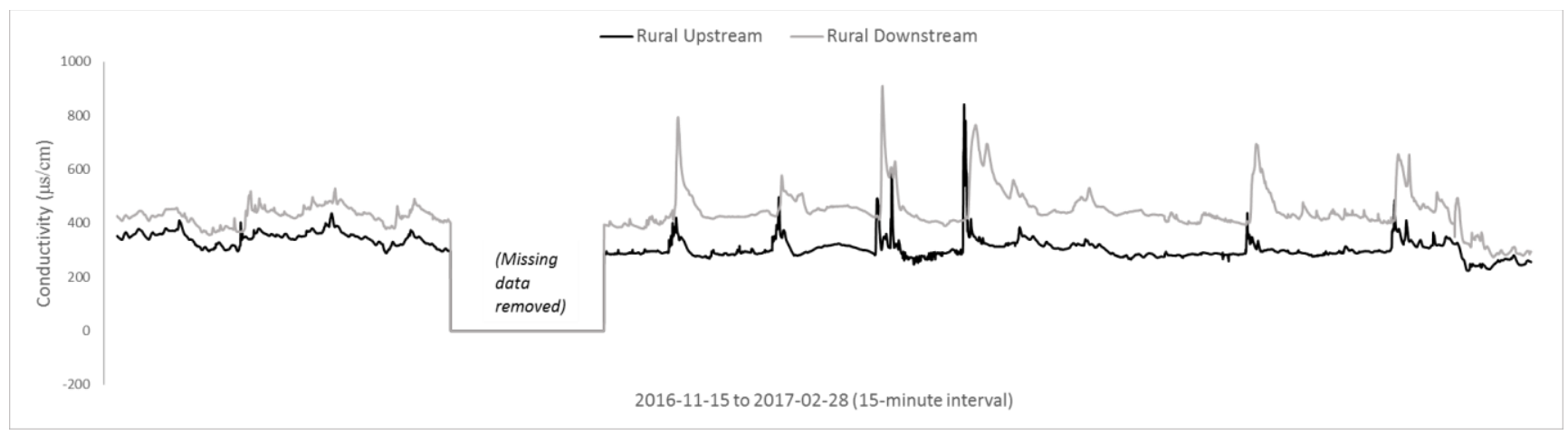

FIGURE A-1.8 Conductivity (EC) time series for the rural upstream and downstream stream sensors, from November 15, 2016 to February 28, 2017. Data were corrected for human errors on sampling events and missing data were removed. 


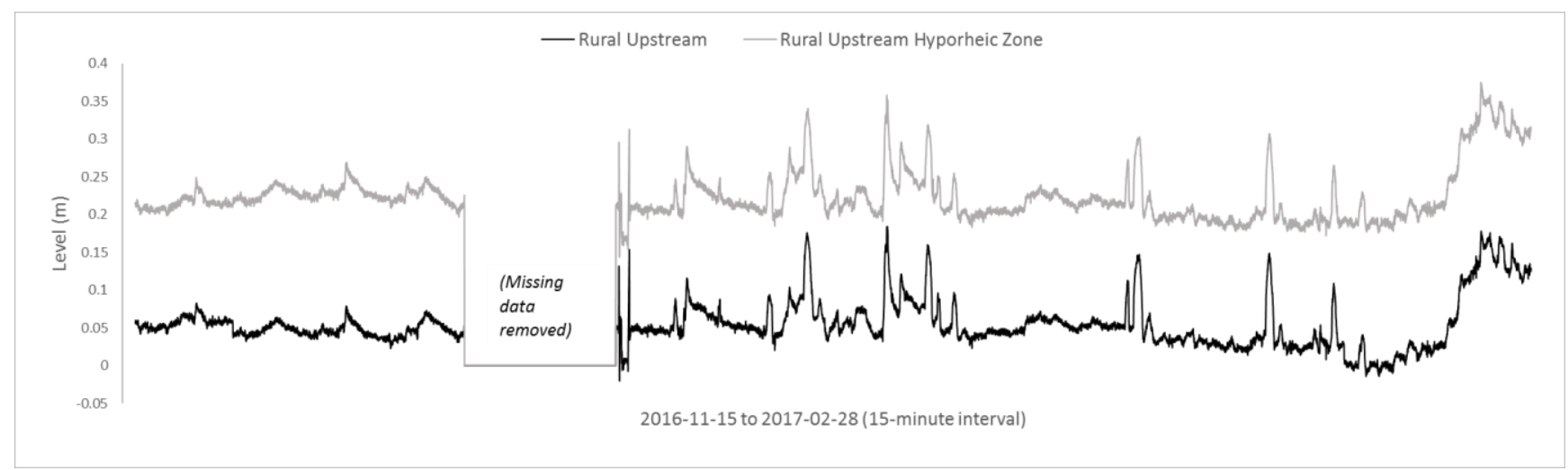

FIGURE A-1.9 Water level time series for the rural upstream stream and hyporheic zone sensors, from November 15, 2016 to February 28, 2017. Data were corrected for human errors on sampling events and missing data were removed.

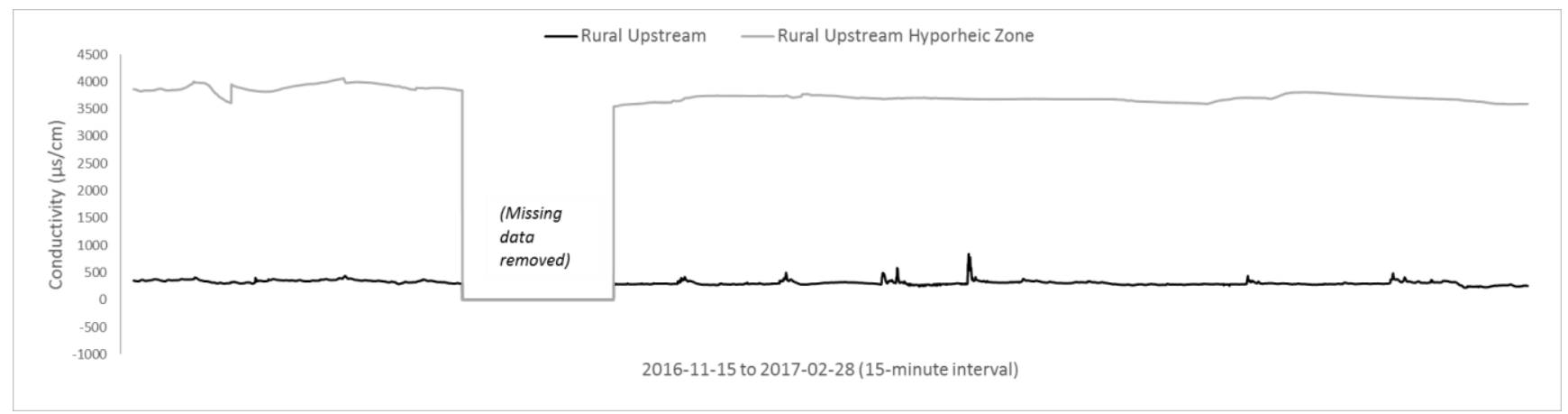

FIGURE A-1.10 Conductivity (EC) time series for the rural upstream stream and hyporheic zone sensors, from November 15, 2016 to February 28, 2017. Data were corrected for human errors on sampling events and missing data were removed.

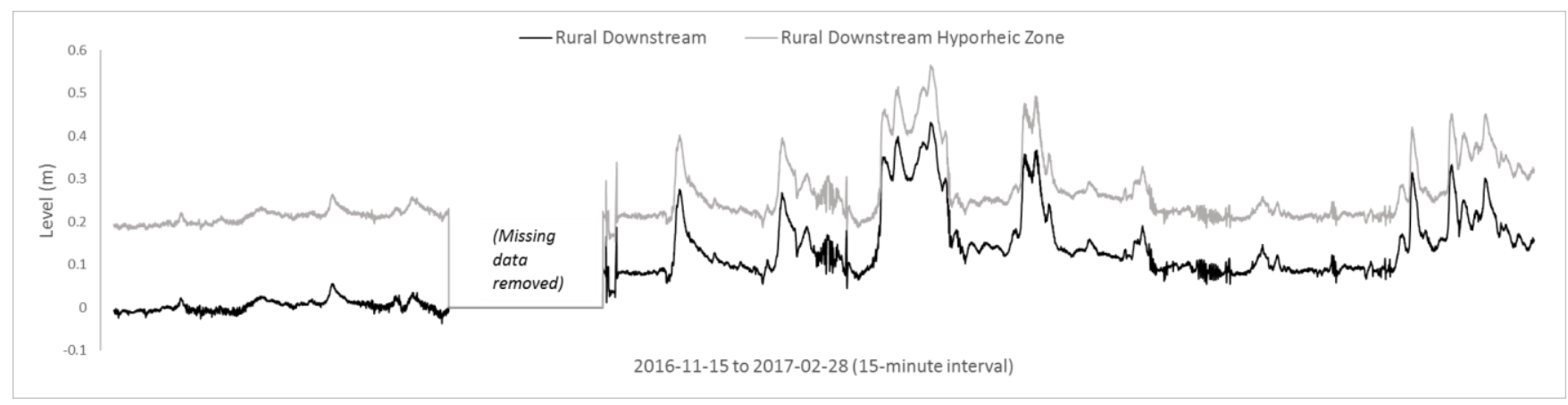

FIGURE A-1.11 Water level time series for the rural downstream stream and hyporheic zone sensors, from November 15, 2016 to February 28, 2017. Data were corrected for human errors on sampling events and missing data were removed. 


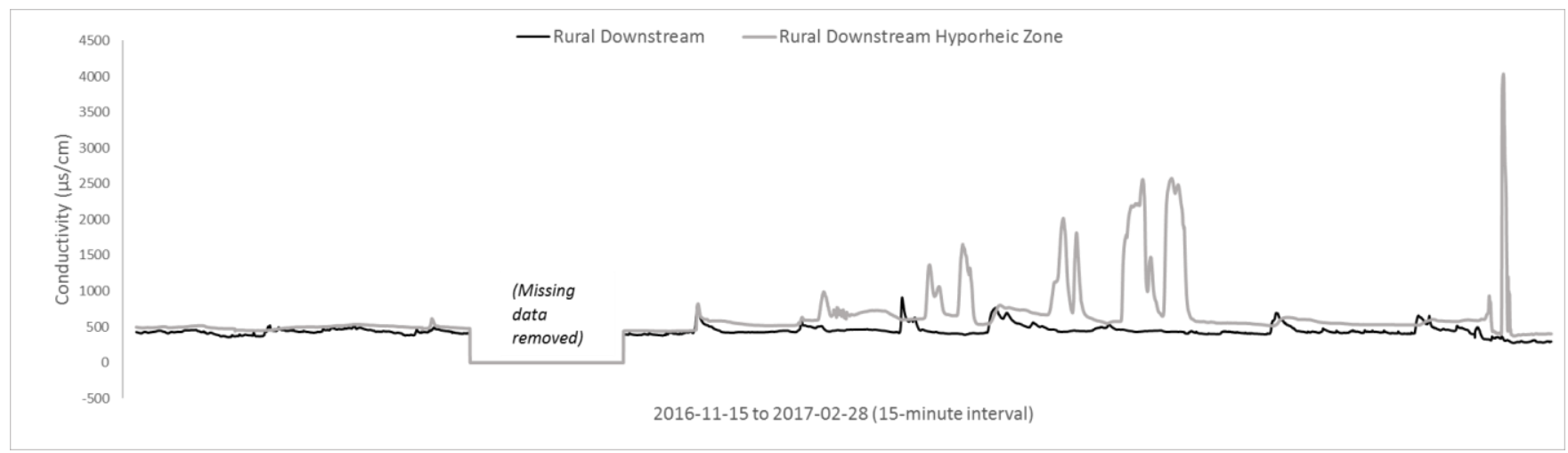

FIGURE A-1.12 Conductivity (EC) time series for the rural downstream stream and hyporheic zone sensors, from November 15, 2016 to February 28, 2017. Data were corrected for human errors on sampling events and missing data were removed.

\section{A-2 Summer Growing Season (hourly interval)}

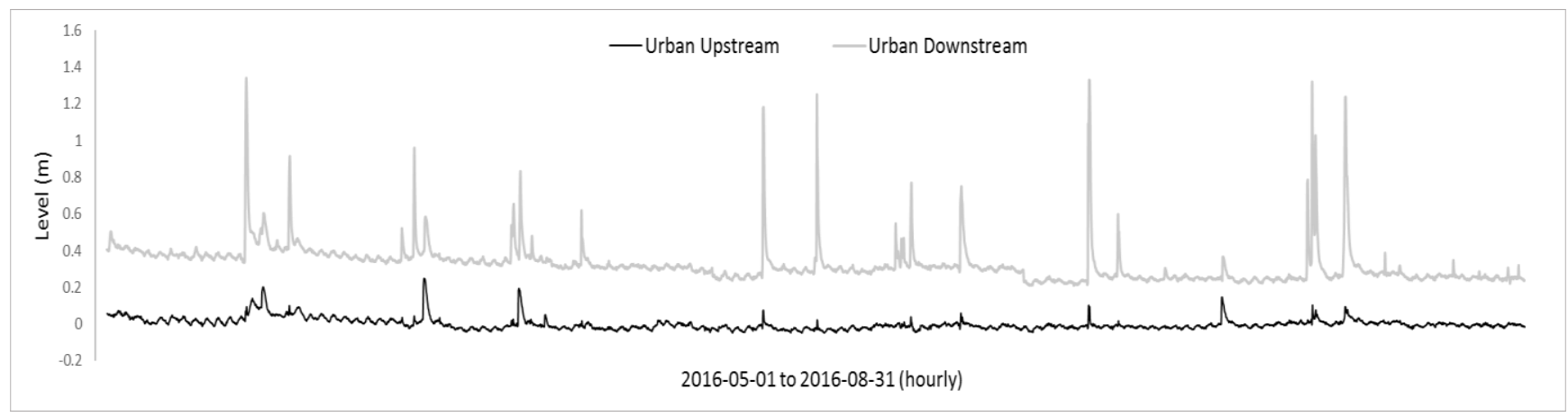

FIGURE A-2.1 Water level time series for the urban upstream and downstream stream sensors, from May 1 to August 31, 2016. Data were corrected for human errors on sampling events. 


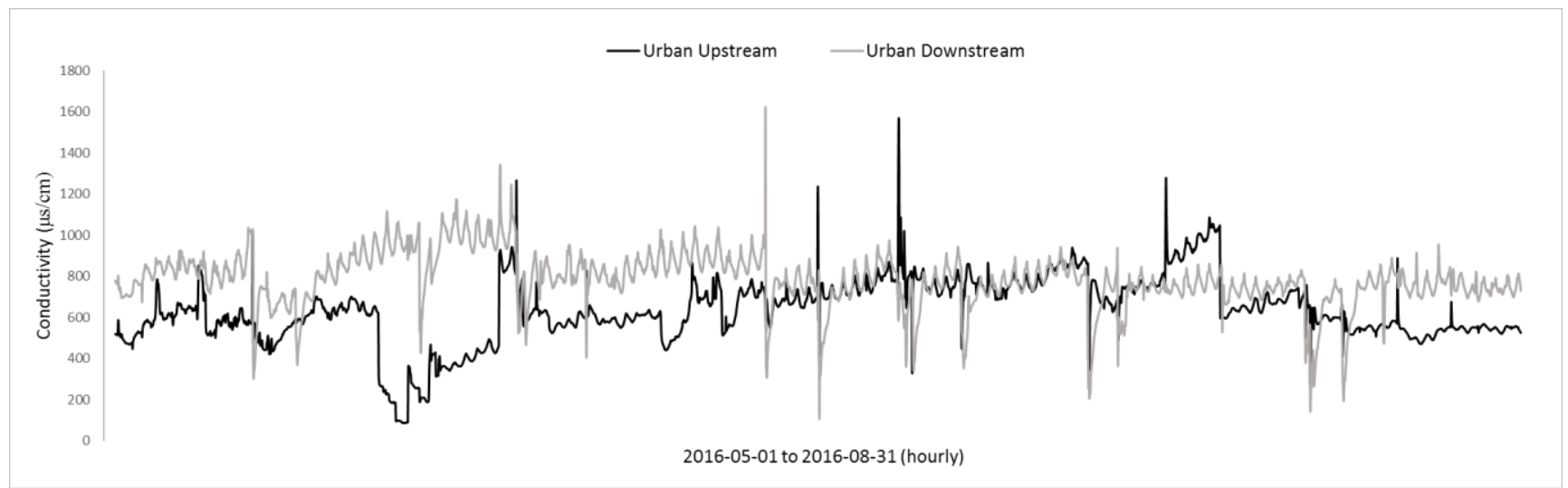

FIGURE A-2.2 Conductivity (EC) time series for the urban upstream and downstream stream sensors, from May 1 to August 31, 2016. Data were corrected for human errors on sampling events.

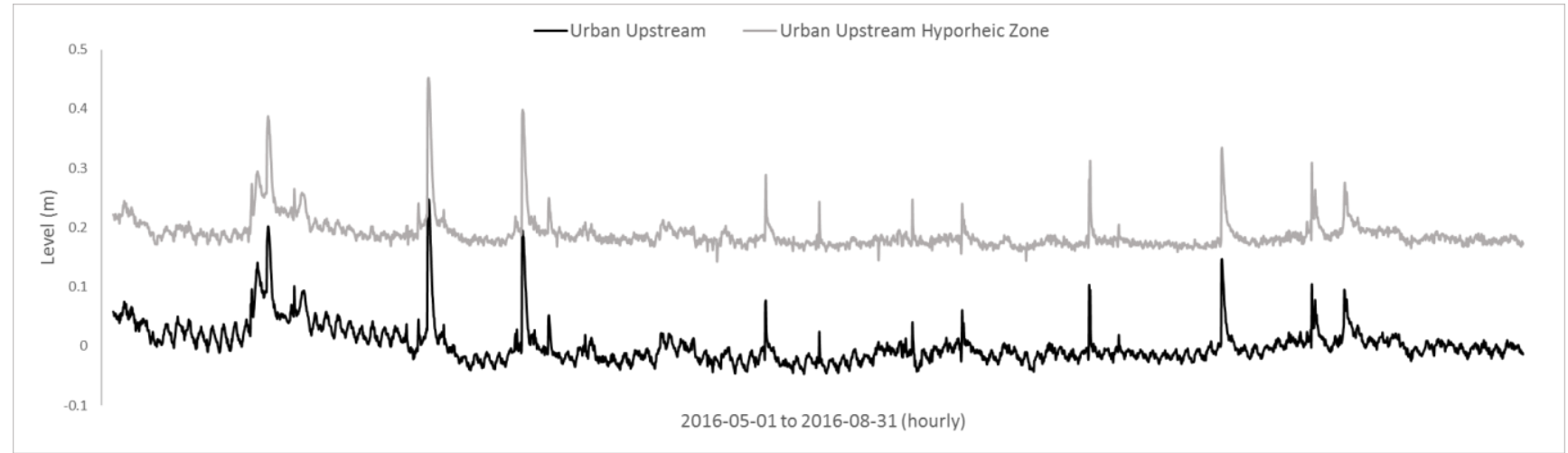

FIGURE A-2.3 Water level time series for the urban upstream stream and hyporheic zone sensors, from May 1 to August 31, 2016. Data were corrected for human errors on sampling events.

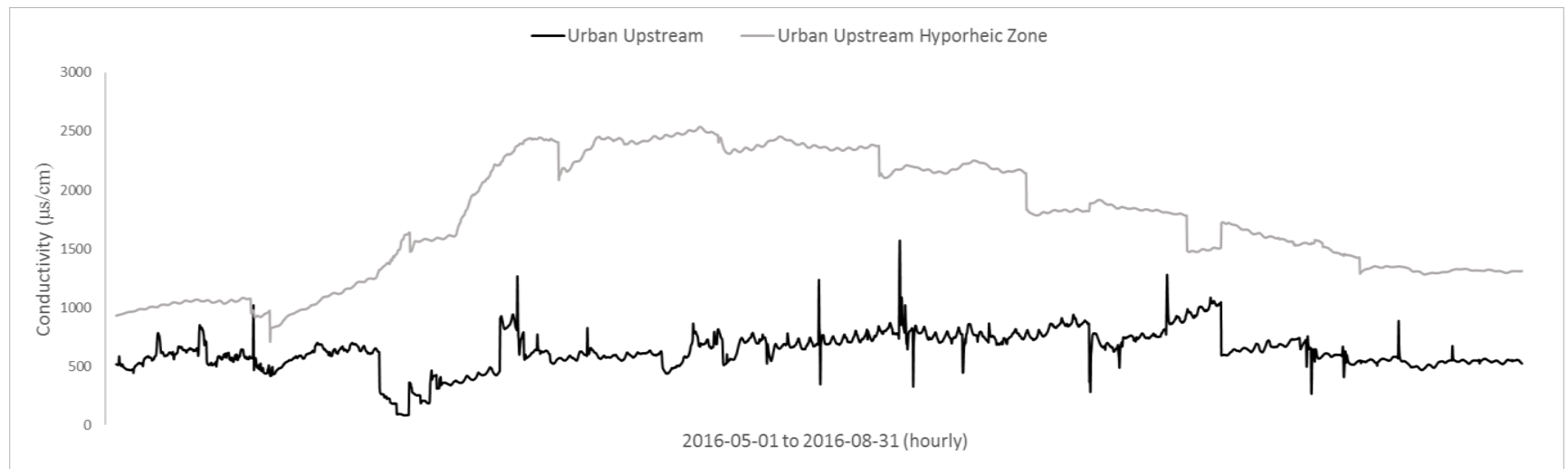

FIGURE A-2.4 Conductivity (EC) time series for the urban upstream stream and hyporheic zone sensors, from May 1 to August 31, 2016. Data were corrected for human errors on sampling events. 


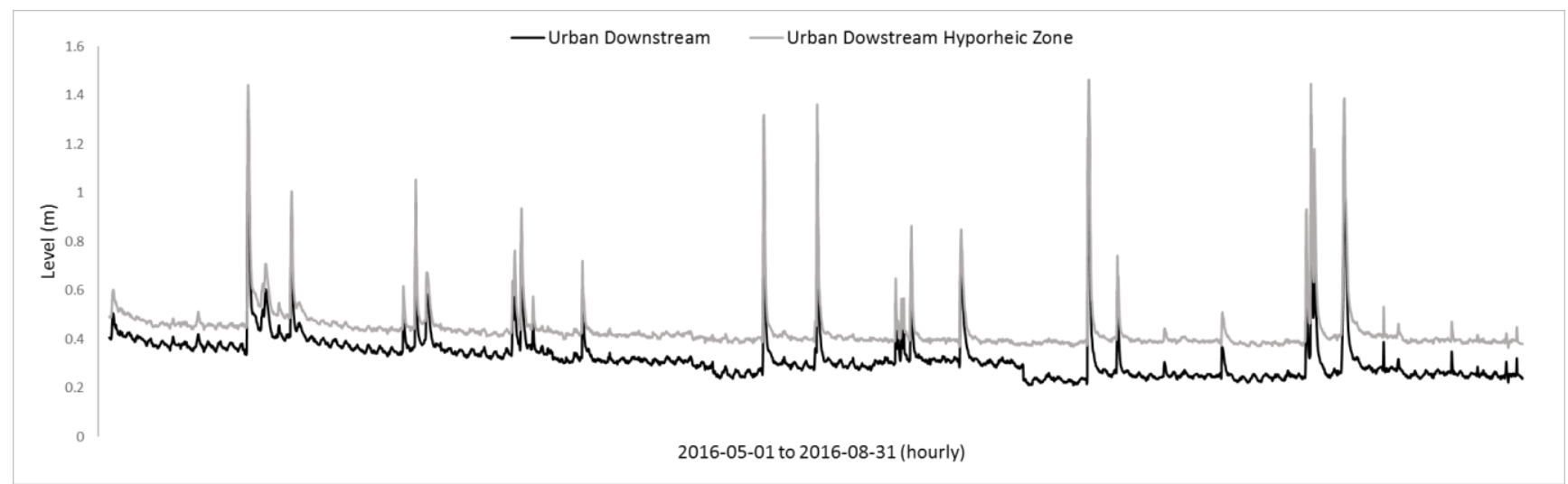

FIGURE A-2.5 Water level time series for the urban downstream stream and hyporheic zone sensors, from May 1 to August 31, 2016. Data were corrected for human errors on sampling events.

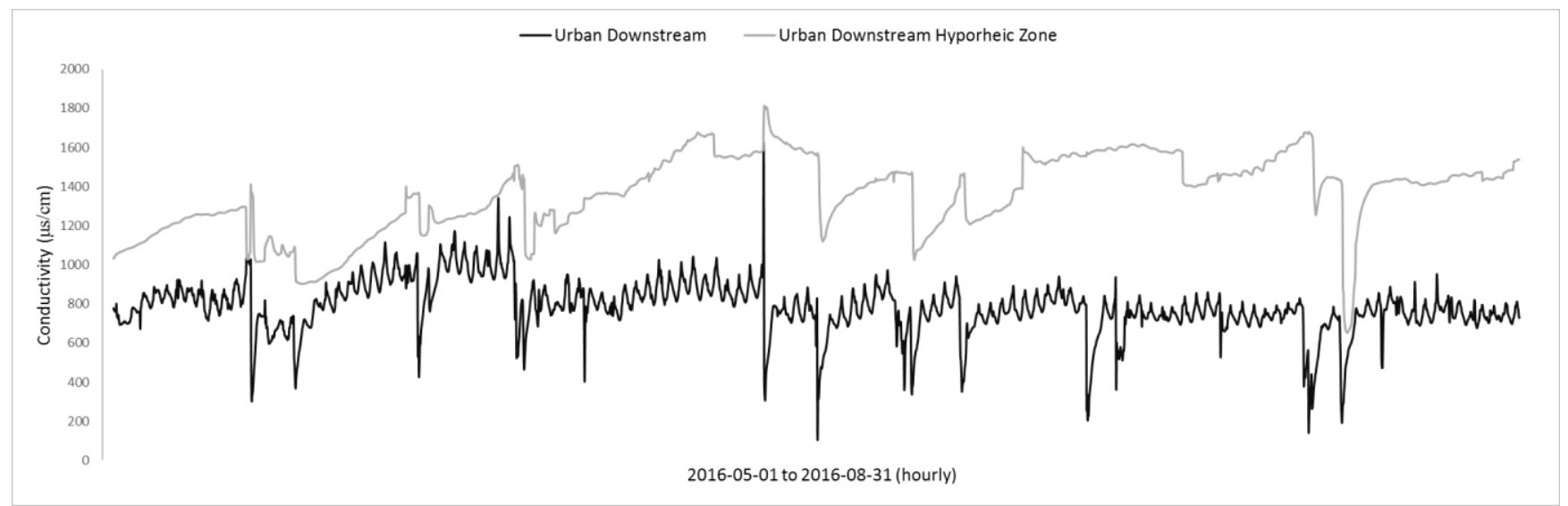

FIGURE A-2.6 Conductivity (EC) time series for the urban downstream stream and hyporheic zone sensors, from May 1 to August 31, 2016. Data were corrected for human errors on sampling events.

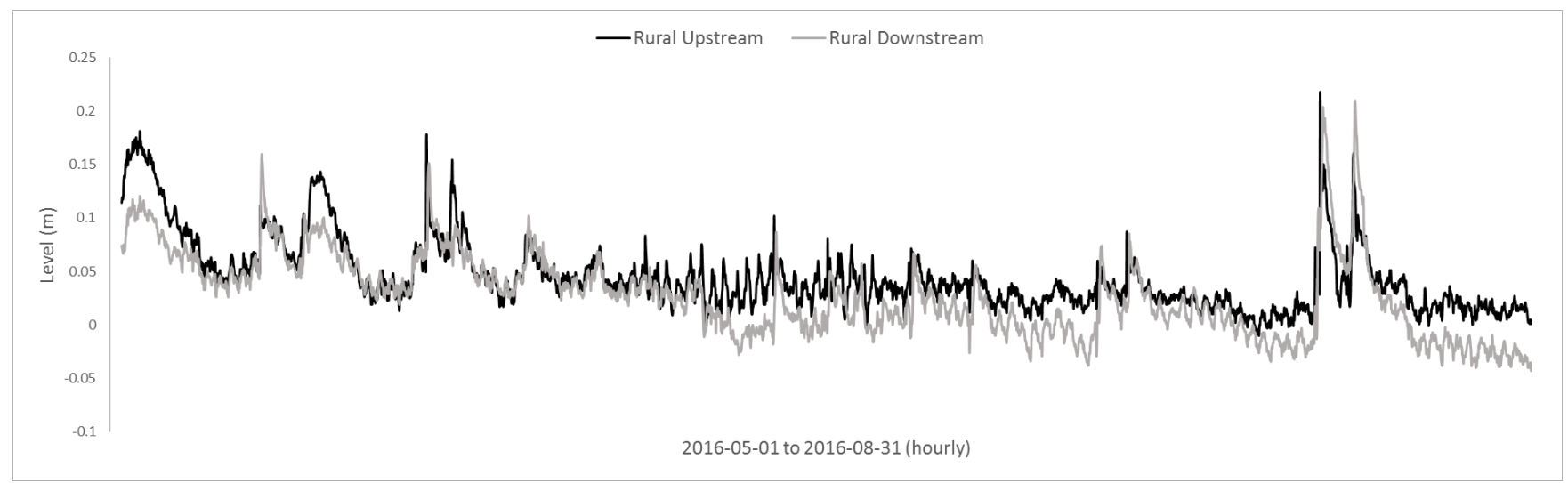

FIGURE A-2.7 Water level time series for the rural upstream and downstream stream sensors, from May 1 to August 31, 2016. Data were corrected for human errors on sampling events. 


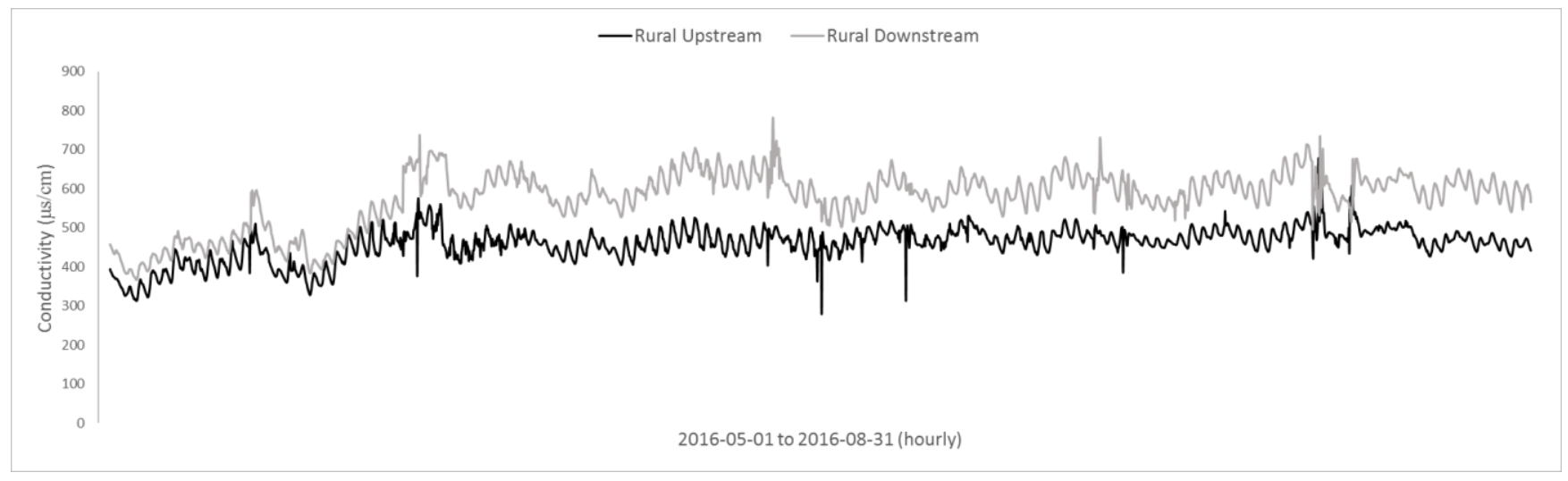

FIGURE A-2.8 Conductivity (EC) time series for the rural upstream and downstream stream sensors, from May 1 to August 31, 2016. Data were corrected for human errors on sampling events.

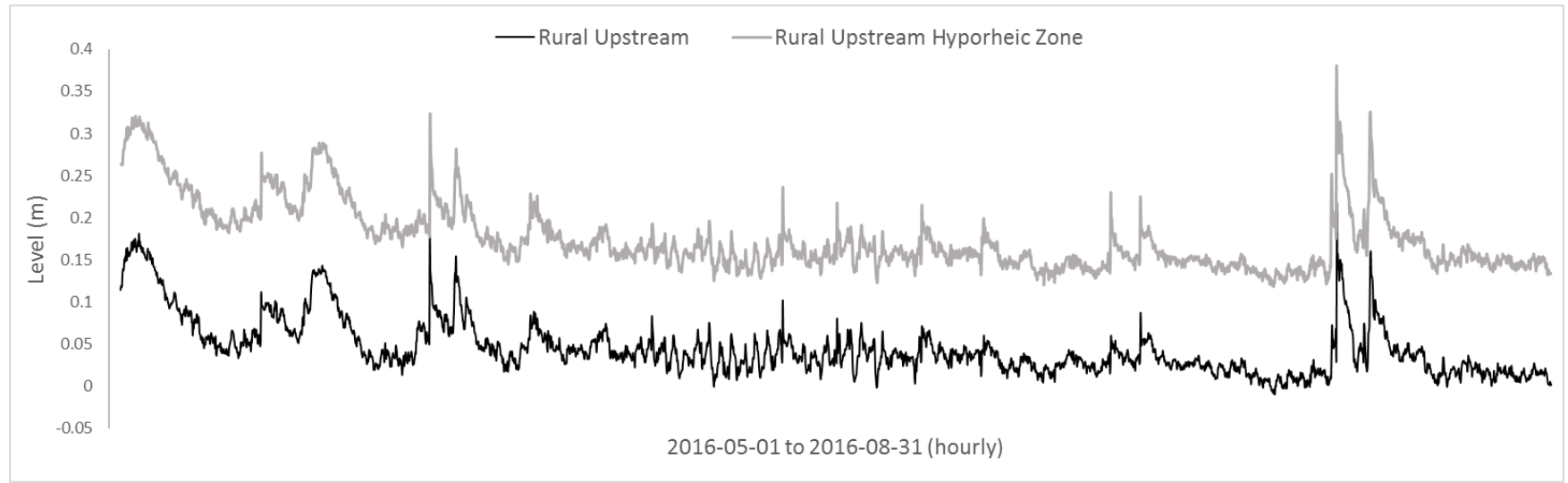

FIGURE A-2.9 Water level time series for the rural upstream stream and hyporheic zone sensors, from May 1 to August 31, 2016. Data were corrected for human errors on sampling events.

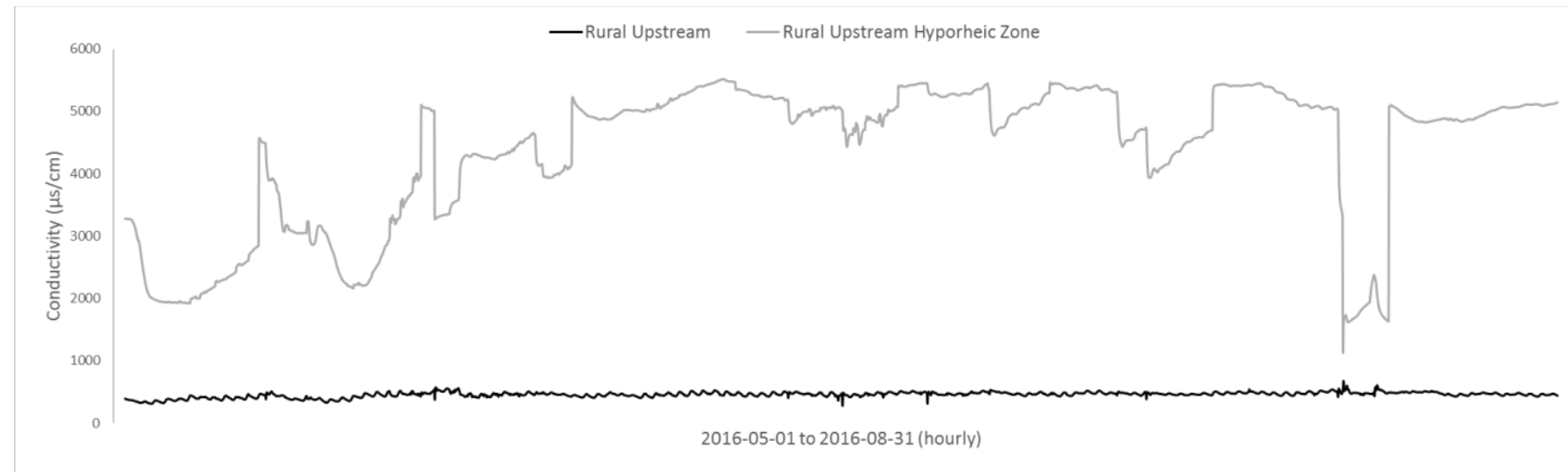

FIGURE A-2.10 Conductivity (EC) time series for the rural upstream stream and hyporheic zone sensors, from May 1 to August 31, 2016. Data were corrected for human errors on sampling events. 


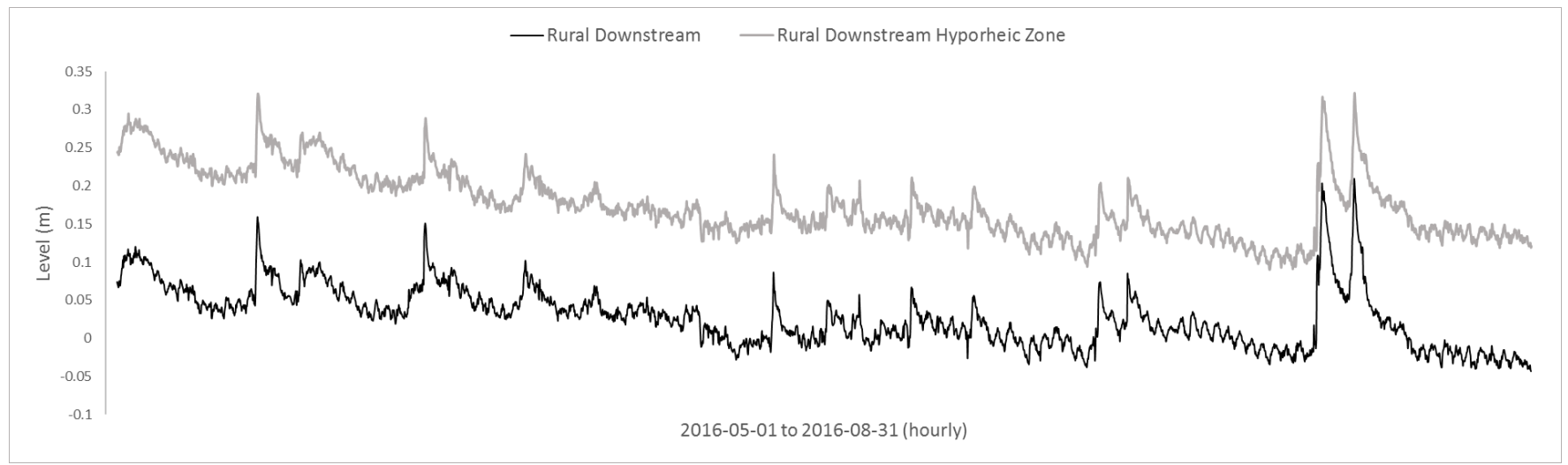

FIGURE A-2.11 Water level time series for the rural downstream stream and hyporheic zone sensors, from May 1 to August 31, 2016. Data were corrected for human errors on sampling events.

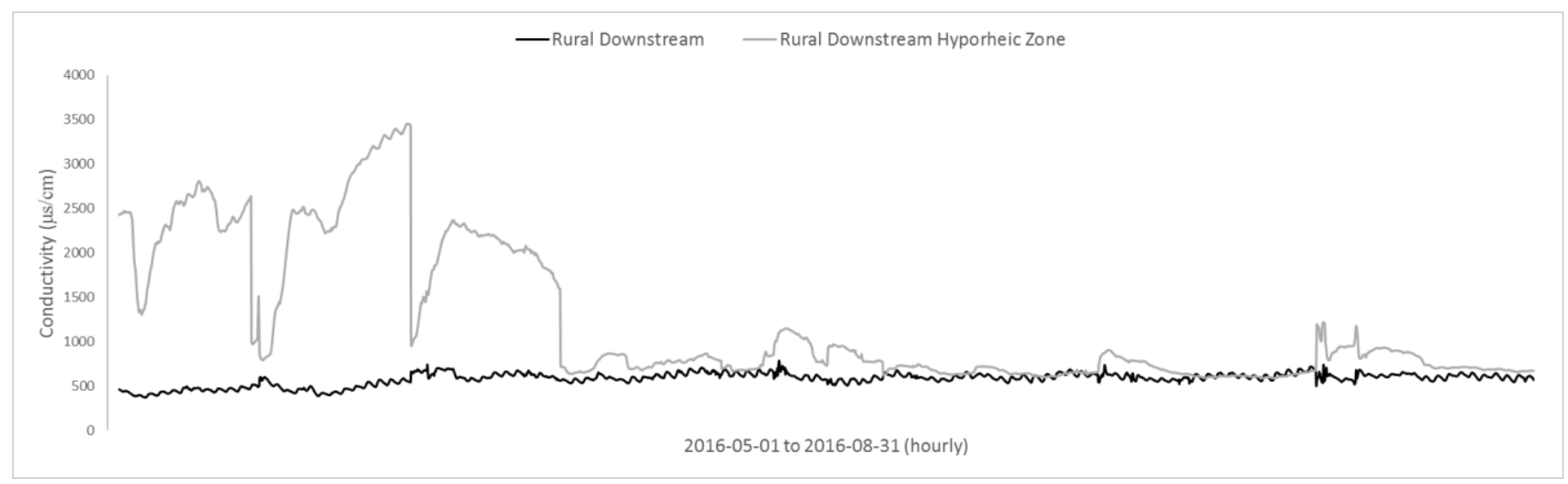

FIGURE A-2.12 Conductivity (EC) time series for the rural downstream stream and hyporheic zone sensors, from May 1 to August 31, 2016. Data were corrected for human errors on sampling events. 
Appendix B: Coherency Plots

B-1 Coherency Plots for Winter Data Pairs

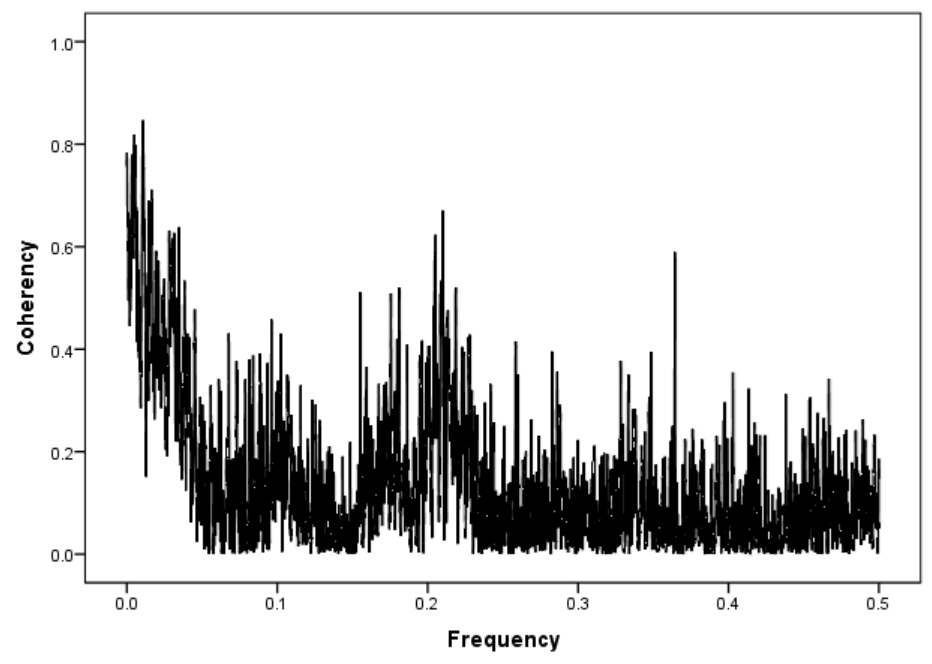

Figure B-1.1 Coherency (squared coherence or $\omega^{2}$ ) of the urban upstream and downstream stream time series, from November 15, 2016 to February 28, 2017.

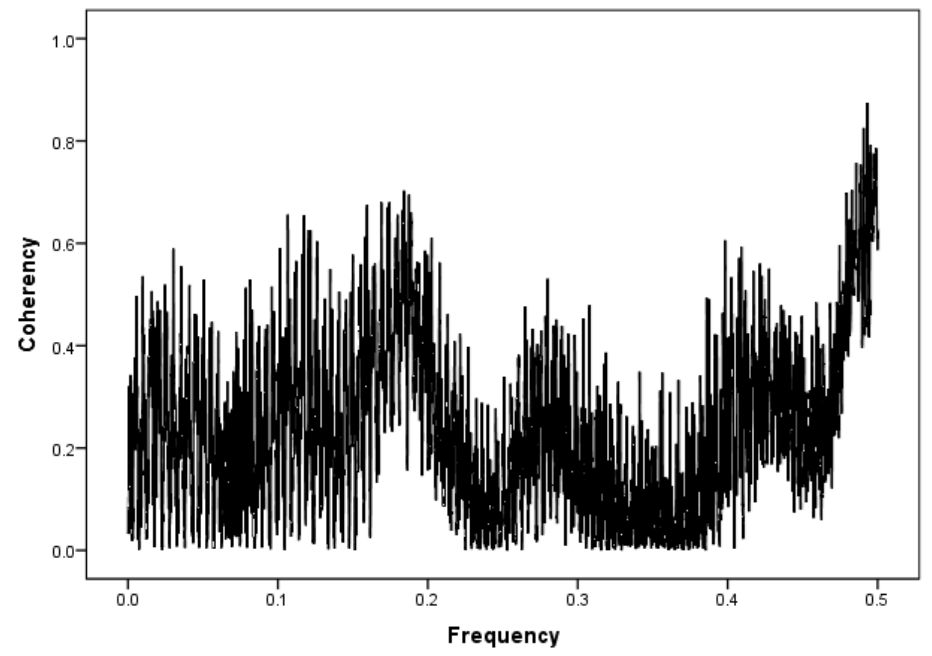

Figure B-1.2 Coherency (squared coherence or $\omega^{2}$ ) of the urban upstream stream and hyporheic zone time series, from November 15, 2016 to February 28, 2017. 


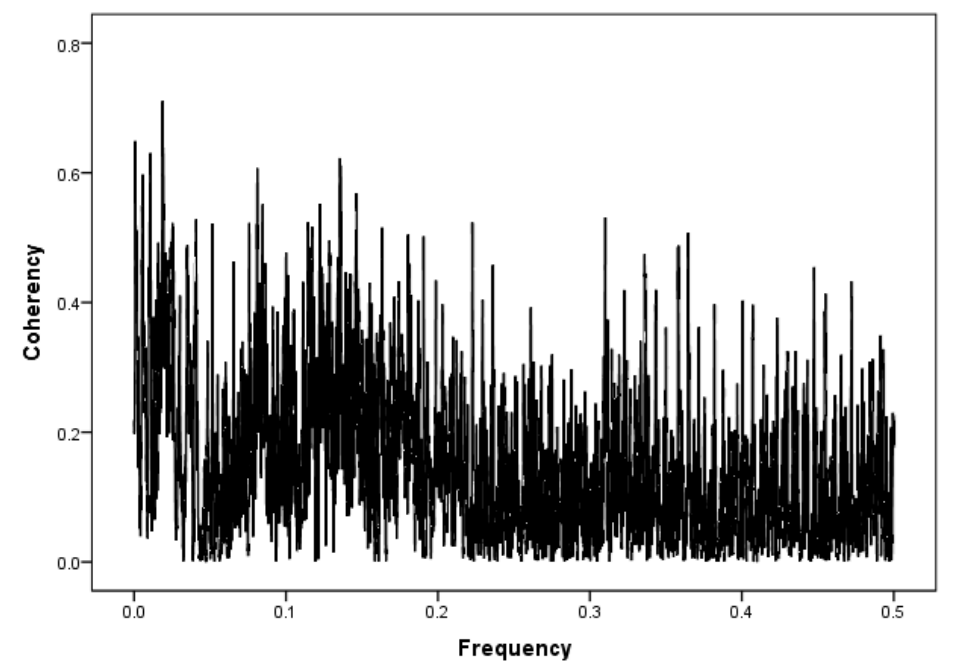

Figure B-1.3 Coherency (squared coherence or $\omega^{2}$ ) of the urban downstream stream and hyporheic zone time series, from November 15, 2016 to February 28, 2017.

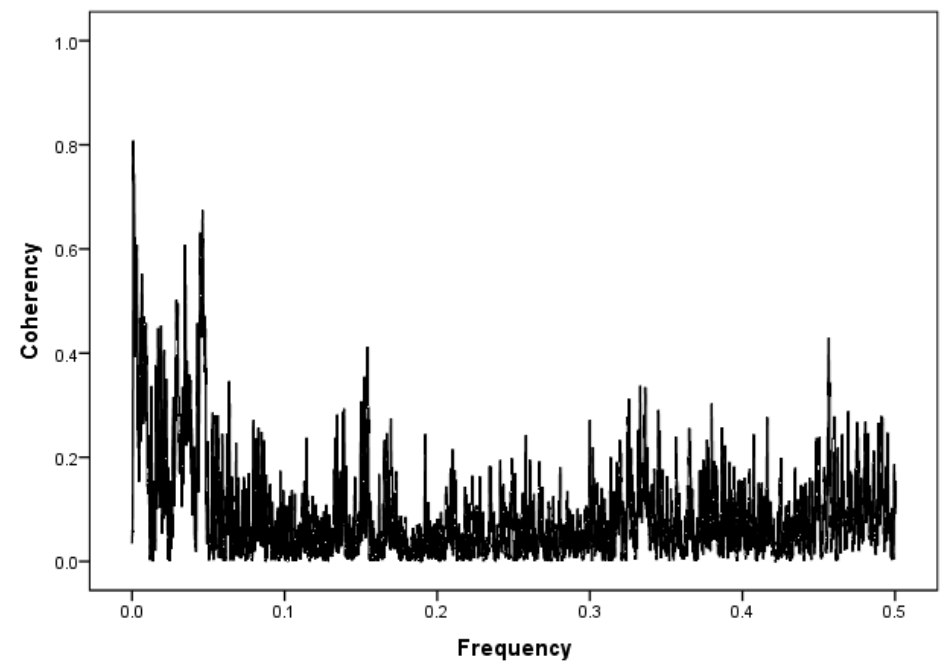

Figure B-1.4 Coherency (squared coherence or $\omega^{2}$ ) of the rural upstream and downstream stream time series, from November 15, 2016 to February 28, 2017. 


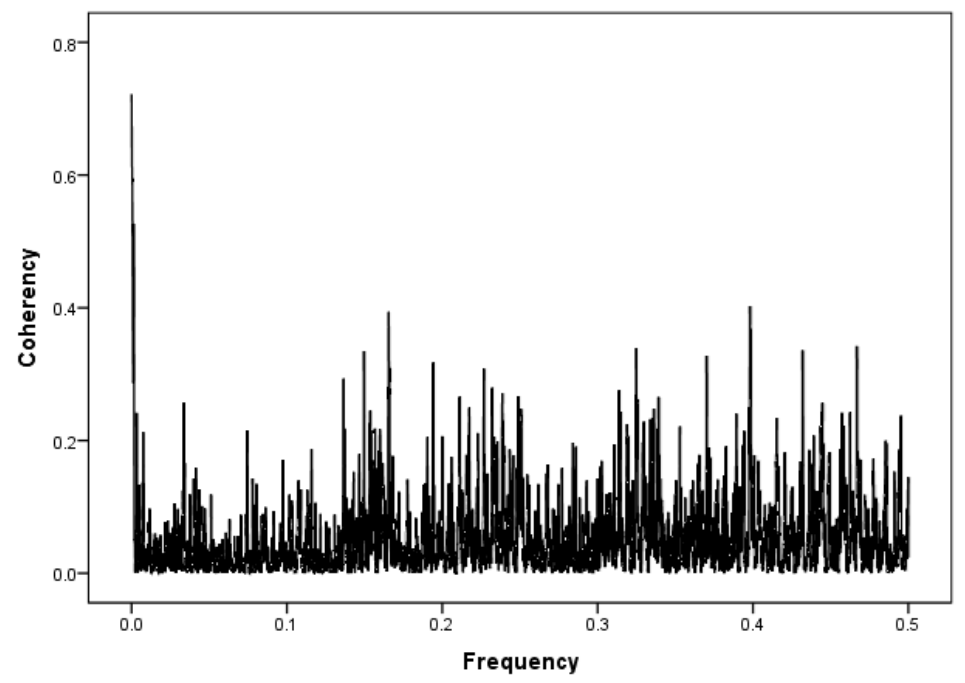

Figure B-1.2 Coherency (squared coherence or $\omega^{2}$ ) of the rural upstream stream and hyporheic zone time series, from November 15, 2016 to February 28, 2017.

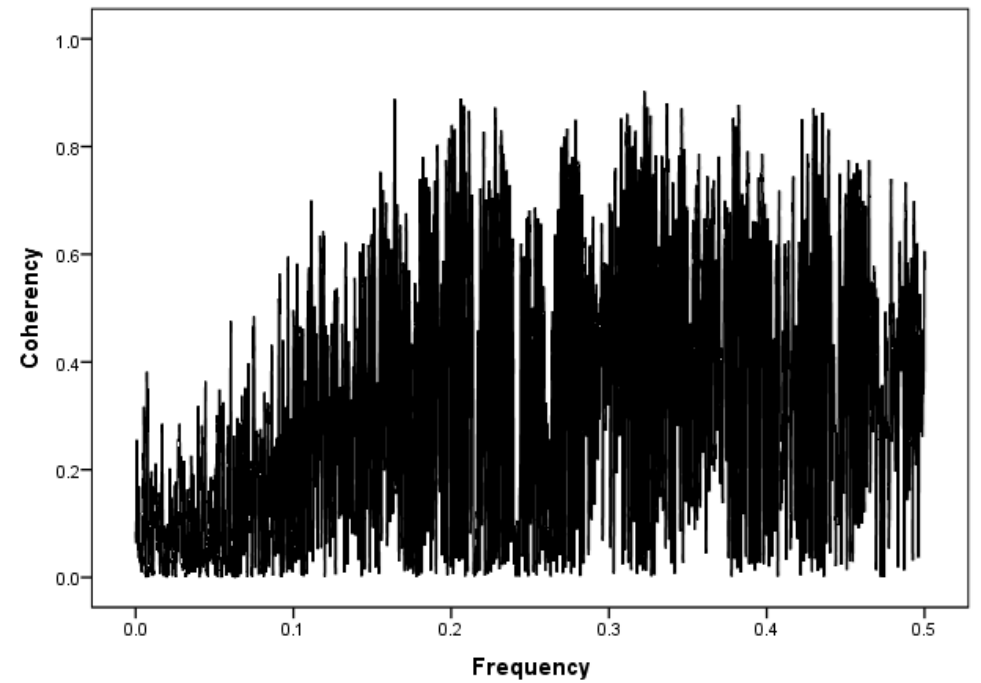

Figure B-1.2 Coherency (squared coherence or $\omega^{2}$ ) of the rural downstream stream and hyporheic zone time series, from November 15, 2016 to February 28, 2017. 


\section{B-2 Coherency Plots for Summer Data Pairs}

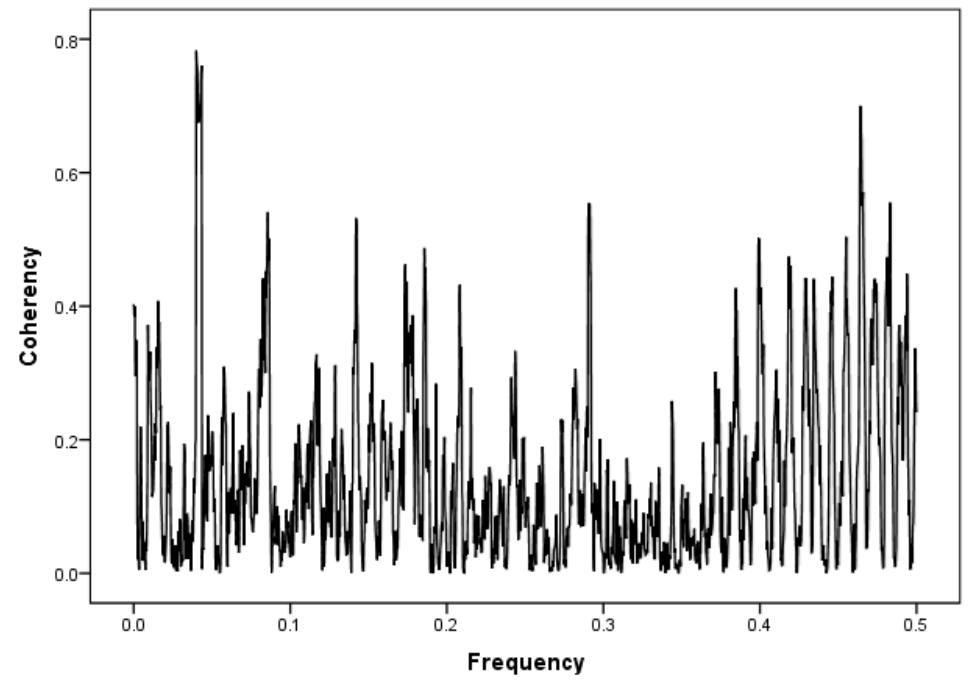

Figure B-2.1 Coherency (squared coherence or $\omega^{2}$ ) of the urban upstream and downstream stream time series, from May 1 to August 31, 2016.

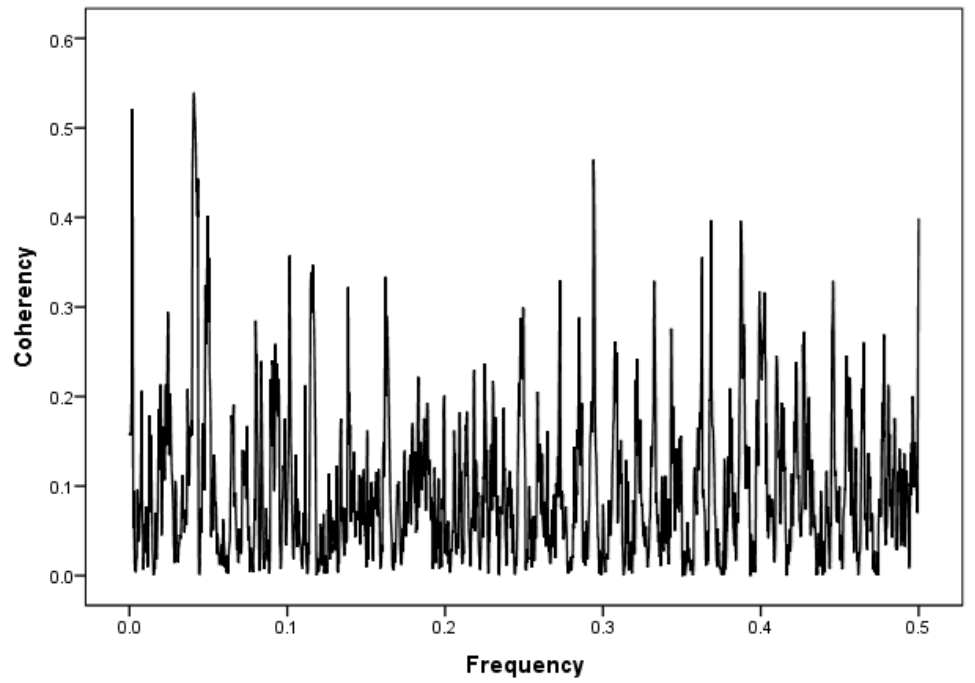

Figure B-2.2 Coherency (squared coherence or $\omega^{2}$ ) of the urban upstream stream and hyporheic zone time series, from May 1 to August 31, 2016 


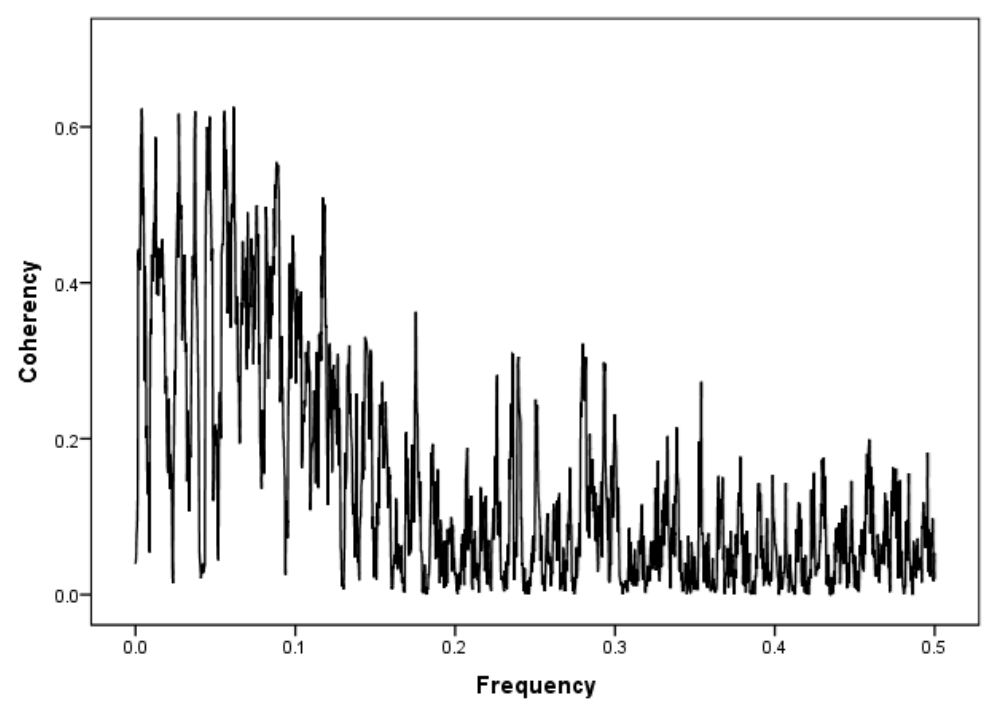

Figure B-2.3 Coherency (squared coherence or $\omega^{2}$ ) of the urban downstream stream and hyporheic zone time series, from May 1 to August 31, 2016

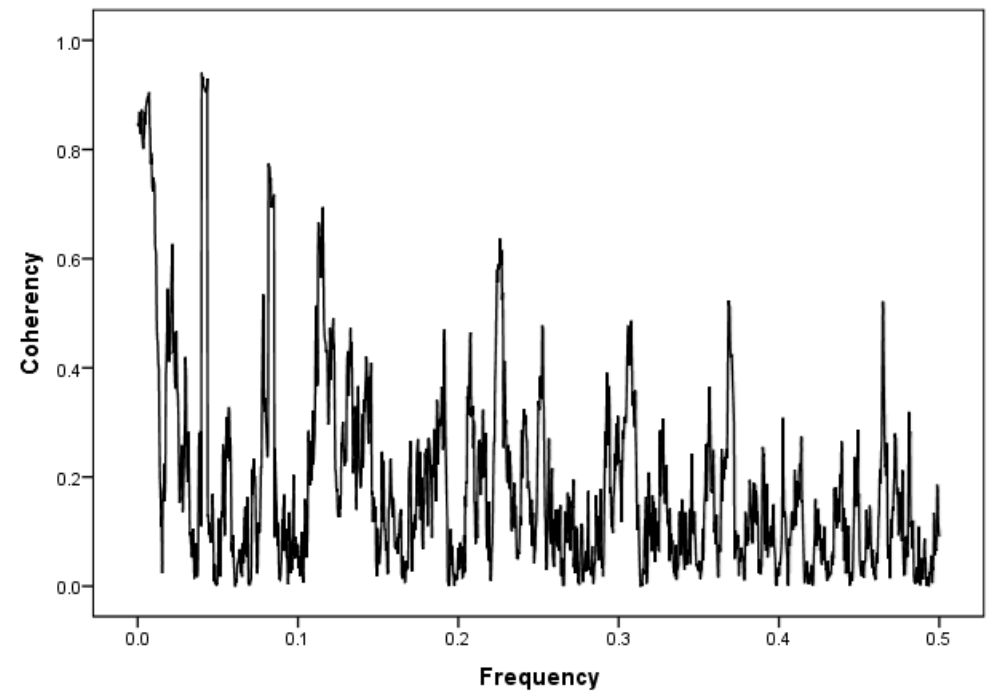

Figure B-2.4 Coherency (squared coherence or $\omega^{2}$ ) of the rural upstream and downstream stream time series, from May 1 to August 31, 2016 


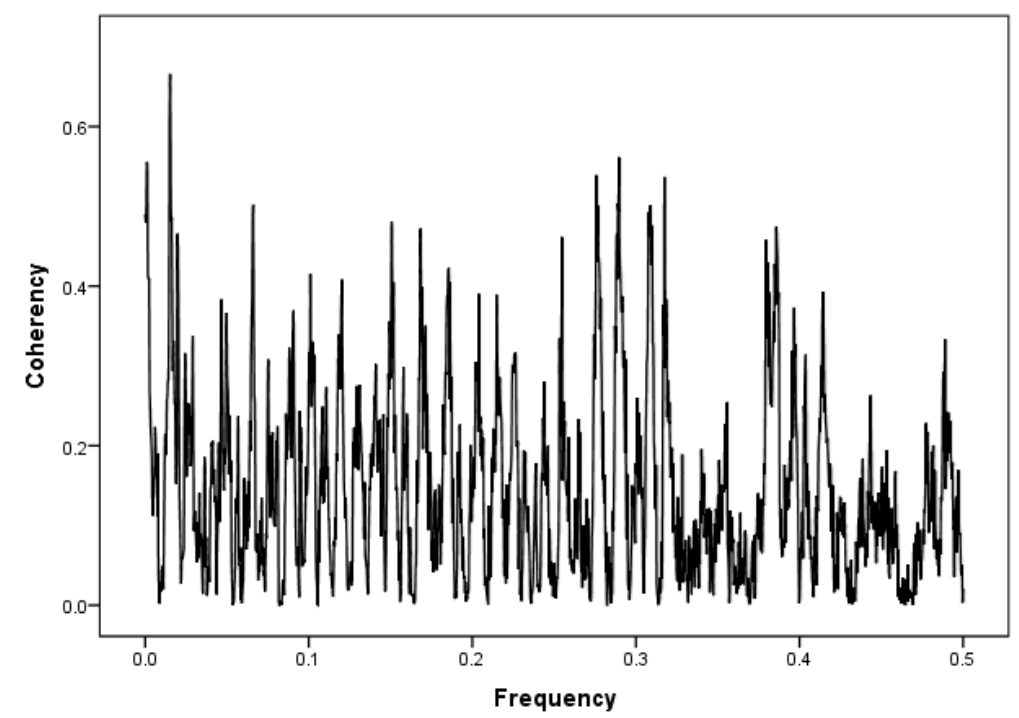

Figure B-2.5 Coherency (squared coherence or $\omega^{2}$ ) of the rural upstream stream and hyporheic zone time series, from May 1 to August 31, 2016

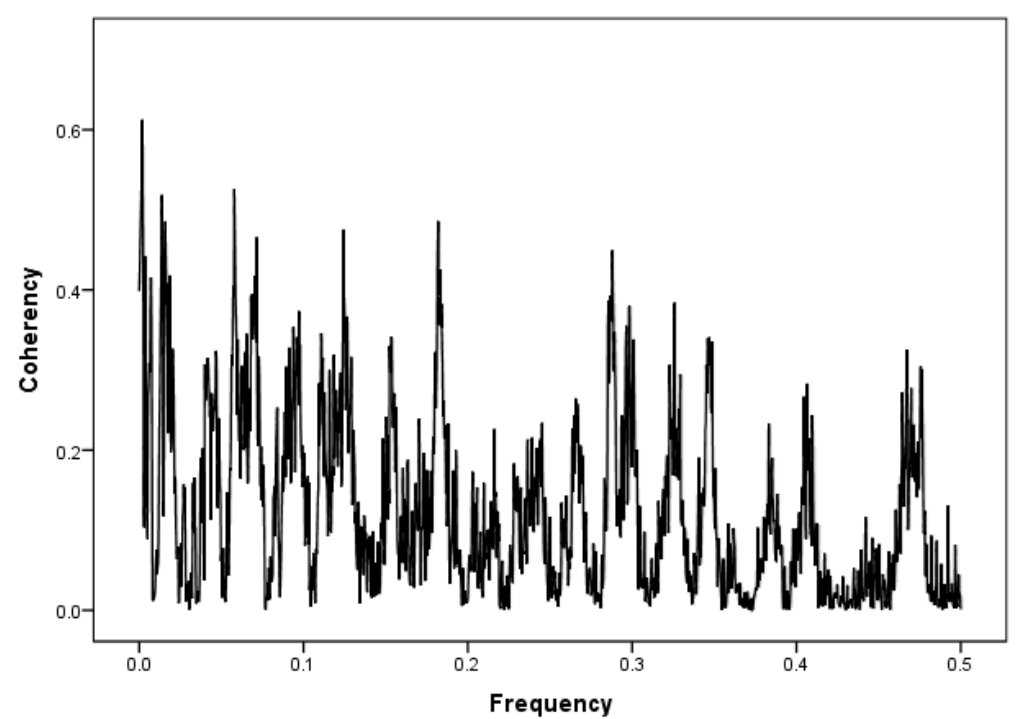

Figure B-2.6 Coherency (squared coherence or $\omega^{2}$ ) of the rural downstream stream and hyporheic zone time series, from May 1 to August 31, 2016 
1. Batchelor, C., \& Gu, C. (2014). Hyporheic Exchange and Nutrient Uptake in A Forested and Urban Stream in the Southern Appalachians. Environment and Natural Resources Research,4(3).

2. Bergstrom, A., Mcglynn, B., Mallard, J., \& Covino, T. (2016). Watershed structural influences on the distributions of stream network water and solute travel times under baseflow conditions. Hydrological Processes, 30(15), 2671-2685.

3. Boano, F., Harvey, J. W., Marion, A., Packman, A. I., Revelli, R., Ridolfi, L., \& Wörman, A. (2014). Hyporheic flow and transport processes: Mechanisms, models, and biogeochemical implications. Reviews of Geophysics, 52(4), 603-679.

4. Booth, D. B. (1991). Urbanization and the natural drainage system--impacts, solutions, and prognoses.

5. Burges, S. J., Wigmosta, M. S., \& Meena, J. M. (1998). Hydrological Effects of Land-Use Change in a Zero-Order Catchment. Journal of Hydrologic Engineering,3(2), 86-97.

6. Casey, R. E., Lev, S. M., \& Snodgrass, J. W. (2013). Stormwater ponds as a source of long-term surface and ground water salinisation. Urban Water Journal, 10(3), 145-153.

7. Chandler, R. E., \& Scott, E. M. (2011). Statistical methods for trend detection and analysis in the environmental sciences. Chichester, West Sussex, U.K.: Wiley. Section 3.4.3.

8. Chen, Y. (2015). A New Methodology of Spatial Cross-Correlation Analysis. Plos One,10(5).

9. Collins, S.J. and Russell R.W. (2009). Toxicity of Road Salt to Nova Scotia Amphibians. Environmental Pollution, Volume 157, Issue 1, p 320-324

10. Corsi, S. R., Cicco, L. A., Lutz, M. A., \& Hirsch, R. M. (2015). River chloride trends in snowaffected urban watersheds: increasing concentrations outpace urban growth rate and are common among all seasons.Science of The Total Environment, 508, 488-497.

11. Corsi, S. R., Graczyk, D. J., Geis, S. W., Booth, N. L., \& Richards, K. D. (2010). A Fresh Look at Road Salt: Aquatic Toxicity and Water-Quality Impacts on Local, Regional, and National Scales. Environmental Science \& Technology, 44(19), 7376-7382.

12. Davis, J. C. (1986). Statistics and Data Analysis in Geology, $2^{\text {nd }}$ Edition. John Wiley and Sons, New York, 646.

13. Dietz, M. E., Angel, D. R., Robbins, G. A., \& Mcnaboe, L. A. (2017). Permeable Asphalt: A New Tool to Reduce Road Salt Contamination of Groundwater in Urban Areas. Groundwater, 55(2), $237-$ 243.

14. Environment Canada (2001). Road Salts: Priority substances list assessment report. Environment Canada, p 67-80 
15. Eyles, N., \& Meriano, M. (2010). Road-impacted sediment and water in a Lake Ontario watershed and lagoon, City of Pickering, Ontario, Canada: An example of urban basin analysis. Sedimentary Geology,224(1-4), 15-28.

16. Feinstein, A. R. (1996). Multivariable Analysis: An Introduction. Yale University Press, New Haven and London, 612.

17. Findlay, S. E., \& Kelly, V. R. (2011). Emerging indirect and long-term road salt effects on ecosystems. Annals of the New York Academy of Sciences, 1223(1), 58-68.

18. Fleckenstein, J. H., Krause, S., Hannah, D. M., \& Boano, F. (2010). Groundwater-surface water interactions: New methods and models to improve understanding of processes and dynamics. Advances in Water Resources, 33(11), 1291-1295.

19. Germer, S., Neill, C., Vetter, T., Chaves, J., Krusche, A. V., \& Elsenbeer, H. (2009). Implications of long-term land-use change for the hydrology and solute budgets of small catchments in Amazonia. Journal of Hydrology,364(3-4), 349-363.

20. Granger, C. W. (1969). Investigating Causal Relations by Econometric Models and Cross-Spectral Methods. Essays in Econometrics Vol II: Collected Papers of Clive W. J. Granger, 31-47.

21. Granger, C. W. J. (2015). Spectral Analysis of Economic Time Series, Princeton Studies in Mathematical Economics PSME-1. Princeton University Press, New Jersey, 147-158. Original work published 1964.

22. Hester, E. T., \& Gooseff, M. N. (2010). Moving Beyond the Banks: Hyporheic Restoration Is Fundamental to Restoring Ecological Services and Functions of Streams. Environmental Science \& Technology,44(5), 1521-1525.

23. Kalyanapu, A. J., Burian, S. J., \& McPherson, T. N. (2009). Effect of land use-based surface roughness on hydrologic model output. Journal of Spatial Hydrology, 9(2), 51-71.

24. Kelly, V. R., Lovett, G. M., Weathers, K. C., Findlay, S. E., Strayer, D. L., Burns, D. J., \& Likens, G. E. (2008). Long-Term Sodium Chloride Retention in a Rural Watershed: Legacy Effects of Road Salt on Streamwater Concentration. Environmental Science \& Technology, 42(2), 410-415.

25. Kelting, D. L., Laxson, C. L., \& Yerger, E. C. (2012). Regional analysis of the effect of paved roads on sodium and chloride in lakes. Water Research, 46(8), 2749-2758.

26. Kerr, J. G. (2017). Multiple land use activities drive riverine salinization in a large, semi-arid river basin in western Canada. Limnology and Oceanography,62(4), 1331-1345.

27. Kirchner, J. W., Feng, X., Neal, C., \& Robson, A. J. (2004). The fine structure of water-quality dynamics: the (high-frequency) wave of the future. Hydrological Processes, 18(7), 1353-1359.

28. Kirchner, J. W., Tetzlaff, D., \& Soulsby, C. (2010). Comparing chloride and water isotopes as hydrological tracers in two Scottish catchments. Hydrological Processes,24(12), 1631-1645.

29. Ko, C., \& Cheng, Q. (2004). GIS spatial modeling of river flow and precipitation in the Oak Ridges Moraine area, Ontario. Computers \& Geosciences, 30(4), 379-389. 
30. Konrad, C. P., \& Booth, D. B. (2002). Hydrologic trends associated with urban development for selected streams in the Puget Sound Basin, Western Washington. U.S. Geological Survey, 2002-4040.

31. Lake Simcoe Region Conservation Authority (2010). East Holland Subwatershed Plan. Retrieved May 2017 from http://www.lsrca.on.ca/Shared\%20Documents/reports/east-holland-subwatershedplan.pdf

32. Lake Simcoe Region Conservation Authority (2015). The identification of Salt Vulnerable Areas in the Lake Simcoe watershed. Watershed Health: Report \& Studies. Retrieved May 2017 from http://www.lsrca.on.ca/Shared\%20Documents/reports/salt-vulnerable-areas.pdf

33. Lake Simcoe Region Conservation Authority (2017). Lake Simcoe Watershed land cover from 2013 aerial photography. Ontario Geospatial Data Exchange Agreement.

34. Lake Simcoe Region Conservation Authority. (n.d.). Sodium chloride (winter salt). Lake Simcoe Science Newsletters. Volume 8. Retrieved May 2017 from http://www.lsrca.on.ca/Shared\%20Documents/newsletter/science-newsletter-vol8.pdf

35. Lawrence, J. E., Skold, M. E., Hussain, F. A., Silverman, D. R., Resh, V. H., Sedlak, D. L., Luthy, R. G., \& Mccray, J. E. (2013). Hyporheic Zone in Urban Streams: A Review and Opportunities for Enhancing Water Quality and Improving Aquatic Habitat by Active Management. Environmental Engineering Science,30(8), 480-501.

36. Long, D. T., Voice, T. C., Chen, A., Xing, F., \& Li, S. (2015). Temporal and spatial patterns of Cland $\mathrm{Na}$ concentrations and $\mathrm{Cl} / \mathrm{Na}$ ratios in salted urban watersheds. Elementa: Science of the Anthropocene, 3, 000049.

37. Martin, S. L., Hayes, D. B., Kendall, A. D., \& Hyndman, D. W. (2017). The land-use legacy effect: Towards a mechanistic understanding of time-lagged water quality responses to land use/cover. Science of the Total Environment, 579, 1794-1803.

38. Mayer, P.M., Striz, E.A., Doheny, E., Kaushal, S., and Groffman, P. (2006) Road salt application creates a unique chloride biochemistry in an urban stream of the Chesapeake Bay watershed. Presented at American Geophysical Union Meeting, Baltimore, MD, May 22-26, 2006.

39. McCuen, R. H. (1998). Hydrologic analysis and design, Prentice-Hall, New Jersey.

40. Meriano, M., Eyles N., and Howard K.W.F. (2009). Hydrogeological impacts of road salt from Canada's busiest highway on a Lake Ontario watershed. Journal of Contaminant Hydrogeology, Volume 107 Issues 1-2, p 66-81

41. Ministry of Natural Resources (2013). Ontario Flow Assessment Tool. Updated in 2017, retrieved May 2017 from https://www.ontario.ca/page/watershed-flow-assessment-tool

42. Morgan, R. P., Kline, K. M., Kline, M. J., Cushman, S. F., Sell, M. T., Weitzell, R. E., \& Churchill, J. B. (2012). Stream Conductivity: Relationships to Land Use, Chloride, and Fishes in Maryland Streams. North American Journal of Fisheries Management,32(5), 941-952.

43. O’Driscoll, M., Clinton, S., Jefferson, A., Manda, A., \& Mcmillan, S. (2010). Urbanization Effects on Watershed Hydrology and In-Stream Processes in the Southern United States. Water,2(3), 605-648. 
44. Ontario Ministry of Agriculture, Food and Rural Affairs (2016). Classifying prime and marginal agricultural soils and landscapes: Guidelines for application of the Canada Land Inventory in Ontario. Updated in 2016, retrieved May 2017 from http://www.omafra.gov.on.ca/english/landuse/classify.htm

45. Ontario Ministry of Natural Resources and Forestry (2013). Ontario Flow Assessment Tool. Updated in 2017, retrieved May 2017 from https://www.ontario.ca/page/watershed-flow-assessment-tool

46. Ontario Open Data Catalogue (2015). Provincial Digital Elevation Model, Version 3.0. Added in 2015, retrieved April 2017 from https://www.ontario.ca/data/provincial-digital-elevation-modelversion-30

47. Perera, N., Gharabaghi, B., \& Howard, K. (2013). Groundwater chloride response in the Highland Creek watershed due to road salt application: A re-assessment after 20years. Journal of Hydrology, 479, 159-168.

48. Perera, N., Gharabaghi, P., Noehammer, P., \& Kilgour, B. (2009). Stream Chloride Monitoring Program of City of Toronto: Implications of Road Salt Application. Water Quality Research Journal of Canada, 44(2), 451-461.

49. Regional Municipality of York. (2015). Draft Growth Scenarios and Land Budget. Retrieved May 2017 from http://www.york.ca/wps/wcm/connect/yorkpublic/2ad65882-740e-4833-be8522cd1a2df67d/apr+9+draft+ex.pdf?MOD=AJPERES

50. Rowe, R. K., \& Badv, K. (1996). Chloride Migration through Clayey Silt Underlain by Fine Sand or Silt. Journal of Geotechnical Engineering,122(1), 60-68.

51. Ryan, R. J., \& Packman, A. I. (2006). Changes in streambed sediment characteristics and solute transport in the headwaters of Valley Creek, an urbanizing watershed. Journal of Hydrology,323(1-4), 74-91.

52. Schmidt, C., Musolff, A., Trauth, N., Vieweg, M., \& Fleckenstein, J. H. (2012). Transient analysis of fluctuations of electrical conductivity as tracer in the stream bed. Hydrology and Earth System Sciences, 16(10), 3689-3697.

53. Tanaka, T. (1992). Storm runoff processes in a small forested drainage basin. Environmental Geology and Water Sciences,19(3), 179-191.

54. Valett, H. M., Morrice, J. A., Dahm, C. N., \& Campana, M. E. (1996). Parent lithology, surfacegroundwater exchange, and nitrate retention in headwater streams. Limnology and Oceanography, 41(2), 333-345.

55. Ward, A. D. Trimble, S. W., Burckhard, S. R., \& Lyron, J. G. (2015). Environmental Hydrology, $3^{\text {rd }}$ Edition. CRC Press, 288.

56. Warner, R. M. (1998). Spectral Analysis of Time-Series Data, Illustrated Edition. Guilford Press, New York, 145.

57. Williams D.D., Williams N.E., and Cao Y. (2000). Road Salt Contamination of Groundwater in a Major Metropolitan Area and Development of a Biological Index to Monitor its Impact. Water Research, Volume 34 Issue 1, p 127-138 
58. Winter, J. G., Landre, A., Lembcke, D., O'connor, E. M., \& Young, J. D. (2011). Increasing chloride concentrations in Lake Simcoe and its tributaries. Water Quality Research Journal of Canada, 46(2), 157.

59. York Region (n.d.). Voyager open data license. Retrieved June 2017 from http://findit.york.ca/yorkod/navigo/\#/home?disp=ace4bb77\&view=card

60. Zhou, B., \& Wang, Q. (2017). Effect of pore water velocities and solute input methods on chloride transport in the undisturbed soil columns of Loess Plateau. Applied Water Science,7(5), 2321-2328. 